\title{
Diversiform and Transformable Glyco-Nanostructures Constructed from Amphiphilic Supramolecular Metallocarbohydrates through Hierarchical Self- Assembly: The Balance between Metallacycles and Saccharides
}

Guang Yang, ${ }^{\dagger}$, ๆ, $\nabla$ Wei Zheng, ${ }^{\ddagger}, \nabla$ Guoqing Tao, ${ }^{\dagger}$ Libin $\mathrm{Wu},{ }^{\dagger}$ Qi-feng Zhou, ${ }^{\dagger}$ Zdravko

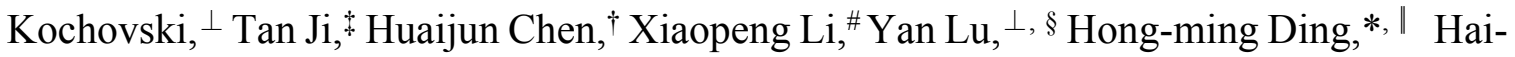
Bo Yang, ${ }^{*}+$ Guosong Chen, ${ }^{*}, \dagger$ Ming Jiang ${ }^{\dagger}$

$\dagger$ The State Key Laboratory of Molecular Engineering of Polymers and Department of Macromolecular Science, Fudan University, Shanghai 200433, P. R. China

¥ Shanghai Key Laboratory of Green Chemistry and Chemical Processes, School of Chemistry and Molecular Engineering, East China Normal University, Shanghai 200062, P. R. China

\| Center for Soft Condensed Matter Physics and Interdisciplinary Research, School of Physical Science and Technology, Soochow University, Suzhou 215006, P. R. China

\# Department of Chemistry, University of South Florida, Tampa, Florida 33620, United States

$\perp$ Soft Matter and Functional Materials, Helmholtz-Zentrum Berlin für Materialien und Energie, 14109 Berlin, Germany.

$\S$ Institute of Chemistry, University of Potsdam, 14467 Potsdam, Germany

"Biomass Molecular Engineering Center, Anhui Agricultural University, Hefei, Anhui 230036, P. R. China

\footnotetext{
Email: *guosong@fudan.edu.cn,

* hbyang@chem.ecnu.edu.cn,

* dinghm@suda.edu.cn
} 


\section{Table of Contents}

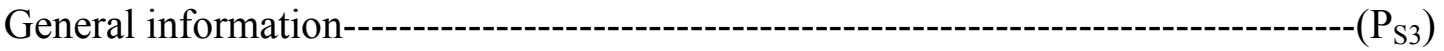

Synthetic procedures of ligands and metallacycles------------------------------------- $\left(\mathrm{P}_{\mathrm{S4}-\mathrm{S} 14}\right)$

NMR characterization and geometric illustration---------------------------------------- $\left(\mathrm{P}_{\mathrm{S} 15-\mathrm{S} 16}\right)$

Characterization of 2-Man in aqueous soltion------------------------------------------- $\left(\mathrm{P}_{\mathrm{S} 17-\mathrm{S} 18}\right)$

Molecular simulations------------------------------------------------------------------------ $\left(\mathrm{P}_{\mathrm{S} 19-S 22}\right)$

${ }^{1} \mathrm{H}$ NMR of 3-Man and 6-Man in aqueous solution----------------------------------- $\left(\mathrm{P}_{\mathrm{S} 23}\right)$

Characterization of 3-Man and 6-Man in aqueous soltion---------------------------( $\left(\mathrm{P}_{\mathrm{S} 24-\mathrm{S} 28}\right)$

TEM image of 2-Man, and stability chracterizationof 2-Man, 3-Man and 6-Man with time

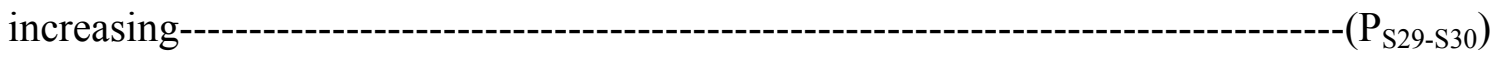

Characterization of 6-Man in aqueous solution with time increasing----------------( $\left(\mathrm{P}_{\mathrm{S} 31-\mathrm{S} 34}\right)$

Characterization of 2-Mal, 3-Mal and 6-Mal in aqueous solution-------------------( $\left.\mathrm{P}_{\mathrm{S} 35-\mathrm{S} 37}\right)$

The binding between ConA and glyco-nanopaticles-----------------------------------(P $\left(\mathrm{P}_{\mathrm{S} 38-\mathrm{S} 39}\right)$

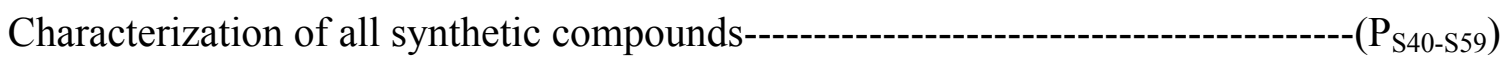

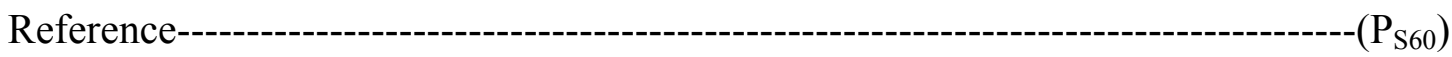




\section{i. General information}

A1, A2, a4 and a6 were synthesized following previous reported procedures. ${ }^{1}$ 2bromoethanol (J\&K, 98\%), potassium thioacetate (J\&K, 98\%), sodium methoxide (TCI, 99\%), dimethylphenylphosphine (J\&K, 99\%), hydrogen bromide, 33 wt.\% solution in acetic acid $\left(\mathrm{HBr} / \mathrm{CH}_{3} \mathrm{COOH}, \mathrm{J} \& \mathrm{~K}\right)$, triethylamine $\left(\mathrm{NEt}_{3}, \mathrm{~J} \& \mathrm{~K}, 99 \%\right)$, methacryloyl chloride (J\&K, 98\%). manganese nitrate, 50 wt.\% solution in $\mathrm{H}_{2} \mathrm{O}(\mathrm{J} \& \mathrm{~K})$, calcium nitrate (Guoyao), 4-(2-hydroxyethyl)piperazine-1-ethanesulfonic acid (J\&K, 99\%). Dichloromethane (DCM), methanol and N,N-dimethylformamide (DMF) were purchased from J\&K. Concanavalin A (ConA) protein was purchased from Alladin and used as received. All the reagents and solvents were used as received. 
ii. Synthetic procedures of ligands and metallacycles.

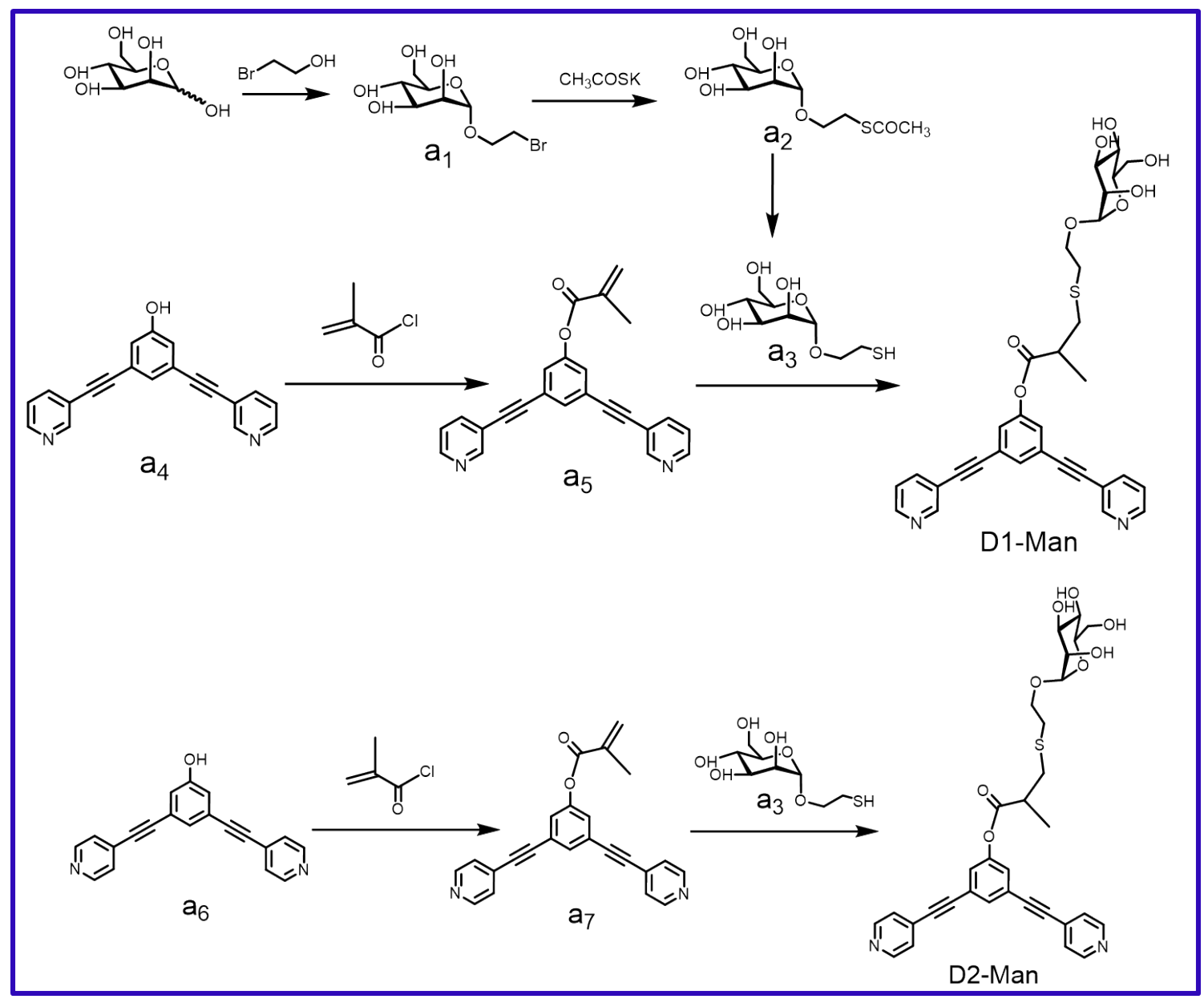

Scheme 1. Synthetic procedures of D1-Man and D2-Man 


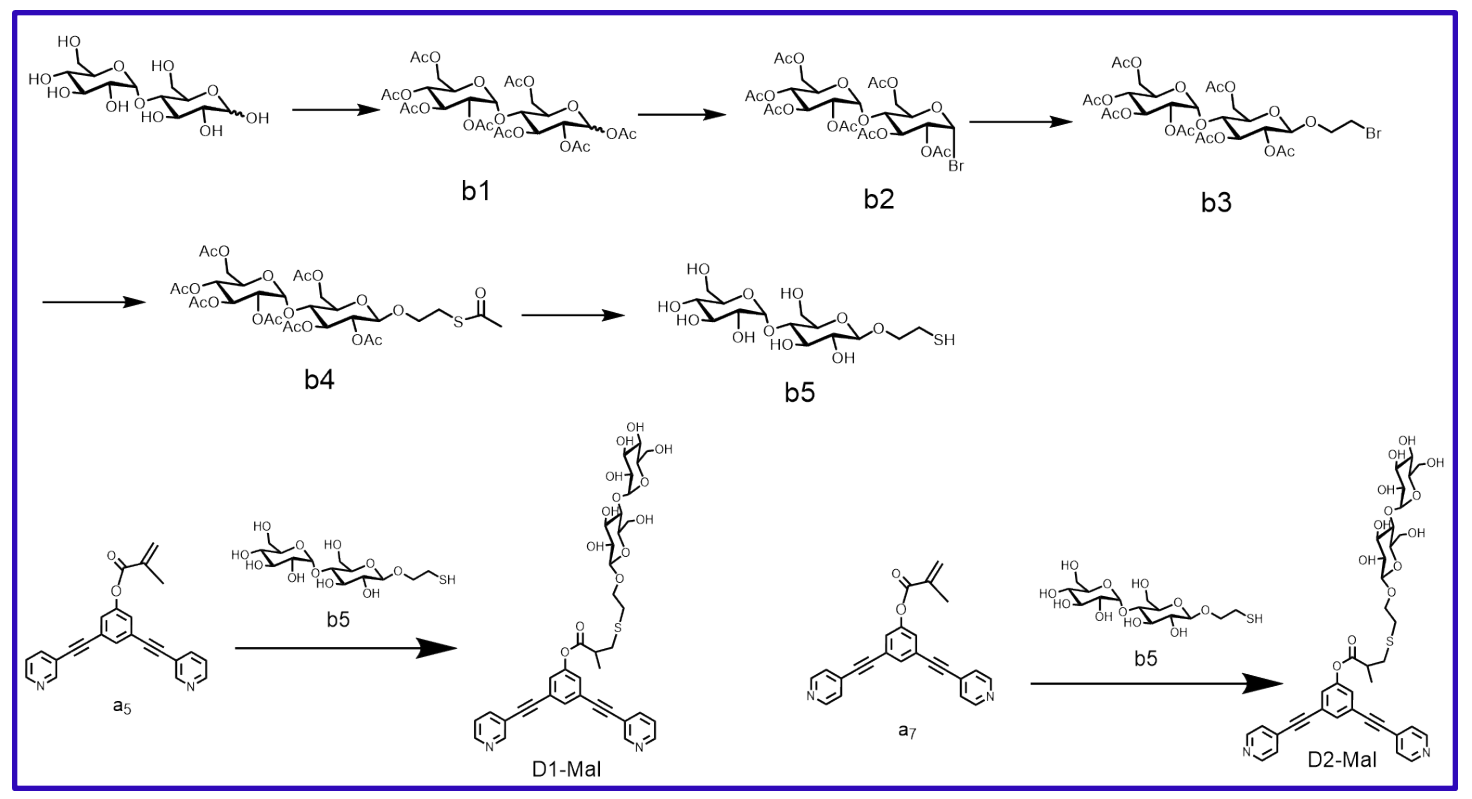

Scheme 2. Synthetic procedures of D1-Mal and D2-Mal.

2.1 Synthesis of $\mathbf{a}_{1}$ : The synthesis of al was according to our previous report ${ }^{2} .3 \mathrm{~g}$ (17 mmol) mannose, $9 \mathrm{~mL}$ 2-bromoethanol and $200 \mathrm{mg} \mathrm{H}_{2} \mathrm{SO}_{4}-\mathrm{SiO}_{2}$ were mixed in roundbottom flask. After keeping reaction $\sim 6 \mathrm{~h}$ at $60^{\circ} \mathrm{C}$, the compound was seperated via chromatography column using methanol/DCM $\left(\mathrm{V}_{\text {methanol }}: \mathrm{V}_{\mathrm{DCM}}=1: 6\right)$ mixtures as eluting solvent. The product as oil was $\sim 2.6 \mathrm{~g} .{ }^{1} \mathrm{H}$ NMR (400 MHz, $\mathrm{CD}_{3} \mathrm{OD}, 298 \mathrm{~K}$, Figure S38) $\delta 4.92(\mathrm{~d}, 1 \mathrm{H})$; 4.05-3.99 (m, 2H); 3.92-3.85 (m, 3H); 3.76-3.71 (m, 2H); 3.66-3.61 (m, $3 \mathrm{H})$.

2.2 Synthesis of a2: $2.6 \mathrm{~g}(9 \mathrm{mmol})$ a1 and $3 \mathrm{~g}(26 \mathrm{mmol})$ potassium thioacetate were mixed in $50 \mathrm{~mL}$ DMF. The reaction was continuously stirred at $60^{\circ} \mathrm{C}$ overnight. After evaporating the solvent, the compound was seperated via chromatography column using methanol/DCM mixture $\left(\mathrm{V}_{\text {methanol }}: \mathrm{V}_{\mathrm{DCM}}=1: 6\right)$ as eluting solvent. The final product was 1.9 g. ${ }^{1} \mathrm{H}$ NMR (400 MHz, CD $\mathrm{OD}, 298 \mathrm{~K}$, Figure S39) $\delta 4.79(\mathrm{~d}, 1 \mathrm{H}), 3.85-3.79(\mathrm{~m}, 3 \mathrm{H})$, 3.74-3.58 (m, 5H), 3.15-3.12 (t, 2H), 2.35 (s, 3H). ${ }^{13} \mathrm{C}$ NMR (100 MHz, $\mathrm{CD}_{3} \mathrm{OD}, 298 \mathrm{~K}$, Figure S40) $\delta 195.51,100.18,73.46,71.11,70.66,67.07,65.79,61.47,29.07,28.33$.

2.3 Synthesis of a3: $1.9 \mathrm{~g}(6.7 \mathrm{mmol})$ a2 was added in $30 \mathrm{~mL}$ methanol, then $0.2 \mathrm{~g}(3.7$ mmol) sodium methoxide was added in the solution and kept stired $1 \mathrm{~h}$ at room temperature. Hydrogen ion exchange resin was introduced to neutralize the $\mathrm{pH}$ to about 5.5. Then the product was filtered and collected via evaporating. The compound as yellow oil was $1.2 \mathrm{~g}$. 
${ }^{1} \mathrm{H}$ NMR (400 MHz, $\mathrm{CD}_{3} \mathrm{OD}, 298 \mathrm{~K}$, Figure S41) $\delta$ 4.82-4.81 (d, 1H), 3.87-3.81 (m, 3H), 3.75-3.70 (m, 2H), 3.63-3.57 (m, 3H), 2.74-2.70 (m, 2H). ${ }^{13} \mathrm{C}$ NMR (100 MHz, $\mathrm{CD}_{3} \mathrm{OD}$, 298 K, Figure S42) $\delta$ 100.25, 73.43, 71.17, 70.70, 69.18, 67.17, 61.51, 23.36.

2.4 Synthesis of a5: $1.5 \mathrm{~g}(4.8 \mathrm{mmol}) \mathrm{a}_{4}$ and $0.51 \mathrm{~g}(5 \mathrm{mmol})$ triethylamine were added into $50 \mathrm{~mL}$ dried DCM. Then $2 \mathrm{~mL}$ ( $22.7 \mathrm{mmol})$ methacryloyl chloride was dropwised into the solution at $0{ }^{\circ} \mathrm{C}$. After stiring for $4 \mathrm{~h}$ at room temperature, the solvent was removed via evaporation. The compound was seperated via chromatography column using methanol/DCM mixture $\left(\mathrm{V}_{\text {methanol }}: \mathrm{V}_{\mathrm{DCM}}=1: 10\right)$ as eluting solvent. The collected solid product was 1.1 g. ${ }^{1} \mathrm{H}$ NMR (400 MHz, $\mathrm{CDCl}_{3}, 298 \mathrm{~K}$, Figure S43) $\delta$ 8.79-8.78 (d, 2H); 8.61-8.59 (m, 2H), 7.84-7.81 (m, 2H), $7.63(\mathrm{t}, 1 \mathrm{H})$; 7.37-7.31 (m, 4H); 6.40 (s, 1H); 5.83$5.82(\mathrm{t}, 1 \mathrm{H}) ; 2.10-2.09(\mathrm{t}, 3 \mathrm{H})$.

2.5 Synthesis of D1-Man: $0.2 \mathrm{~g}(0.5 \mathrm{mmol}) \mathrm{a}$, $0.12 \mathrm{~g}(0.5 \mathrm{mmol}) \mathrm{a} 3$ and $7 \mathrm{mg}$ dimethylphenylphosphine were dissoved into $10 \mathrm{~mL}$ DMF. After stiring for $24 \mathrm{~h}$ at $50^{\circ} \mathrm{C}$ under Ar protection, the solvent was removed by evaporation. The compound was seperated via chromatography column using methanol/DCM mixture $\left(\mathrm{V}_{\text {methanol }}: \mathrm{V}_{\mathrm{DCM}}=1: 6\right)$ as eluting solvent. The collected solid product was $27 \mathrm{mg}$. ${ }^{1} \mathrm{H}$ NMR $\left(400 \mathrm{MHz}, \mathrm{CD}_{3} \mathrm{OD}\right.$, $298 \mathrm{~K}$, Figure S44) $\delta 8.76$ (t, 2H); 8.57-8.55 (m, 2H), 8.06-8.03 (m, 2H), 7.69-7.68 (t, 1H); 7.52-7.49 (m, 2H); 7.41-7.40 (d, 2H); $4.83(\mathrm{~d}, 1 \mathrm{H}) ; 4.00-3.93(\mathrm{~m}, 1 \mathrm{H}) ; 3.85-3.80(\mathrm{~m}, 2 \mathrm{H})$; 3.75-3.69 (m, 3H); 3.64-3.51 (m, 3H); 3.12-2.99 (m, 2H); 2.91-2.84 (m, 2H); 1.43-1.41 (d, $3 \mathrm{H}) ;{ }^{13} \mathrm{C}$ NMR (100 MHz, $\mathrm{CD}_{3} \mathrm{OD}, 298 \mathrm{~K}$, Figure S45) $\delta$ 173.44, 173.42 151.22, 150.91, $148.27,139.35,131.75,125.23,124.05,123.70,120.19,100.31,90.29,86.52,73.46,71.19$, $70.73,67.17,65.74,61.53,40.32,35.29,31.51 .29 .30,27.52$, 24.51, 24.48. ESI-MS $(\mathrm{m} / \mathrm{z})$ [D1-Man $+\mathrm{H}]^{+}$calculated for $\mathrm{C}_{32} \mathrm{H}_{33} \mathrm{~N}_{2} \mathrm{O}_{8} \mathrm{~S}, 605.19$; found: 605.20 or [D1-Man + $\mathrm{Na}]^{+}$calculated for $\mathrm{C}_{32} \mathrm{H}_{32} \mathrm{~N}_{2} \mathrm{O}_{8} \mathrm{SNa}, 627.18$; found: 627.18 (Figure $\mathrm{S} 46$ )

2.6 The synthetic procedures of a7 and D2-Man were similar with a5 and D1-Man.

a7: ${ }^{1} \mathrm{H}$ NMR $\left(400 \mathrm{MHz}, \mathrm{CDCl}_{3}, 298 \mathrm{~K}\right.$, Figure $\left.\mathrm{S} 47\right) \delta 8.66-8.64(\mathrm{~m}, 4 \mathrm{H}), 7.65-7.64(\mathrm{t}, 1 \mathrm{H})$, 7.41-7.39 (m, 6H), $6.40(\mathrm{t}, 1 \mathrm{H}), 5.84-5.83(\mathrm{t}, 1 \mathrm{H}), 2.10(\mathrm{t}, 3 \mathrm{H})$.

D2-Man: ${ }^{1} \mathrm{H}$ NMR (400 MHz, $\mathrm{CD}_{3} \mathrm{OD}, 298 \mathrm{~K}$, Figure S48) $\delta$ 8.61-8.59 (t, 4H), 7.71-7.70 (t, 1H), 7.59-7.57 (m, 4H), 7.45-7.44 (d, 2H), $4.83(\mathrm{~d}, 1 \mathrm{H}), 3.98-3.94$ (m, 1H), 3.86-3.84 (m, 2H), 3.76-3.68 (m, 3H), 3.65-3.62 (m, 2H), 3.09-2.98 (m, 2H), 2.94-2.84 (m, 3H), 1.43- 
$1.41(\mathrm{~d}, 3 \mathrm{H}),{ }^{13} \mathrm{C}$ NMR (100 MHz, $\mathrm{CD}_{3} \mathrm{OD}, 298 \mathrm{~K}$, Figure S49) $\delta 177.30,177.28$, $154.85,152.96,136.12,135.42,129.81,127.58,104.27,95.60,91.31,77.42$, $75.19,74.68,71.15,71.11,71.09,44.31,44.28,39.26,35.55,25.52,19.70$. ESI-MS (m/z) [D2-Man $+\mathrm{H}]^{+}$calculated for $\mathrm{C}_{32} \mathrm{H}_{33} \mathrm{~N}_{2} \mathrm{O}_{8} \mathrm{~S}, 605.19$; found: 605.20 or [D2$\mathrm{Man}+\mathrm{Na}]^{+}$calculated for $\mathrm{C}_{32} \mathrm{H}_{32} \mathrm{~N}_{2} \mathrm{O}_{8} \mathrm{SNa}$, 627.18; found: 627.18 (Figure S50)

2.7 Synthesis of b1. $5 \mathrm{~g}(15 \mathrm{mmol})$ maltose, $18 \mathrm{~mL}$ acetic anhydride and $100 \mathrm{mg} \mathrm{I}_{2}$ were mixed into round-bottom flask at room temperature. After solid dissolution, $150 \mathrm{~mL}$ DCM was added into the solution. Then the solution was extracted using saturated $\mathrm{NaHSO}_{3}$ and $\mathrm{NaHCO}_{3}$, respectively. Finally, the organic phase was dried by $\mathrm{MgSO}_{4}$. After evaporating DCM, the product as white solid was $\sim 10 \mathrm{~g}$.

2.8 Synthesis of b2. $10 \mathrm{~g}$ (14.7 mmol) b1 was dissoved in $200 \mathrm{~mL}$ DCM, then $20 \mathrm{~mL} 33 \%$ $\mathrm{HBr} / \mathrm{CH}_{3} \mathrm{COOH}$ was added into the solution at room temperature. After reaction finished, using TLC monitering, the solution was extracted using saturated $\mathrm{NaHCO}_{3}$. After removing the solvent, the compound was seperated via chromatography column using ethyl acetate/petroleum ether mixture (2:1) as eluting solvent. The collected solid product was 5.3 g. ${ }^{1} \mathrm{H}$ NMR (400 MHz, $\mathrm{CDCl}_{3}, 298 \mathrm{~K}$, Figure S51) $\delta$ 6.52-6.51 (d, 1H), 5.64-5.60 (m, $1 \mathrm{H})$, 5.44-5.36 (m, 2H), 5.11-5.06 (m, 1H), 4.89-4.86 (m, 1H), 4.74-4.70 (m, 1H), 4.55$4.51(\mathrm{~m}, 1 \mathrm{H}), 4.30-4.23(\mathrm{~m}, 3 \mathrm{H}), 4.15-4.04(\mathrm{~m}, 2 \mathrm{H}), 3.97-3.93(\mathrm{~m}, 1 \mathrm{H}), 2.16(\mathrm{~s}, 3 \mathrm{H}), 2.11-$ 2.08 (m, 9H), 2.05-2.02 (m, 9H). ${ }^{13} \mathrm{C} \mathrm{NMR} \mathrm{(100} \mathrm{MHz,} \mathrm{CDCl}_{3}, 298 \mathrm{~K}$, Figure S52) $\delta 170.62$, $170.43,170.22,169.80,169.78,169.47,169.37,95.71,86.07,72.49,72.26,71.50,70.94$, $69.95,69.17,68.57,67.83,61.79,61.27,60.32,20.98,20.81,20.72,20.62,20.58,20.54$, 20.53 .

2.9 Synthesis of b3. $5.3 \mathrm{~g}(7.6 \mathrm{mmol}) \mathrm{b} 2$ and $10 \mathrm{~mL}$ 2-bromorthanol were dissoved into $100 \mathrm{~mL}$ DCM. Then $5 \mathrm{~g}(19 \mathrm{mmol})$ silver trifluoromethanesulfonate was added into the solution at room temperature under stirring. After $1 \mathrm{~h}$, the solution was filtered and then the collected solution was evaporated. The compound was seperated via chromatography column using ethyl acetate/petroleum ether mixture (2:1) as eluting solvent. The collected oil product was 3.7 g. ${ }^{1} \mathrm{H}$ NMR (400 MHz, $\mathrm{CDCl}_{3}, 298 \mathrm{~K}$, Figure S53) $\delta 5.43-5.42$ (d, 1H), 5.40-5.35 (t, $1 \mathrm{H}), 5.30-5.25(\mathrm{t}, 1 \mathrm{H}), 5.09-5.04(\mathrm{~m}, 1 \mathrm{H}), 4.89-4.84(\mathrm{~m}, 2 \mathrm{H}), 4.62-4.60(\mathrm{~d}$, $1 \mathrm{H}), 4.55-4.54(\mathrm{~m}, 3 \mathrm{H}), 4.29-4.21(\mathrm{~m}, 2 \mathrm{H}), 4.17-4.11(\mathrm{~m}, 1 \mathrm{H}), 4.08-4.02(\mathrm{~m}, 1 \mathrm{H}), 4.00-$ 
3.96 (m, 1H), 3.87-3.82 (m, 1H), 3.72-3.70 (m, 1H), 3.48-3.45 (m, 1H), 2.16-2.02 (m, 21H). ${ }^{13} \mathrm{C}$ NMR (100 MHz, $\mathrm{CDCl}_{3}, 298 \mathrm{~K}$, Figure S54) $\delta$ 170.42, 170.35, 170.08, 169.86, 169.65, 169.62, 169.34, 100.36, 95.51, 75.01, 72.19, 71.84, 71.80, 69.96, 69.71, 69.22, 68.44, 67.98, $64.62,62.62,61.48,29.93,20.79,20.73,20.61,20.53,20.50,20.47$. MALDI-TOF (m/z) $[\mathrm{b} 3+\mathrm{Na}]^{+}$calculated for $\mathrm{C}_{28} \mathrm{H}_{39} \mathrm{BrO}_{18} \mathrm{Na}, 765.12$ and 767.12; found: 765.13 and 767.13 (Figure S55).

2.10 Synthesis of b4. $3.7 \mathrm{~g}(5.0 \mathrm{mmol}) \mathrm{b} 3,1.42 \mathrm{~g}(12.5 \mathrm{mmol})$ potassium thioacetate and $184 \mathrm{mg}$ tetrabutylammonium iodide were dissoved into $40 \mathrm{~mL}$ DMF. After stiring for 24 $\mathrm{h}$ at $60{ }^{\circ} \mathrm{C}$ under Ar protection, the solvent was removed by evaporating. The compound was seperated via chromatography column using ethyl acetate/petroleum ether mixture (2:1) as eluting solvent. The collected yellow solid product was $2.6 \mathrm{~g} .{ }^{1} \mathrm{H}$ NMR $(400 \mathrm{MHz}$, $\mathrm{CDCl}_{3}, 298 \mathrm{~K}$, Figure S56) $\delta$ 5.37-5.36 (d, 1H), 5.34-5.29 (m, 1H), 5.23-5.19 (t, 1H), 5.03$4.98(\mathrm{t}, 1 \mathrm{H}), 4.83-4.76(\mathrm{~m}, 4 \mathrm{H}), 4.53-4.51(\mathrm{~d}, 1 \mathrm{H}), 4.46-4.42(\mathrm{~m}, 1 \mathrm{H}), 4.23-4.17(\mathrm{~m}, 2 \mathrm{H})$, 4.02-3.87 (m, 4H), 3.61-3.53 (m, 2H), $2.30(\mathrm{~s}, 3 \mathrm{H}), 2.10$ (s, 3H), 2.06 (s, 3H), 2.01-1.96 $(\mathrm{m}, 15 \mathrm{H}) .{ }^{13} \mathrm{C}$ NMR $\left(100 \mathrm{MHz}, \mathrm{CDCl}_{3}, 298 \mathrm{~K}\right.$, Figure S57) $\delta$ 195.20, 170.53, 170.52, 170.46, 169.20, 169.93, 169.62, 169.42, 100.31, 95.52, 75.26, 72.66, 72.20, 71.96, 69.99, 69.31, 68.60, 68.48, 68.00, 62.73, 61.50, 53.43, 30.51, 28.79, 20.88, 20.81, 20.69, 20.58, 20.56,20.55. MALDI-TOF (m/z) [b4 + Na $]^{+}$calculated for $\mathrm{C}_{30} \mathrm{H}_{42} \mathrm{O}_{19} \mathrm{SNa}, 761.19$; found: 761.20 (Figure S58).

2.11 Synthesis of b5. $2.6 \mathrm{~g}(3.5 \mathrm{mmol}) \mathrm{b} 4$ was dissoved into $40 \mathrm{~mL}$ methanol. Then 190 $\mathrm{mg}(3.5 \mathrm{mmol})$ sodium methoxide was added into the solution at room temperature under stirring. After $1 \mathrm{~h}$, ion-exchange resin (hydrogen form) was added to regulate $\mathrm{pH} \sim 6$. the solution was filtered and then compound was collected by removing the solution via evaporation. The collected product was $1.1 \mathrm{~g}$. ${ }^{1} \mathrm{H}$ NMR ( $400 \mathrm{MHz}, \mathrm{CD}_{3} \mathrm{OD}, 298 \mathrm{~K}$, Figure S59) $\delta$ 5.19-5.18 (d, 1H), 5.35-5.33 (d, 1H), 4.02-3.06 (m, 1H), 3.92-3.80 (m, 3H), 3.75$3.61(\mathrm{~m}, 5 \mathrm{H}), 3.58-3.53(\mathrm{t}, 1 \mathrm{H}), 3.48-3.45(\mathrm{~m}, 1 \mathrm{H}), 3.42-3.38(\mathrm{~m}, 1 \mathrm{H}), 3.29-3.24(\mathrm{~m}, 2 \mathrm{H})$, 2.74-2.71 (m, 2H). ${ }^{13} \mathrm{C}$ NMR (100 MHz, $\mathrm{CDCl}_{3}, 298 \mathrm{~K}$, Figure S60) $\delta 102.19,101.49$, $79.83,76.34,75.21,73.66,73.37,73.25,72.74,71.44,70.08,61.34,60.75,23.43$.

2.12 The synthetic procedures of D1-Mal and D2-Mal were similar with that of D1-Man. 
D1-Mal: ${ }^{1} \mathrm{H}$ NMR $\left(400 \mathrm{MHz}, \mathrm{CD}_{3} \mathrm{OD}, 298 \mathrm{~K}\right.$, Figure $\left.\mathrm{S} 61\right) \delta$ 8.64-8.63 (d, 2H), 8.45-8.43 $(\mathrm{m}, 2 \mathrm{H}), 7.93-7.90(\mathrm{~m}, 2 \mathrm{H}), 7.56-7.55(\mathrm{~m}, 1 \mathrm{H}), 7.39-7.36(\mathrm{~m}, 2 \mathrm{H}), 7.28(\mathrm{~d}, 2 \mathrm{H}), 4.71(\mathrm{~d}$, $1 \mathrm{H}), 3.88-3.80(\mathrm{~m}, 1 \mathrm{H}), 3.76-3.44(\mathrm{~m}, 12 \mathrm{H}), 3.03-2.70(\mathrm{~m}, 7 \mathrm{H}), 1.31-1.29(\mathrm{~d}, 3 \mathrm{H})$. ESIMS (m/z) [D1-Mal $+\mathrm{H}]^{+}$calculated for $\mathrm{C}_{38} \mathrm{H}_{43} \mathrm{~N}_{2} \mathrm{O}_{13} \mathrm{~S}, 767.82$; found: 767.83 or [D1-Mal $+\mathrm{Na}]^{+}$calculated for $\mathrm{C}_{38} \mathrm{H}_{43} \mathrm{~N}_{2} \mathrm{O}_{13} \mathrm{SNa}$, 789.80; found: 789.81 (Figure $\mathrm{S} 62$ )

D2-Mal: ${ }^{1} \mathrm{H}$ NMR $\left(400 \mathrm{MHz}, \mathrm{CD}_{3} \mathrm{OD}, 298 \mathrm{~K}\right.$, Figure S63) $\delta$ 8.61-8.60 (t, 4H), 7.72-7.71 (t, 1H), 7.60-7.59 (m, 4H), $7.45(\mathrm{~d}, 2 \mathrm{H}), 5.15(\mathrm{~d}, 1 \mathrm{H}), 4.37-4.35(\mathrm{~m}, 1 \mathrm{H}), 4.12-4.05(\mathrm{~m}$, $1 \mathrm{H}), 3.92-3.78(\mathrm{~m}, 4 \mathrm{H}), 3.70-3.60(\mathrm{~m}, 4 \mathrm{H}), 3.55-3.50(\mathrm{~m}, 1 \mathrm{H}), 3.47-3.43(\mathrm{~m}, 1 \mathrm{H}), 3.41-$ $3.37(\mathrm{~m}, 1 \mathrm{H}), 3.28-3.25(\mathrm{~m}, 2 \mathrm{H}), 3.13-3.08(\mathrm{~m}, 1 \mathrm{H}), 3.04-2.99(\mathrm{~m}, 1 \mathrm{H}), 2.95-2.86(\mathrm{~m}, 3 \mathrm{H})$, 1.43-1.41 (d, 3H). ESI-MS (m/z) [D2-Mal $+\mathrm{H}]^{+}$calculated for $\mathrm{C}_{38} \mathrm{H}_{43} \mathrm{~N}_{2} \mathrm{O}_{13} \mathrm{~S}, 767.82$; found: 767.83 or [D2-Mal $+\mathrm{Na}]^{+}$calculated for $\mathrm{C}_{38} \mathrm{H}_{43} \mathrm{~N}_{2} \mathrm{O}_{13} \mathrm{SNa}$, 789.80; found: 789.88 (Figure S64)

2.13 the synthesis of 2-Man, 3-Man, 6-Man, 2-Mal, 3-Mal and 6-Mal.

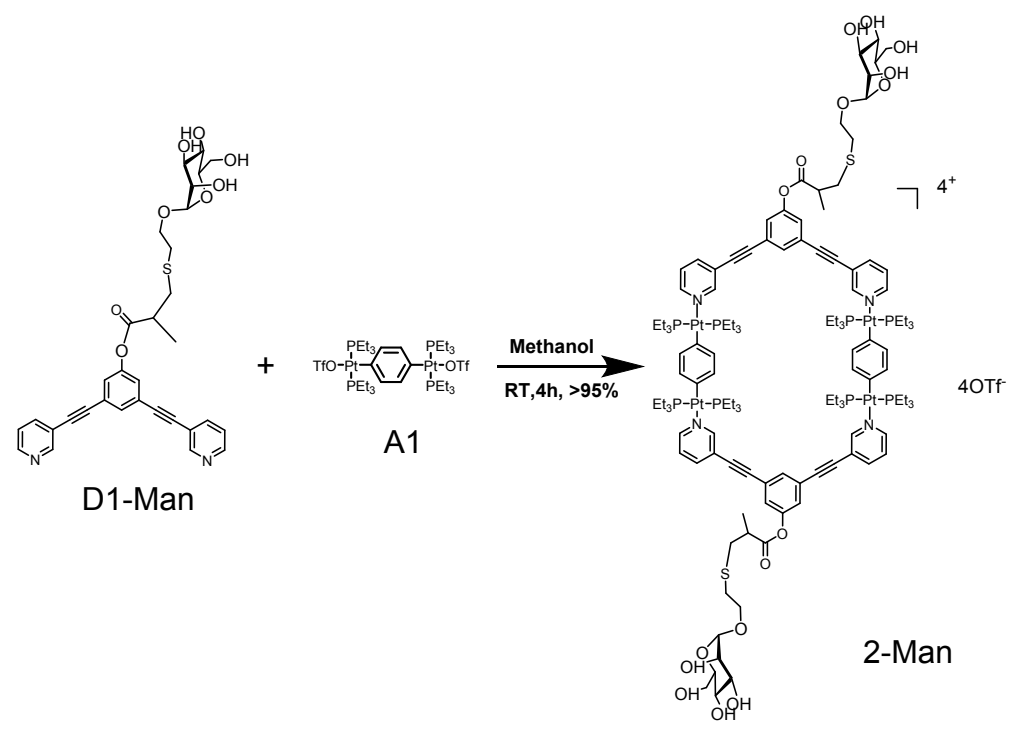

Scheme 3. Self-assembly of 2-Man.

Metallacycle 2-Man: The dipyridyl donor ligand D1-Man $(6.04 \mathrm{mg}, 1 \mu \mathrm{mol})$ and the organoplatinum $180^{\circ}$ acceptor $\mathbf{A 1}(12.36 \mathrm{mg}, 1 \mu \mathrm{mol})$ were weighed accurately into a glass vial. To the vial was added $2.0 \mathrm{~mL}$ methanol and the reaction solution was then stirred at room temperature for $4 \mathrm{~h}$ to yield a homogeneous light solution. Solid product 2-Man was 
obtained by removing the solvent under vacuum. ${ }^{1} \mathrm{H}$ NMR (methanol- $d_{4}, 400 \mathrm{MHz}$ ): $\delta 9.03$ (s, 2H), 8.84-8.86 (d, 2H), 8.25-8.82 (d, 2H), 7.76-7.84 (m, 3H), 7.52-7.54 (m, 4H), ); 4.83 $(\mathrm{d}, 1 \mathrm{H}) ; 4.00-3.93(\mathrm{~m}, 1 \mathrm{H}) ; 3.85-3.80(\mathrm{~m}, 2 \mathrm{H}) ; 3.75-3.69(\mathrm{~m}, 3 \mathrm{H}) ; 3.64-3.51(\mathrm{~m}, 3 \mathrm{H}) ; 3.12-$ 2.99 (m, 2H); 2.91-2.84 (m, 2H); 1.43-1.41 (d, 3H); 1.21-1.43 (m, 24H), 1.14-1.21 (m, $36 \mathrm{H}) .{ }^{31} \mathrm{P}$ NMR (methanol- $d_{4}, 161.9 \mathrm{MHz}$ ): $\delta 13.97$ (s, $J_{\mathrm{Pt}-\mathrm{P}}=2677.4 \mathrm{~Hz}$ ); ESI-TOF-MS of 2-Man: calcd for [M-2OTf] ${ }^{2+}:$ 1690.96, found: 1691.04; calcd for [M -3OTf] ${ }^{3+}$ : 1076.99, found: 1077.05; calcd for [M - 4OTf] ${ }^{4+}$ : 770.75, found: 770.78 .

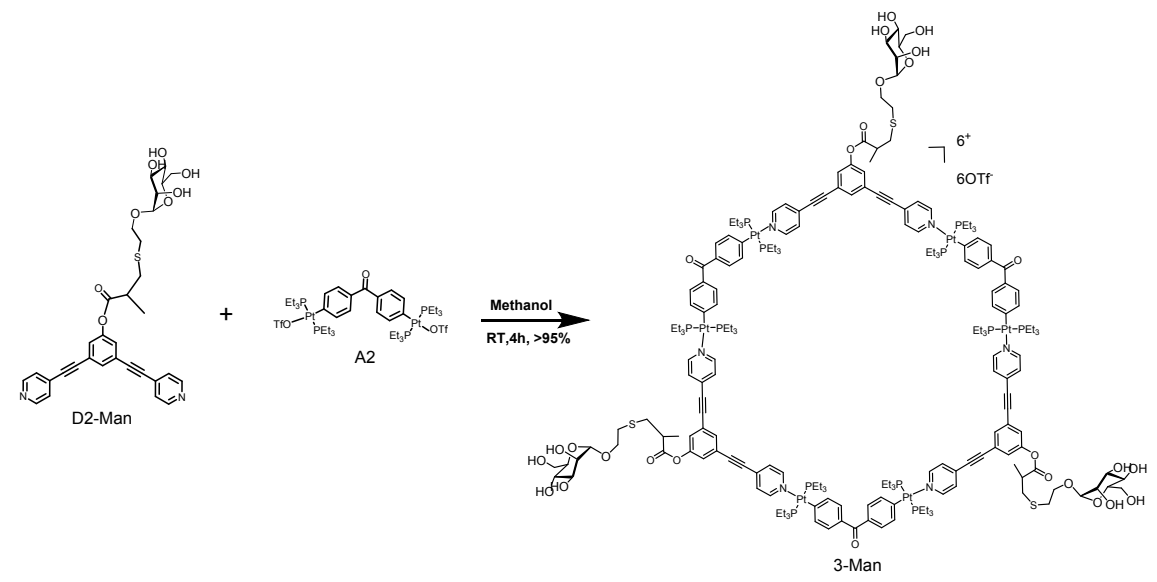

Scheme 4. Self-assembly of 3-Man.

Metallacycle 3-Man: The dipyridyl donor ligand D2-Man (6.04 mg, $1 \mu \mathrm{mol})$ and the organoplatinum $120^{\circ}$ acceptor $\mathbf{A 2}(13.41 \mathrm{mg}, 1 \mu \mathrm{mol})$ were weighed accurately into a glass vial. To the vial was added $2.0 \mathrm{~mL}$ methanol and the reaction solution was then stirred at room temperature for $4 \mathrm{~h}$ to yield a homogeneous light solution. Solid product 3-Man was obtained by removing the solvent under vacuum. ${ }^{1} \mathrm{H}$ NMR (methanol- $d_{4}, 400 \mathrm{MHz}$ ): $\delta$ 8.88-8.89 (d, 4H), 7.85-7.89 (t, 4H), 7.66-7.68 (d, 3H), 7.52-7.58 (m, 6H), ); 4.83 (d, 1H); 4.00-3.93 (m, 1H); 3.85-3.80 (m, 2H); 3.75-3.69 (m, 3H); 3.64-3.51 (m, 3H); 3.12-2.99 (m, $2 \mathrm{H}) ; 2.91-2.84(\mathrm{~m}, 2 \mathrm{H}) ; 1.43-1.41$ (d, 3H), 1.12-1.43 (m, 24H), 1.13-1.23 (m, 36H). ${ }^{31} \mathrm{P}$ NMR (methanol- $\left.d_{4}, 161.9 \mathrm{MHz}\right): \delta 13.73\left(\mathrm{~s}, J_{\mathrm{Pt}-\mathrm{P}}=2640.9 \mathrm{~Hz}\right)$; ESI-TOF-MS of 3-Man: calcd for $[\mathrm{M}-4 \mathrm{OTf}]^{4+}: 1308.87$, found: 1308.81 ; calcd for $[\mathrm{M}-5 \mathrm{OTf}]^{5+}: 1017.31$, found: 1017.32. 


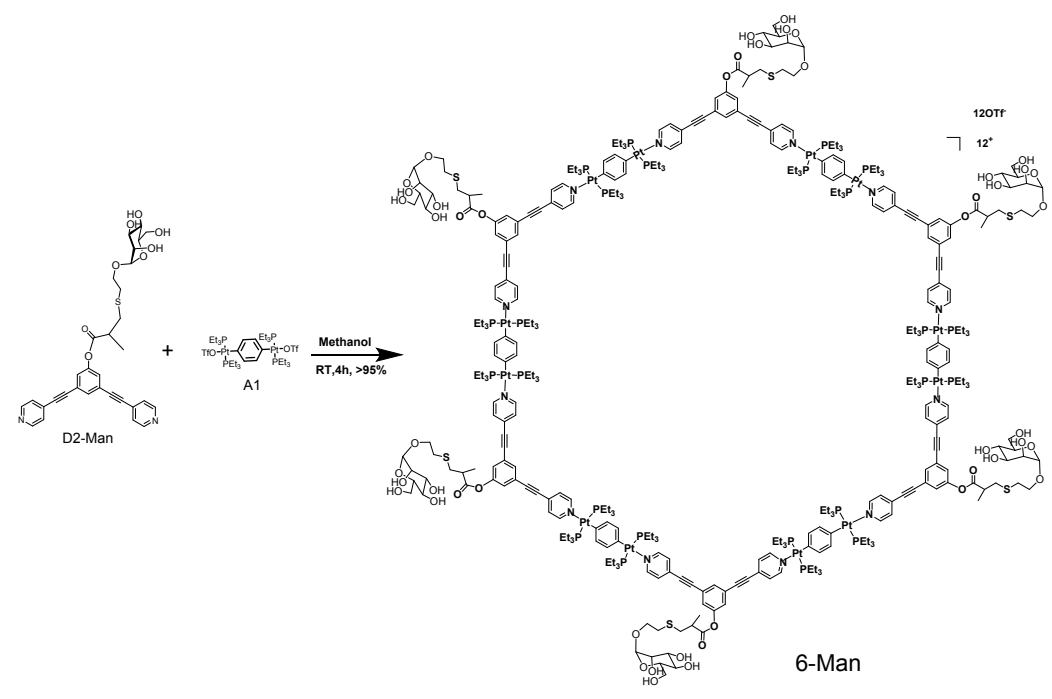

Scheme 5. Self-assembly of 6-Man.

Metallacycle 6-Man: The dipyridyl donor ligand D2-Man (6.04 mg, $1 \mu \mathrm{mol})$ and the organoplatinum $180^{\circ}$ acceptor $\mathbf{A 1}(12.36 \mathrm{mg}, 1 \mu \mathrm{mol})$ were weighed accurately into a glass vial. To the vial was added $2.0 \mathrm{~mL}$ methanol and the reaction solution was then stirred at room temperature for $4 \mathrm{~h}$ to yield a homogeneous light solution. Solid product 6-Man was obtained by removing the solvent under vacuum. ${ }^{1} \mathrm{H}$ NMR (methanol- $d_{4}, 400 \mathrm{MHz}$ ): $\delta 8.85$ (s, 4H), 7.83-7.85 (d, 4H, J=6.0 Hz), 7.52 (s, 2H), 7.12 (s, 4H), ); 4.83 (d, 1H); 4.00-3.93 $(\mathrm{m}, 1 \mathrm{H}) ; 3.85-3.80(\mathrm{~m}, 2 \mathrm{H}) ; 3.75-3.69(\mathrm{~m}, 3 \mathrm{H}) ; 3.64-3.51(\mathrm{~m}, 3 \mathrm{H}) ; 3.12-2.99(\mathrm{~m}, 2 \mathrm{H})$; 2.91-2.84 (m, 2H); 1.43-1.41 (d, 3H) 1.37-1.43 (m, 24H, 1.13-1.18 (m, 36H). ${ }^{31} \mathrm{P}$ NMR (methanol- $\left.d_{4}, 161.9 \mathrm{MHz}\right): \delta 13.70\left(\mathrm{~s}, J_{\mathrm{Pt}-\mathrm{P}}=2712.6 \mathrm{~Hz}\right.$ ); ESI-TOF-MS of 6-Man: calcd for $[\mathrm{M}-7 \mathrm{OTf}]^{7+}: 1428.26$, found: 1428.17 . 


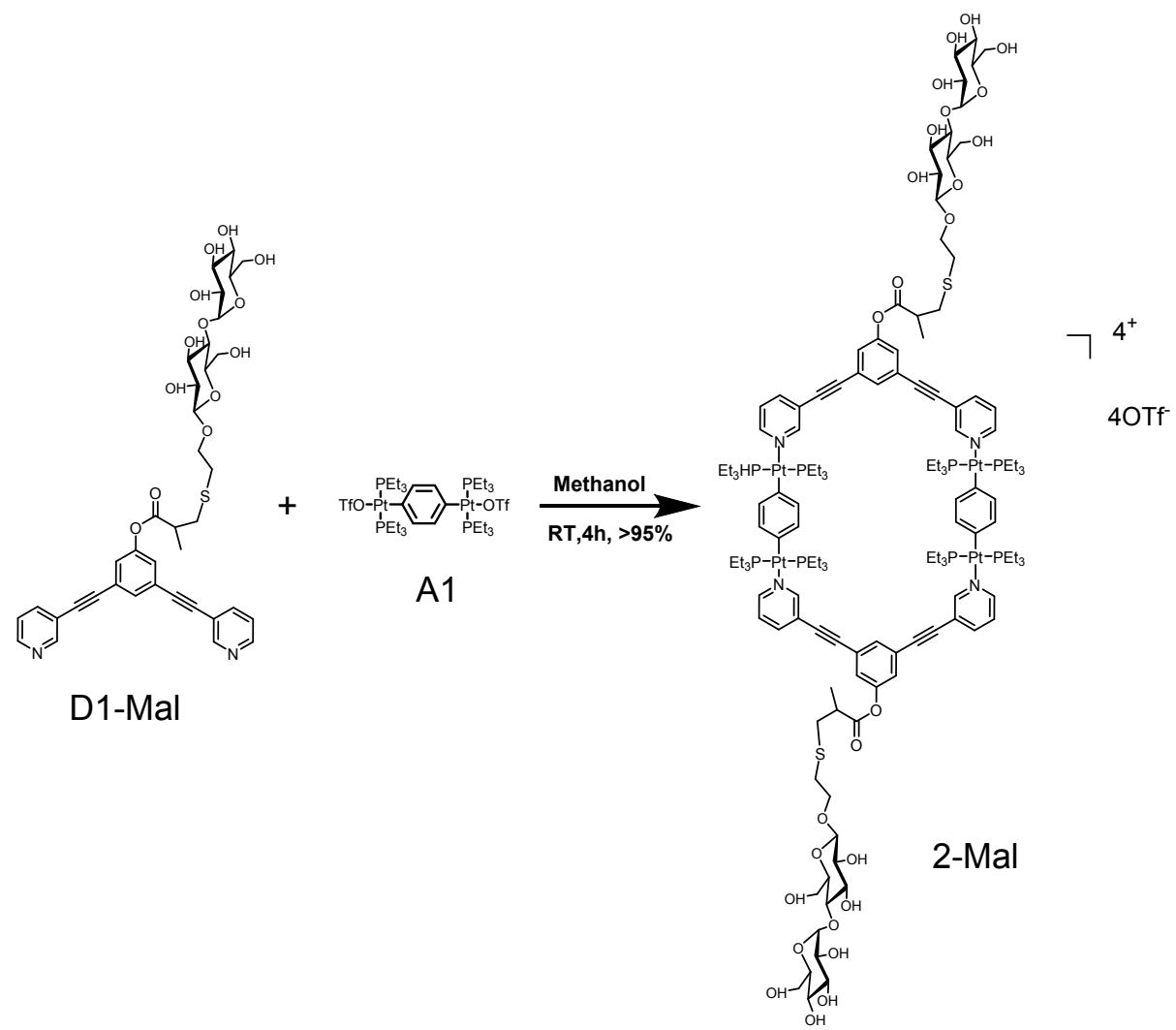

Scheme 6. Self-assembly of 2-Mal.

Metallacycle 2-Mal: The dipyridyl donor ligand D1-Mal $(7.66 \mathrm{mg}, 1 \mu \mathrm{mol})$ and the organoplatinum $180^{\circ}$ acceptor $\mathbf{A 1}(12.36 \mathrm{mg}, 1 \mu \mathrm{mol})$ were weighed accurately into a glass vial. To the vial was added $2.0 \mathrm{~mL}$ methanol and the reaction solution was then stirred at room temperature for $4 \mathrm{~h}$ to yield a homogeneous light solution. Solid product 2-Mal was obtained by removing the solvent under vacuum. ${ }^{1} \mathrm{H}$ NMR (methanol- $d_{4}, 400 \mathrm{MHz}$ ): $\delta 9.04$ $(\mathrm{s}, 2 \mathrm{H}), 8.86(\mathrm{~s}, 2 \mathrm{H}), 8.27(\mathrm{~s}, 2 \mathrm{H}), 7.85(\mathrm{~s}, 1 \mathrm{H}), 7.78(\mathrm{~s}, 2 \mathrm{H})$ 7.53-7.54 (d, 2H), 7.12-7.16 (m, 4H), $4.71(\mathrm{~d}, 1 \mathrm{H}), 3.88-3.80(\mathrm{~m}, 1 \mathrm{H}), 3.76-3.44(\mathrm{~m}, 12 \mathrm{H}), 3.03-2.70(\mathrm{~m}, 7 \mathrm{H}), 1.38-$ 1.67 (m, 24H), 1.31-1.29 (d, 3H), 1.15-1.21 (m, 36H). ${ }^{31} \mathrm{P}$ NMR (methanol- $d_{4}, 161.9 \mathrm{MHz}$ ): $\delta 14.39\left(\mathrm{~s}, J_{\mathrm{Pt}-\mathrm{P}}=2831.0 \mathrm{~Hz}\right)$ 


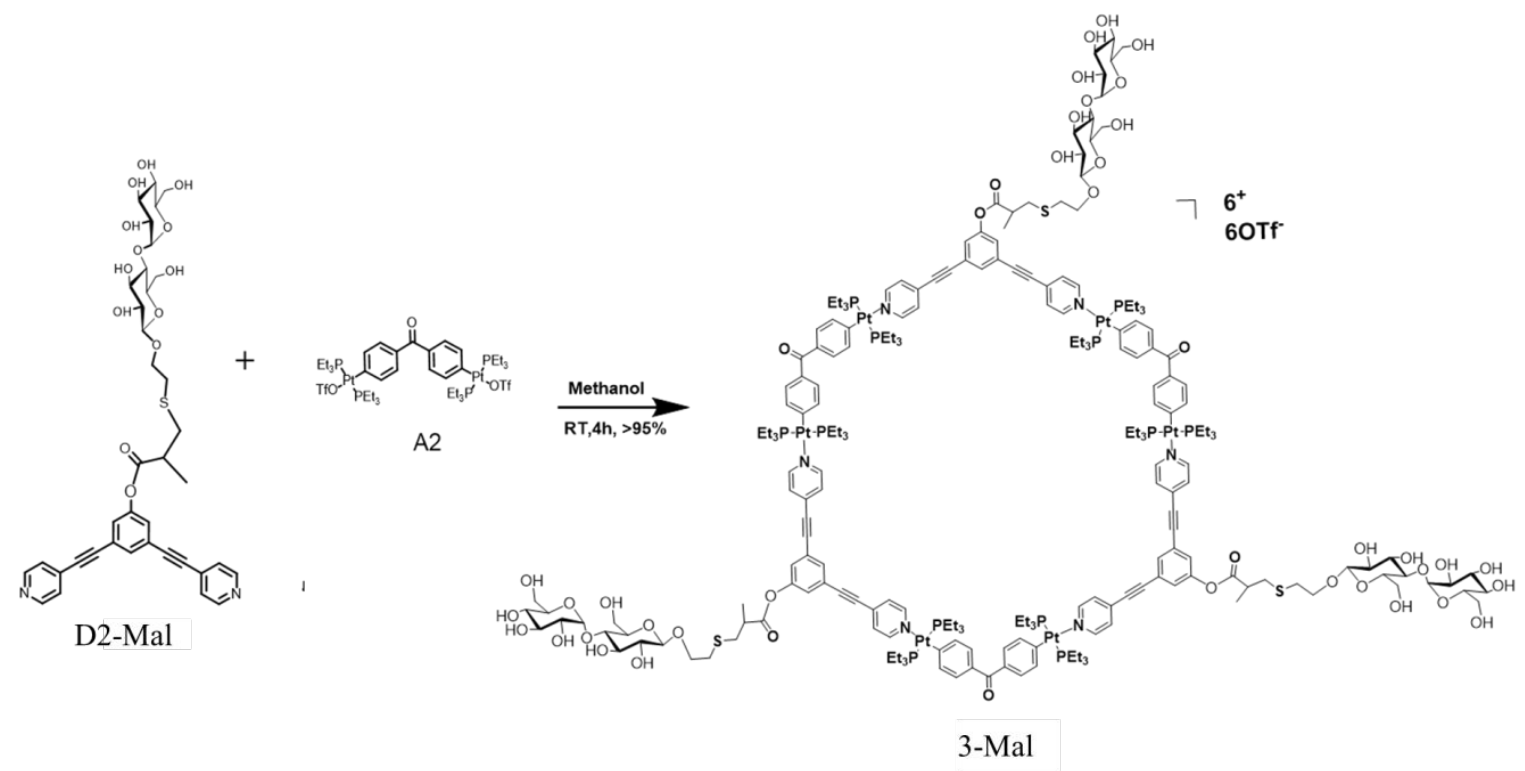

Scheme 7. Self-assembly of 3-Mal.

Metallacycle 3-Mal: The dipyridyl donor ligand D2-Mal $(7.66 \mathrm{mg}, 1 \mu \mathrm{mol})$ and the organoplatinum $120^{\circ}$ acceptor $\mathbf{A 2}(13.41 \mathrm{mg}, 1 \mu \mathrm{mol})$ were weighed accurately into a glass vial. To the vial was added $2.0 \mathrm{~mL}$ methanol and the reaction solution was then stirred at room temperature for $4 \mathrm{~h}$ to yield a homogeneous light solution. Solid product 3-Mal was obtained by removing the solvent under vacuum. ${ }^{1} \mathrm{H}$ NMR (methanol- $d_{4}, 400 \mathrm{MHz}$ ): $\delta$ 8.90-8.92 (d, 4H), 7.90-7.91 (d, 4H), 7.51-7.68 (m, 3H,), 7.38-7.40 (m, 8H), $5.15(\mathrm{~d}, 1 \mathrm{H})$, 4.37-4.35 (m, 1H), 4.12-4.05 (m, 1H), 3.92-3.78 (m, 4H), 3.70-3.60 (m, 4H), 3.55-3.50 (m, 1H), 3.47-3.43 (m, 1H), 3.41-3.37 (m, 1H), 3.28-3.25 (m, 2H), 3.13-3.08 (m, 1H), 3.04$2.99(\mathrm{~m}, 1 \mathrm{H}), 2.95-2.86(\mathrm{~m}, 3 \mathrm{H}), 1.43-1.41(\mathrm{~d}, 3 \mathrm{H}), 1.38-1.67(\mathrm{~m}, 24 \mathrm{H}), 1.15-1.21(\mathrm{~m}$, 36H). ${ }^{31} \mathrm{P}$ NMR (methanol- $\left.d_{4}, 161.9 \mathrm{MHz}\right): \delta 14.80\left(\mathrm{~s}, J_{\mathrm{Pt}-\mathrm{P}}=2731.5 \mathrm{~Hz}\right)$. 


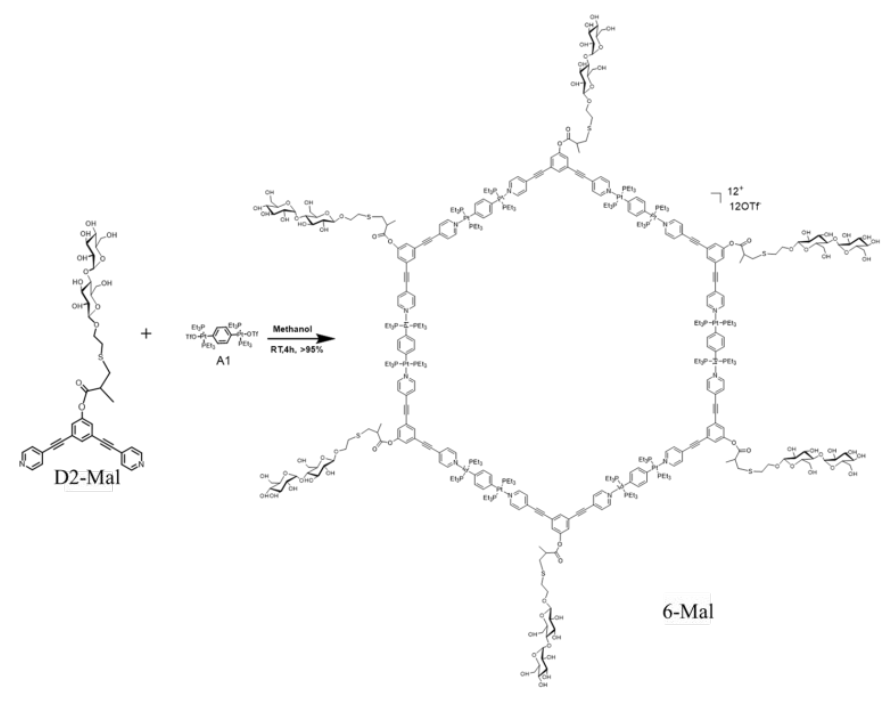

Scheme 8. Self-assembly of 6-Mal.

Metallacycle 6-Mal: The dipyridyl donor ligand D2-Mal $(7.66 \mathrm{mg}, 1 \mu \mathrm{mol})$ and the organoplatinum $180^{\circ}$ acceptor $\mathbf{A 1}(12.36 \mathrm{mg}, 1 \mu \mathrm{mol})$ were weighed accurately into a glass vial. To the vial was added $2.0 \mathrm{~mL}$ methanol and the reaction solution was then stirred at room temperature for $4 \mathrm{~h}$ to yield a homogeneous light solution. Solid product 6-Mal was obtained by removing the solvent under vacuum. ${ }^{1} \mathrm{H}$ NMR (methanol- $d_{4}, 400 \mathrm{MHz}$ ): $\delta$ 8.85-8.87 (d, 4H), 7.84-7.86 (d, 5H), $7.79(\mathrm{~s}, 2 \mathrm{H}), 6.90-7.14(\mathrm{~m}, 4 \mathrm{H}), 5.15(\mathrm{~d}, 1 \mathrm{H}), 4.37-$ $4.35(\mathrm{~m}, 1 \mathrm{H}), 4.12-4.05(\mathrm{~m}, 1 \mathrm{H}), 3.92-3.78(\mathrm{~m}, 4 \mathrm{H}), 3.70-3.60(\mathrm{~m}, 4 \mathrm{H}), 3.55-3.50(\mathrm{~m}, 1 \mathrm{H})$, 3.47-3.43 (m, 1H), 3.41-3.37 (m, 1H), 3.28-3.25 (m, 2H), 3.13-3.08 (m, 1H), 3.04-2.99 (m, 1H), 2.95-2.86 (m, 3H), 1.43-1.41 (d, 3H), 1.38-1.67 (m, 24H), 1.15-1.21 (m, 36H); ${ }^{31} \mathrm{P}$ NMR (methanol- $\left.d_{4}, 161.9 \mathrm{MHz}\right): \delta 14.39$ (s, $\left.J_{\mathrm{Pt}-\mathrm{P}}=2828.6 \mathrm{~Hz}\right)$. 
iii. NMR characterization and geometric illustration

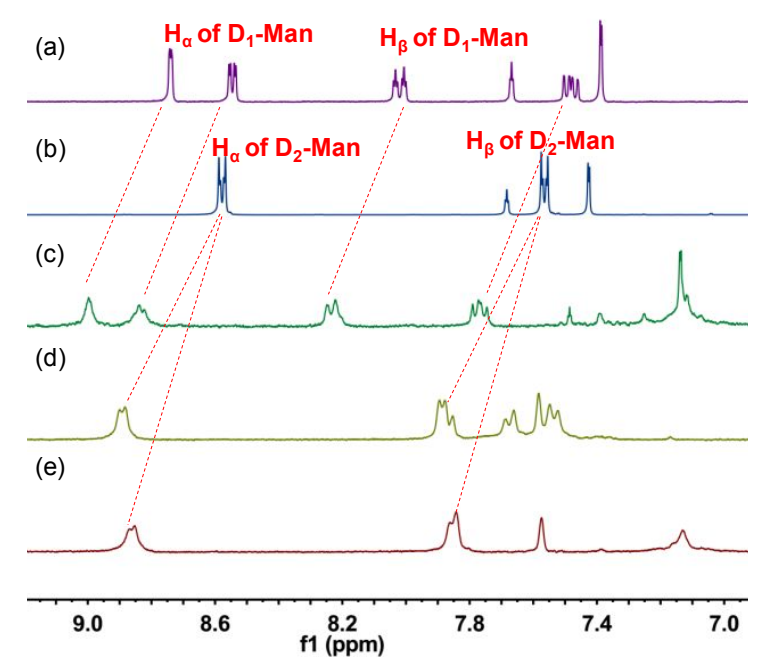

Figure S1. ${ }^{1} \mathrm{H}$ NMR spectra $\left(400 \mathrm{MHz}\right.$, in $\left.\mathrm{CD}_{3} \mathrm{OD}, 25^{\circ} \mathrm{C}\right)$ of $120^{\circ}$ donor D1-Man (a), $0^{\circ}$ donor D2-Man (b), self-assembled hexagon 2-Man (c), self-assembled hexagon 3-Man (d), and self-assembled hexagon 6-Man (e).

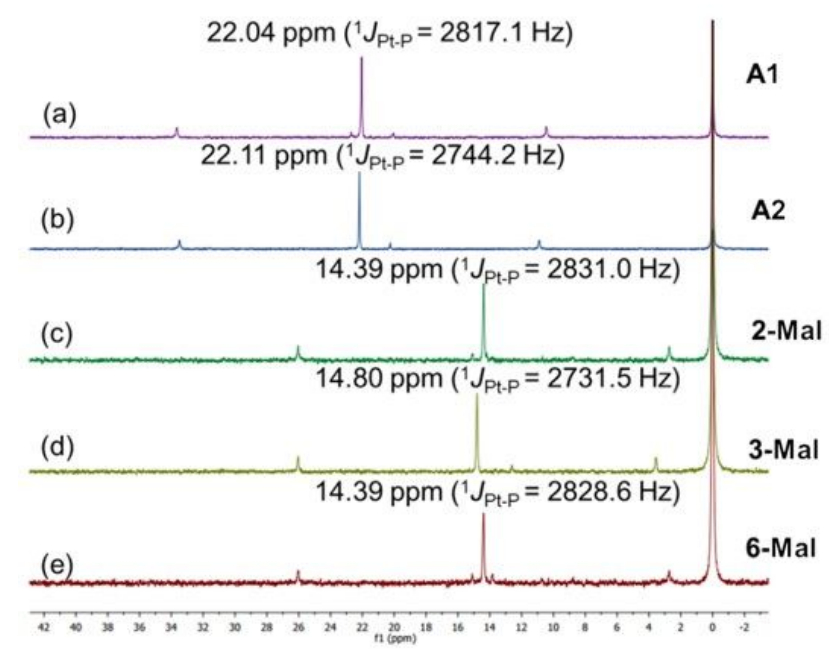

Figure S2. (a)-(e) ${ }^{31} \mathrm{P}$ NMR spectra (161.9 $\mathrm{MHz}$, in $\mathrm{CD}_{3} \mathrm{OD}, 25^{\circ} \mathrm{C}$ ) of (a) $180^{\circ}$ acceptor A1, (b) $120^{\circ}$ acceptor $\mathbf{A 2}$, (c) self-assembled hexagon 2-Mal, (d) self-assembled hexagon 3-Mal, and (e) self-assembled hexagon 6-Mal. 


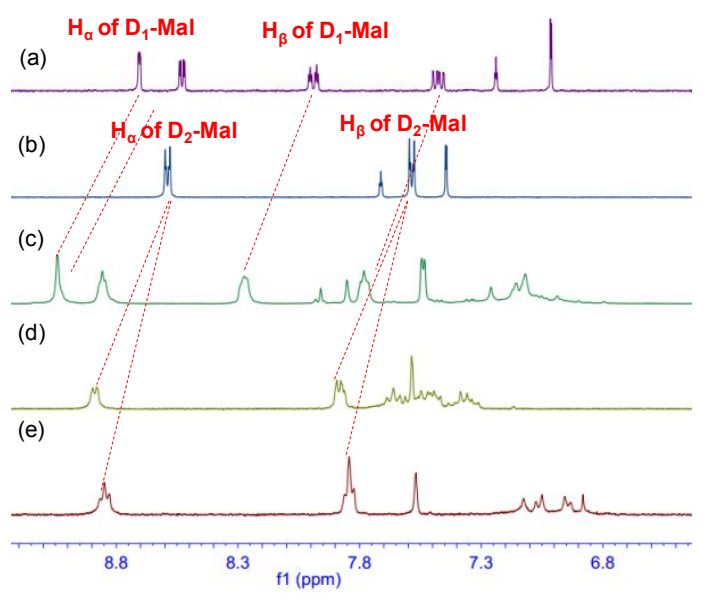

Figure S3. ${ }^{1} \mathrm{H}$ NMR spectra (400 MHz, in $\mathrm{CD}_{3} \mathrm{OD}, 25^{\circ} \mathrm{C}$ ) of $120^{\circ}$ donor D1-Mal (a), $0^{\circ}$ donor D2-Mal (b), self-assembled hexagon 2-Mal (c), self-assembled hexagon 3-Mal (d), and self-assembled hexagon 6-Mal (e).
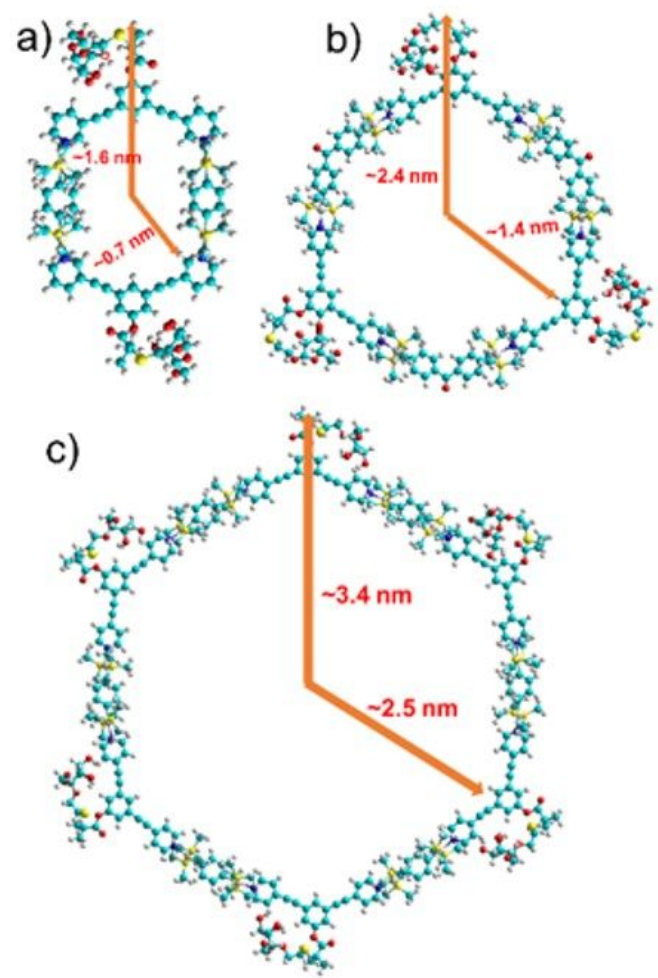

Figure S4. Geometrical structures optimized via the PM6 semiempirical molecular orbital method: (a) 2-Man, (b) 3-Man and (c) 6-Man. 
iv. Characterization of 2-Man in aqueous soltion

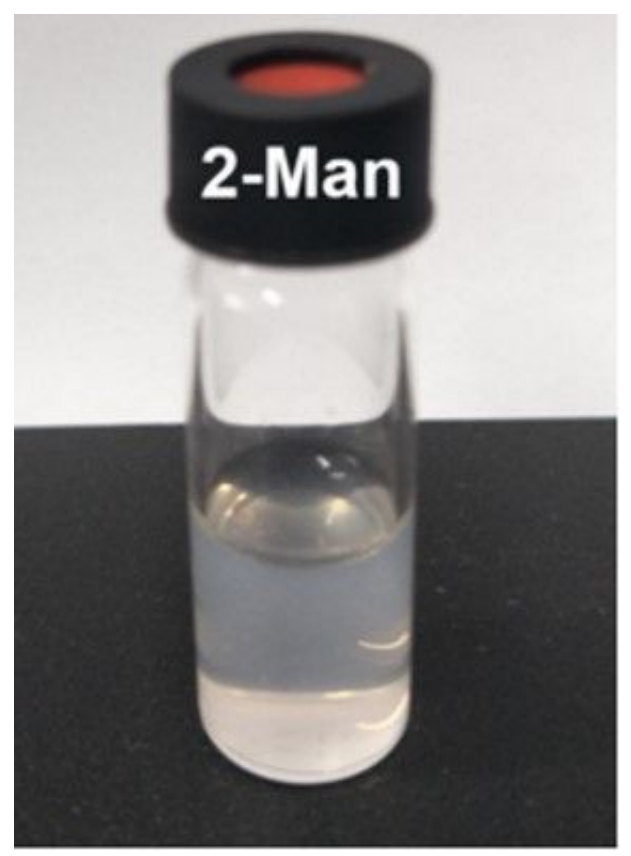

Figure S5. Photo picture of 2-Man in aqueous solution $(0.4 \mathrm{mg} / \mathrm{mL})$.

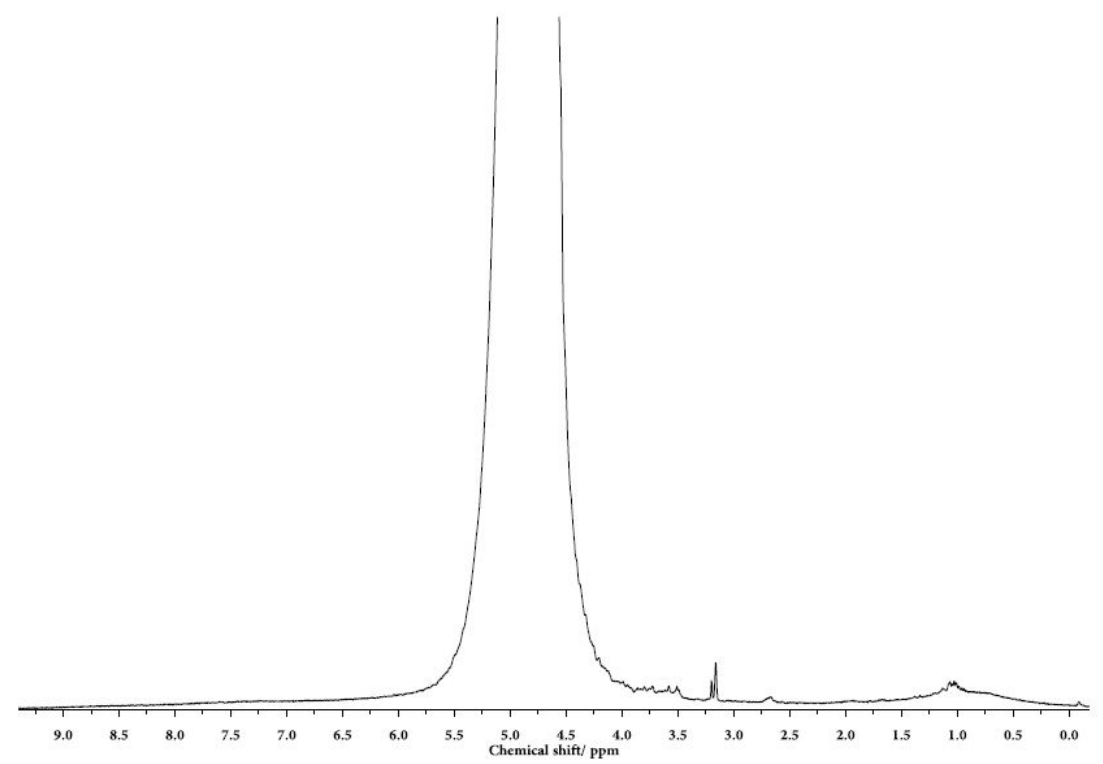

Figure S6. ${ }^{1} \mathrm{H}$ NMR spectrum $\left(400 \mathrm{MHz}\right.$, in $\left.\mathrm{D}_{2} \mathrm{O}: \mathrm{CD}_{3} \mathrm{OD}=20: 1,25^{\circ} \mathrm{C}\right)$ of 2-Man. 


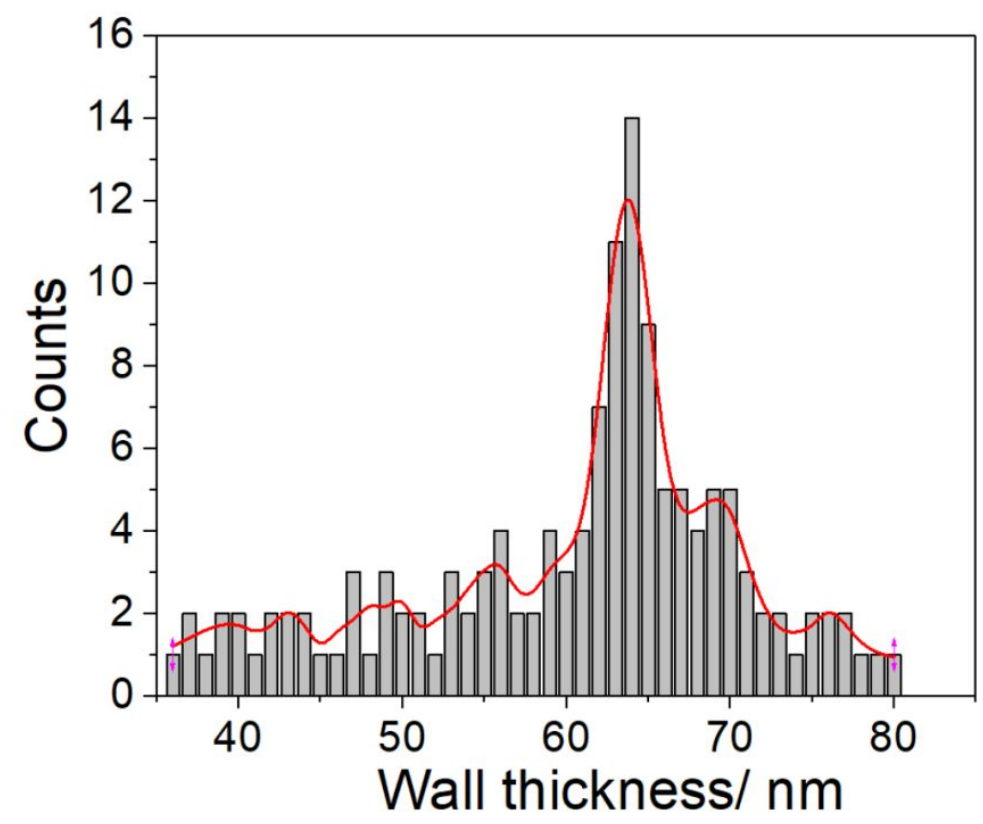

Figure S7. Wall thickness distribution measured from TEM images of multi-layered vesicels of 2-Man in water.
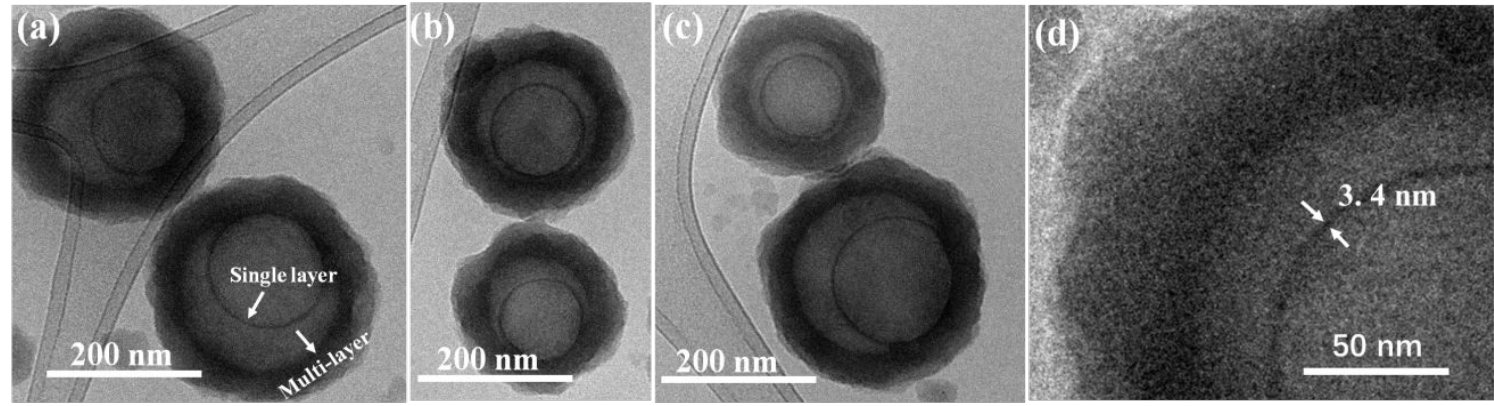

Figure S8. (a)-(c) Cryo-TEM images of 2-Man in aqueous solution. The inside single layer and outside multiple layer were pointed by white arrows. (d) The enlarged Cryo-TEM image with single-layered thickness about $3.4 \mathrm{~nm}$. 
v. Molecular simulations

v-1. Dissipative particle dynamics (DPD) simulation

The dissipative particle dynamics (DPD) simulations were applied to investigate the underlying mechanism of the self-assembly behaviors of different metallacarbohydrates in the water. As shown in Fig. S9, the components of these metallacarbohydrates were very similar, but their topology and size were different. To denote such similarity and difference (among 2-Man, 3-Man, 6-Man), and for the sake of simplicity, we constructed different CG rings with different size using the same type of beads (Py, Bz, Pt, S, L beads) in DPD simulations (see Figure S9). To further differentiate 2-Man (or 3-Man, 6-Man) from 2Mal (or 3-Mal,6-Mal), the number of sugar beads was changed from one to two.

DPD is a coarse-grained (CG) simulation technique with hydrodynamic interaction. ${ }^{3-4}$ The dynamics of the elementary units, which are the so-called DPD beads, is governed by Newton's equation of motion. Typically, there are three types of pairwise forces acting on bead $i$ by bead $j$ in the DPD: ${ }^{5}$ the conservative force, dissipative force, and random force. The conservative force $\boldsymbol{F}_{i j}^{C}=a_{i j}\left(1-r_{i j}\right) / r_{c} \cdot \boldsymbol{e}_{i j}$ is used to model the repulsive interaction between beads $i$ and $j$, where $r_{i j}=\left|\boldsymbol{r}_{i j}\right|$ is the distance between the beads, $\boldsymbol{e}_{i j}=\boldsymbol{r}_{i j} / r_{i j}$ is the unit vector, $r_{c}$ is the cutoff radius of the force, and $a_{i j}$ represents the maximum repulsion interaction between beads $i$ and $j$. For any two beads of the same type, we take the repulsive parameter $a_{i j}=25 k_{B} T / r_{c}$; for any two beads of different types, the interaction parameter $a_{i j}$ can be calculated based on the Flory-Huggins interaction parameter $\chi_{i j}: a_{i j}=a_{i i}$ $+3.497 \chi_{i j}$, where $\chi_{i j}$ is determined by the solubility parameter difference between the beads. ${ }^{5}$ Here for the sake of simplicity, $a_{i j}$ is set as $25 k_{B} T / r_{c}$ when the two beads are both hydrophilic or both hydrophobic; $a_{i j}$ is set as $45 k_{B} T / r_{c}$ when one is hydrophilic and the other is hydrophobic. ${ }^{5-6}$ In particular, to model the effective $\pi-\pi$ stacking between the pyridine and/or benzene molecules (which is proven to play important role in the supramolecular self-assembly), we set $a_{i j}=15 k_{B} T / r_{c}$ between Py beads and/or Bz beads. Besides, since there exist the hydrogen bonds between the coating sugars, we also set $a_{i j}$ $=15 k_{B} T / r_{c}$ between the sugar beads. The dissipative force and random force were served as thermostat. 
Further, we used a harmonic bond $U_{s}=k_{s}\left(1-r_{i, i+1} / l_{0}\right)^{2}\left(k_{s}=1000 k_{B} T / r_{c}^{2}, l_{0}=0.35 \mathrm{~nm}\right)$ between the neighboring beads to ensure the integrality of the ring. We also used a threebody bond angle potential $U_{a}=k_{a}\left(1-\cos \left(\phi-\phi_{0}\right)\right)$ to depict the rigidity of the $\operatorname{ring}\left(k_{a}=10\right.$ $k_{B} T, \phi_{0}=180^{\circ}$ or $120^{\circ}$ ). In particular, to maintain the main structure of the ring, each Py$\mathrm{Bz}-\mathrm{Py}$ unit at the corner of the ring was treated as the rigid body during the simulations.

In the simulations, the velocity-Verlet integration algorithm was used to update the coordination of each bead, with the integration time step $\Delta t=0.016 \tau$. We chose the cutoff radius $r_{c}$, bead mass $\mathrm{m}$, and energy $\mathrm{k}_{\mathrm{B}} \mathrm{T}$ as the simulation units. All simulations were performed in an NVT ensemble with temperature $T=1.0$. The size of the simulation box was about $60 r_{c} \times 60 r_{c} \times 60 r_{c}$ with the number density of $\rho=3$. The periodic boundary conditions were adopted in all three directions. The DPD units can be converted into SI units by matching the volume of one water bead to that of three water molecules and the water bead diffusion constant in the simulation to that of pure water: ${ }^{5} r_{c}=0.65 \mathrm{~nm}$ and $\tau=$ $0.16 \mathrm{~ns}$. All simulations in this work were carried out by using the soft package LAMMPS (1 Feb 2014). ${ }^{7}$

\section{v-2. Brownian dynamics (BD) simulation}

The Brown dynamics simulations ${ }^{8}$ were used to investigate the fusion mechanism of open vesicles (OVs). Here, for the sake of simplicity, the hollow sphere particles with open sites were treated as the OVs (see Fig. Xa), and the particles moved as rigid ones during the

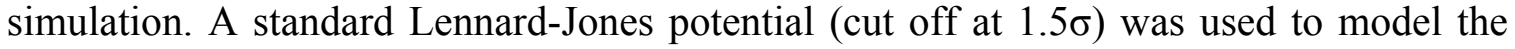
attractive interaction among the mouth beads (green) and the end beads (purple), where $\epsilon$ is chosen as $\epsilon / \mathrm{kT}_{0}=1.0$ and $\sigma=0.8 \mathrm{r}_{0}$. Typically, there were three possible ways for the fusion of particles (Figure Xb), i.e., mouth-to-end (I), mouth-to-mouth (II) and end-to-end (III). To calculate the system energy in the three cases, at the beginning of the simulation, we put two particles closely, with different intial conformations (corresponding to the three cases), respectively. To compare the occurring probability of the three cases, we performed additional simulations for the free assembly of eight particles, where the particles were initially put far away in the simulation box. 
All BD simulations were performed in the NVT ensemble by using the LAMMPS package (1 Feb2014). ${ }^{7}$ During the simulation, the temperature was coupled at $1.0 \mathrm{~T}_{0}$ using the Langevin thermostat. The time step was $0.01 \tau$, and the data were collected every $100 \tau$, with the total simulation time lager than $1000000 \tau$. 

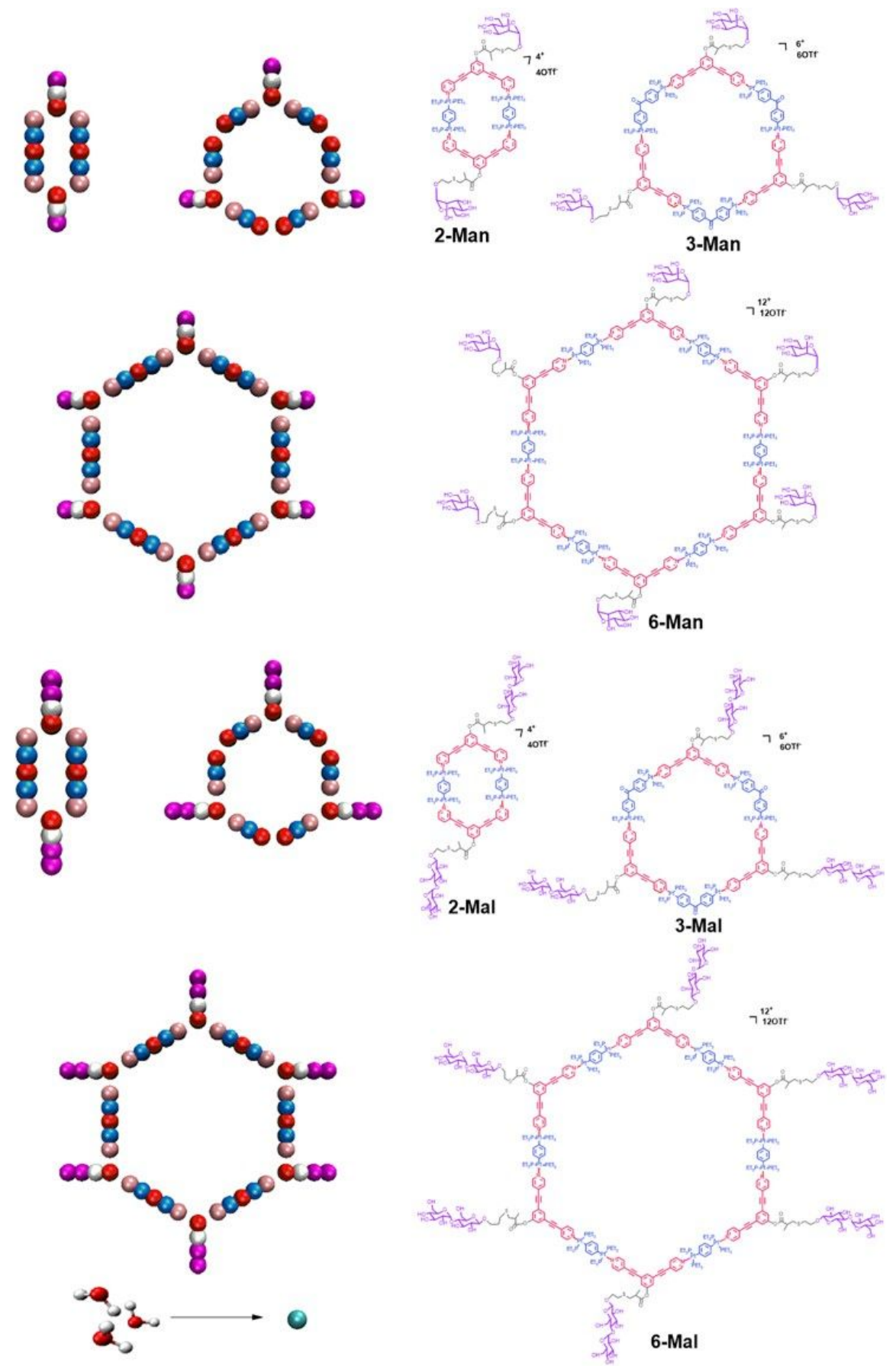

Figure S9. Schematic illustration of the CG models for metallacarbohydrates with different structures and water molecules in DPD simulation: Py bead (pyridine, pink bead), Bz bead (benzene, red bead), Pt bead (Et ${ }_{3} \mathrm{P}-\mathrm{Pt}-\mathrm{PEt}_{3}$, blue bead), L bead (the link that connects the ring and sugar, white bead), S bead (sugar, magenta bead), W bead (water, cyan bead). 
vi. ${ }^{1} \mathrm{H}$ NMR of 3-Man and 6-Man in aqueous solution

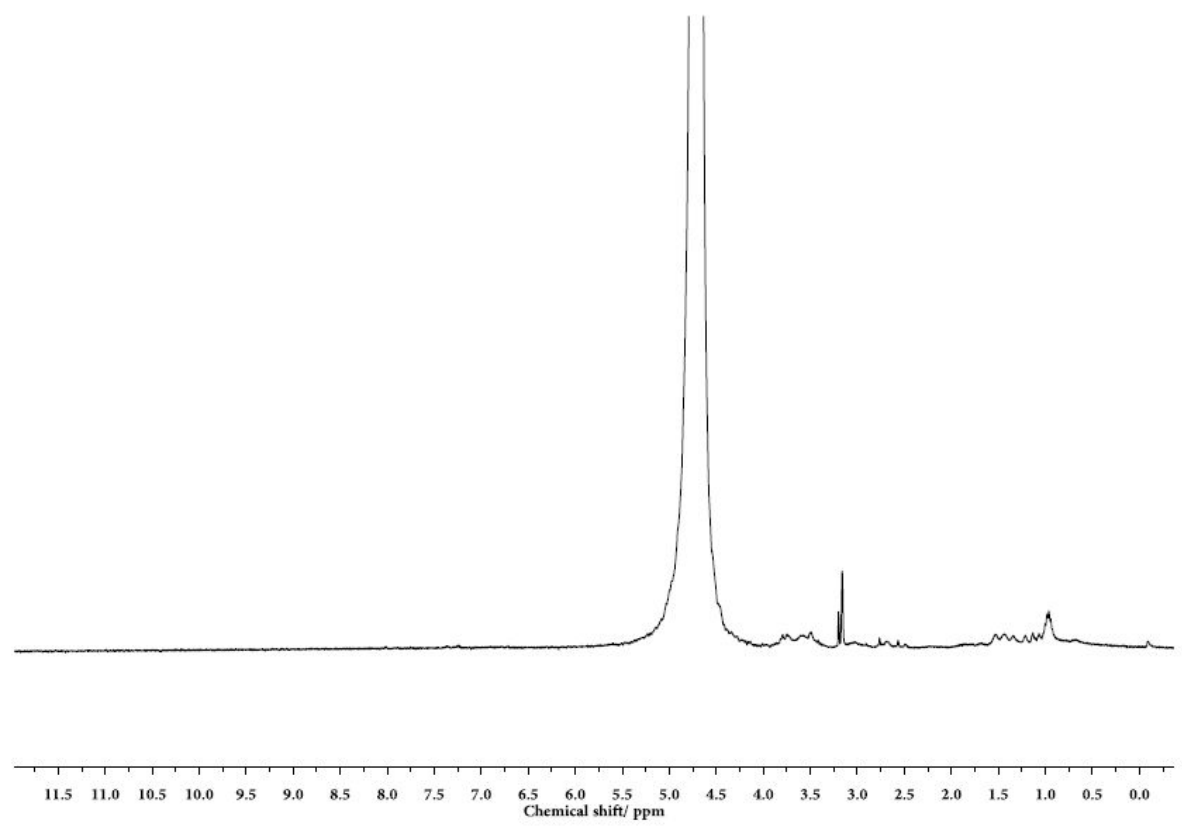

Figure S10. ${ }^{1} \mathrm{H}$ NMR spectrum $\left(400 \mathrm{MHz}\right.$, in $\left.\mathrm{D}_{2} \mathrm{O}: \mathrm{CD}_{3} \mathrm{OD}=20: 1,25^{\circ} \mathrm{C}\right)$ of 3-Man.

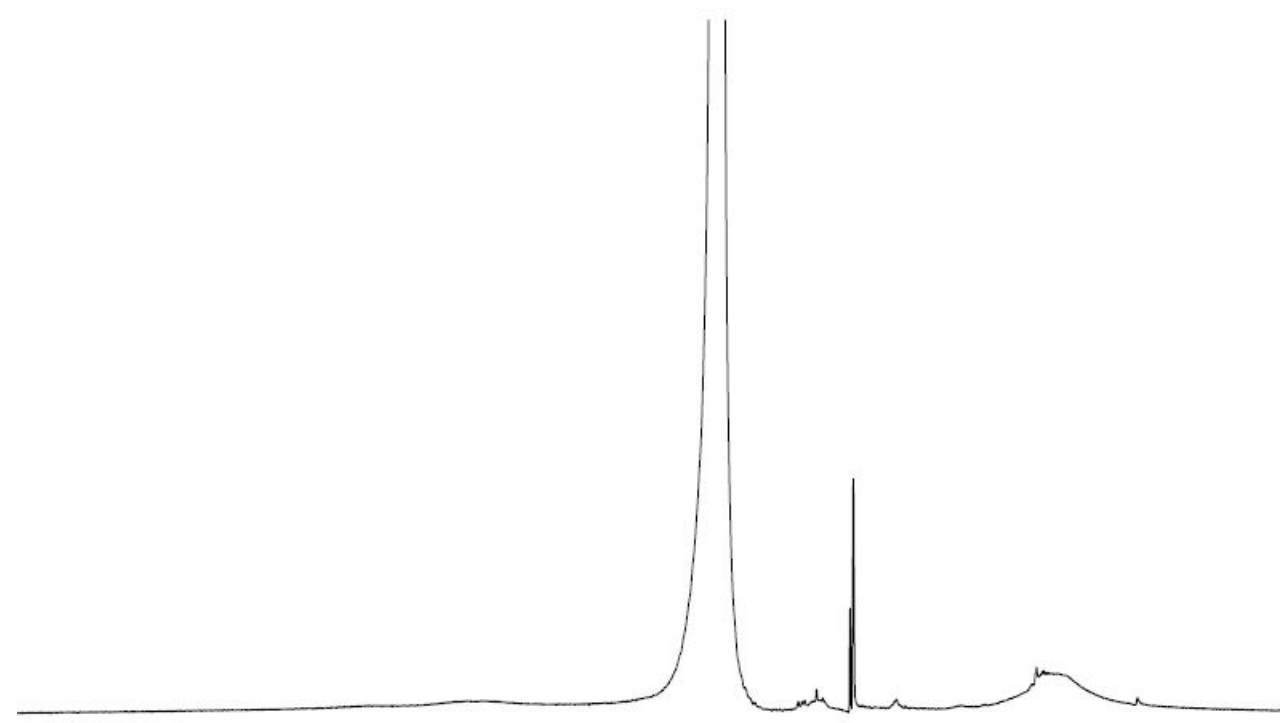

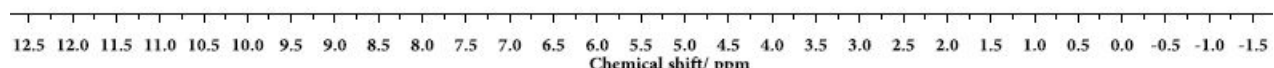

Figure S11. ${ }^{1} \mathrm{H}$ NMR spectrum $\left(400 \mathrm{MHz}\right.$, in $\left.\mathrm{D}_{2} \mathrm{O}: \mathrm{CD}_{3} \mathrm{OD}=20: 1,25^{\circ} \mathrm{C}\right)$ of 6-Man. 
vii. Characterization of 3-Man and 6-Man in aqueous soltion
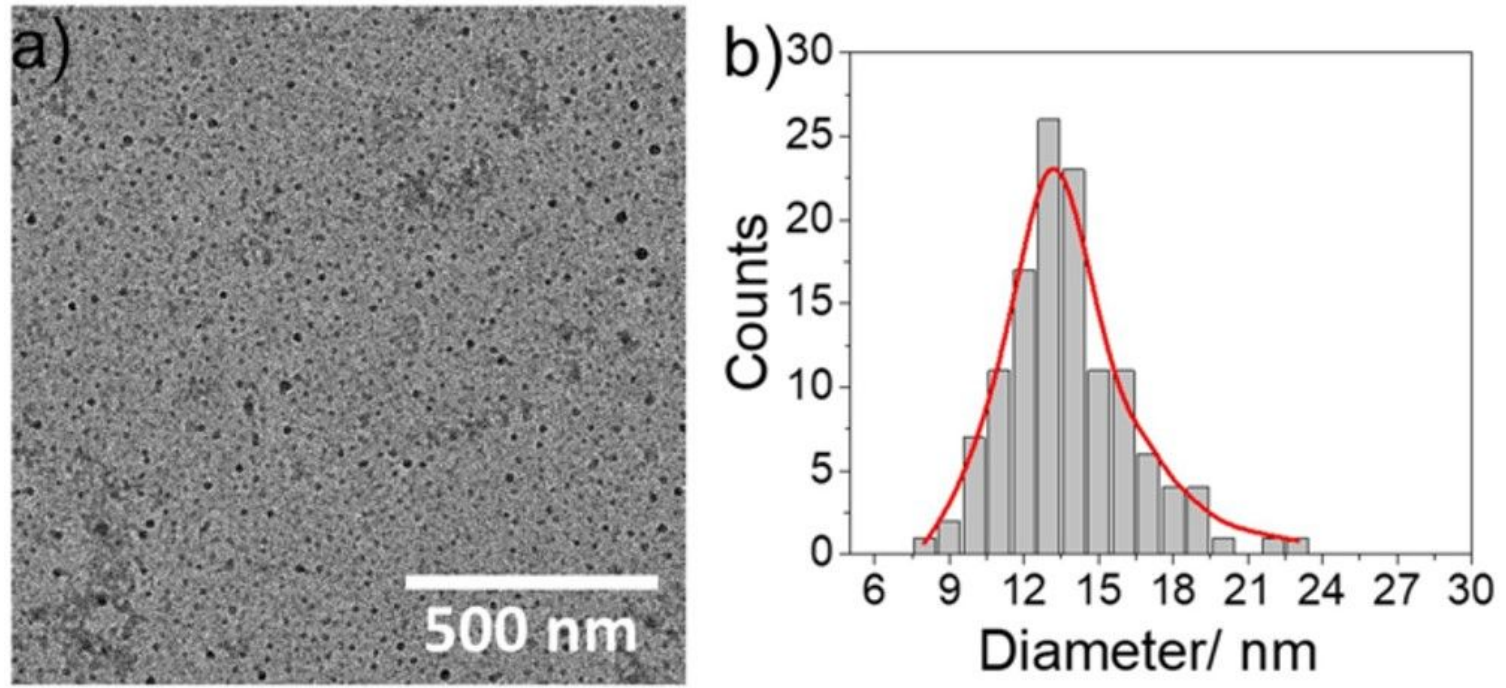

Figure S12. (a) TEM image of 3-Man in aqueous solution. (b) Diameter distribution calculated from TEM image.

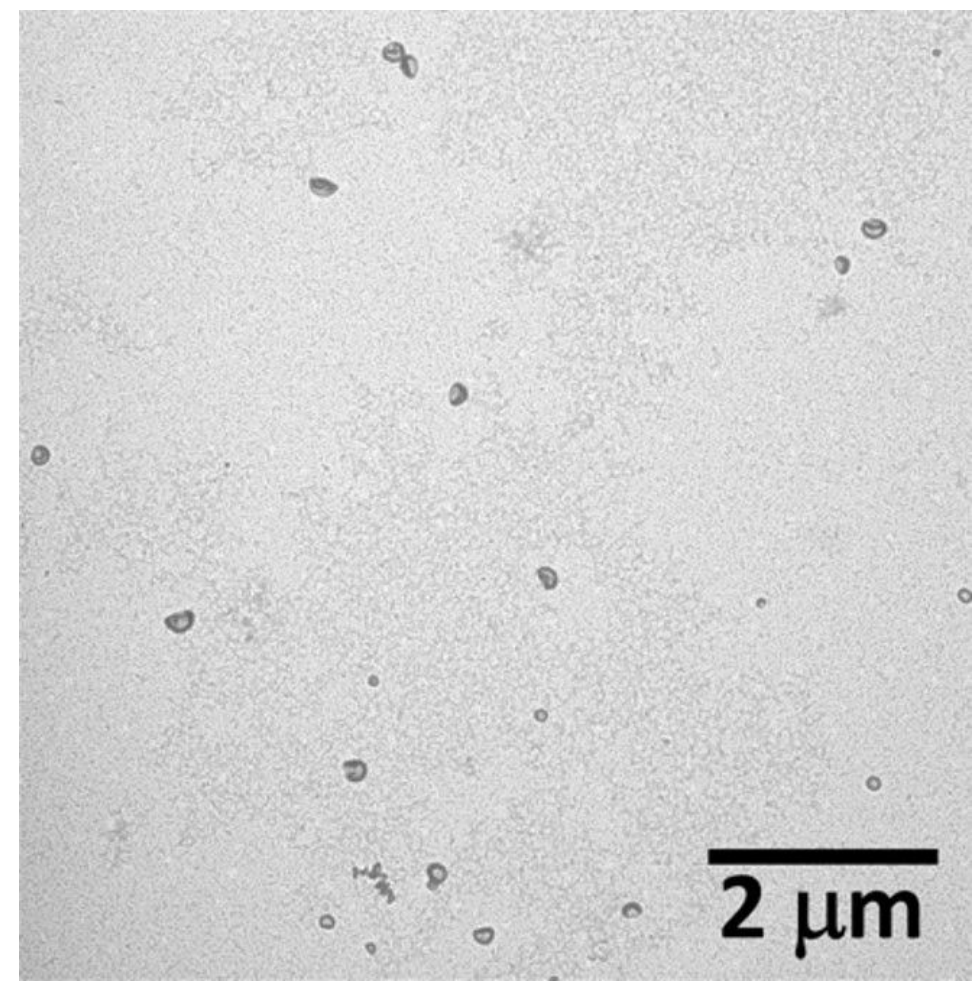

Figure S13. TEM image of 6-Man in aqueous solution. 


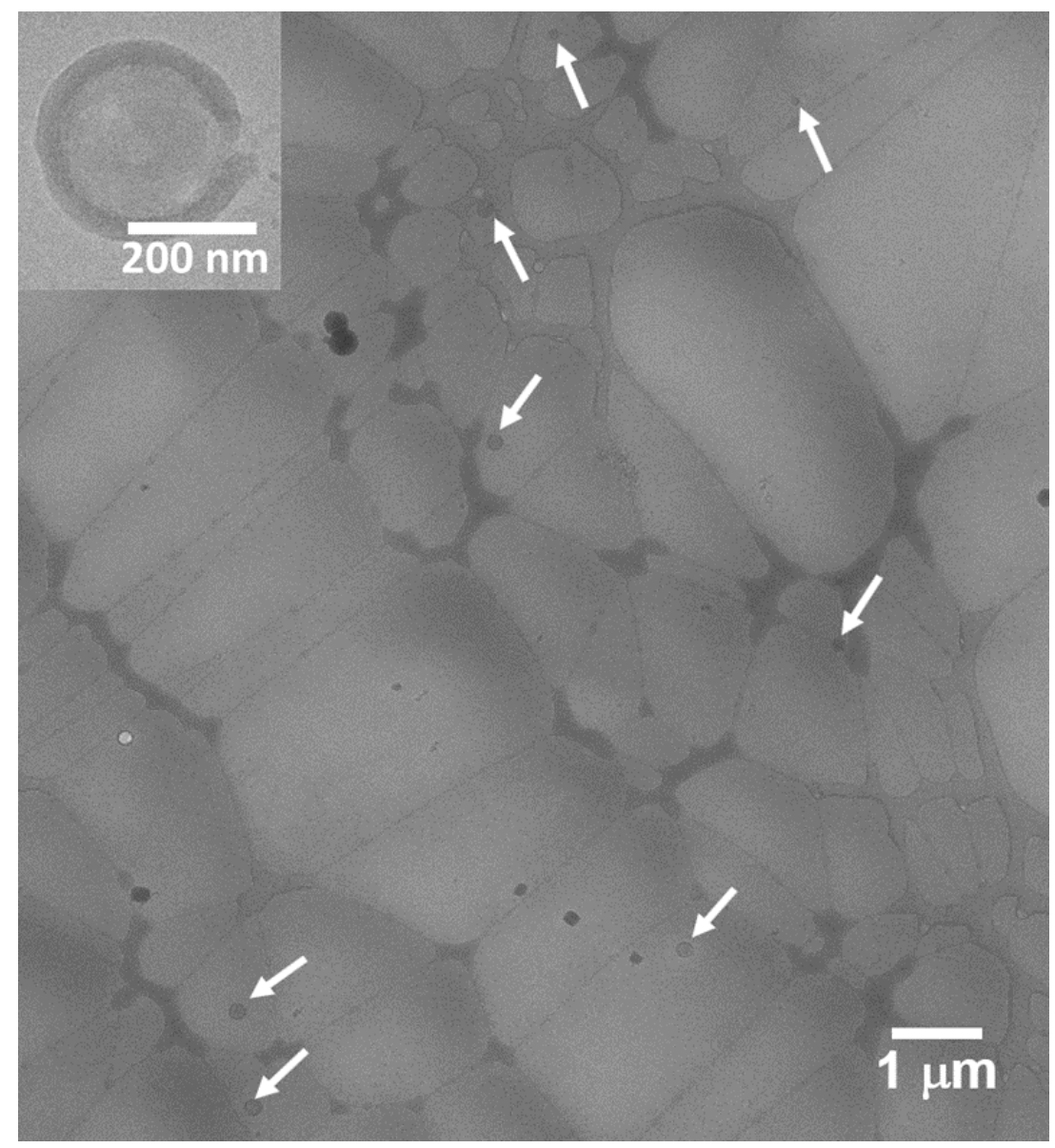

Figure S14. Cryo-TEM image of 6-Man in aqueous solution. Opened vesicles pointed by white arrows. The inset is a Cryo-TEM image with high magnification.
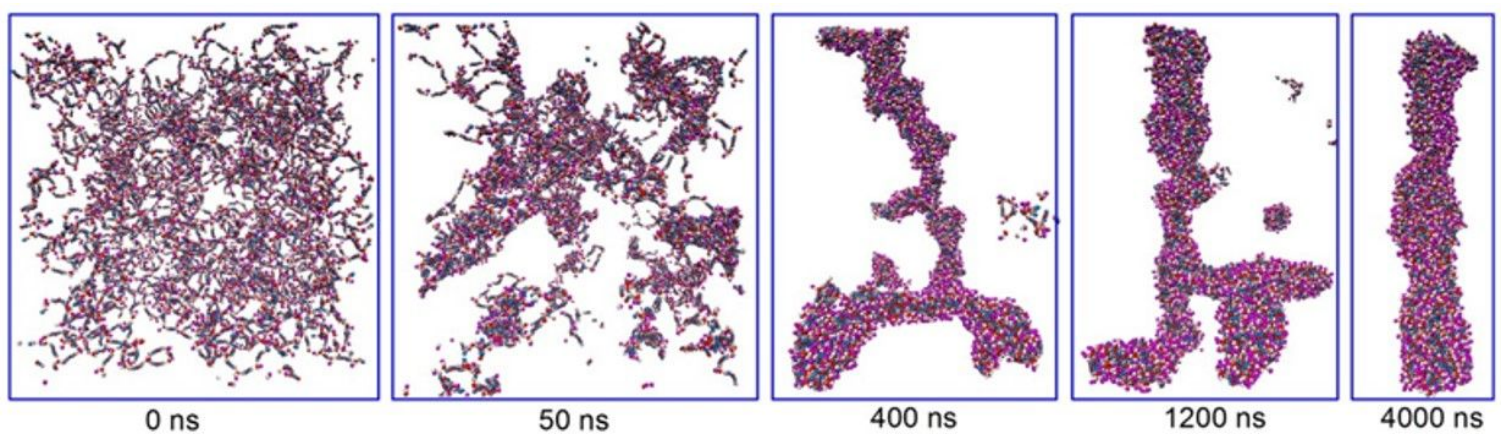

Figure S15. Time sequence of snapshots illustrating the self-assembly process of 6-Man in the simulation. 

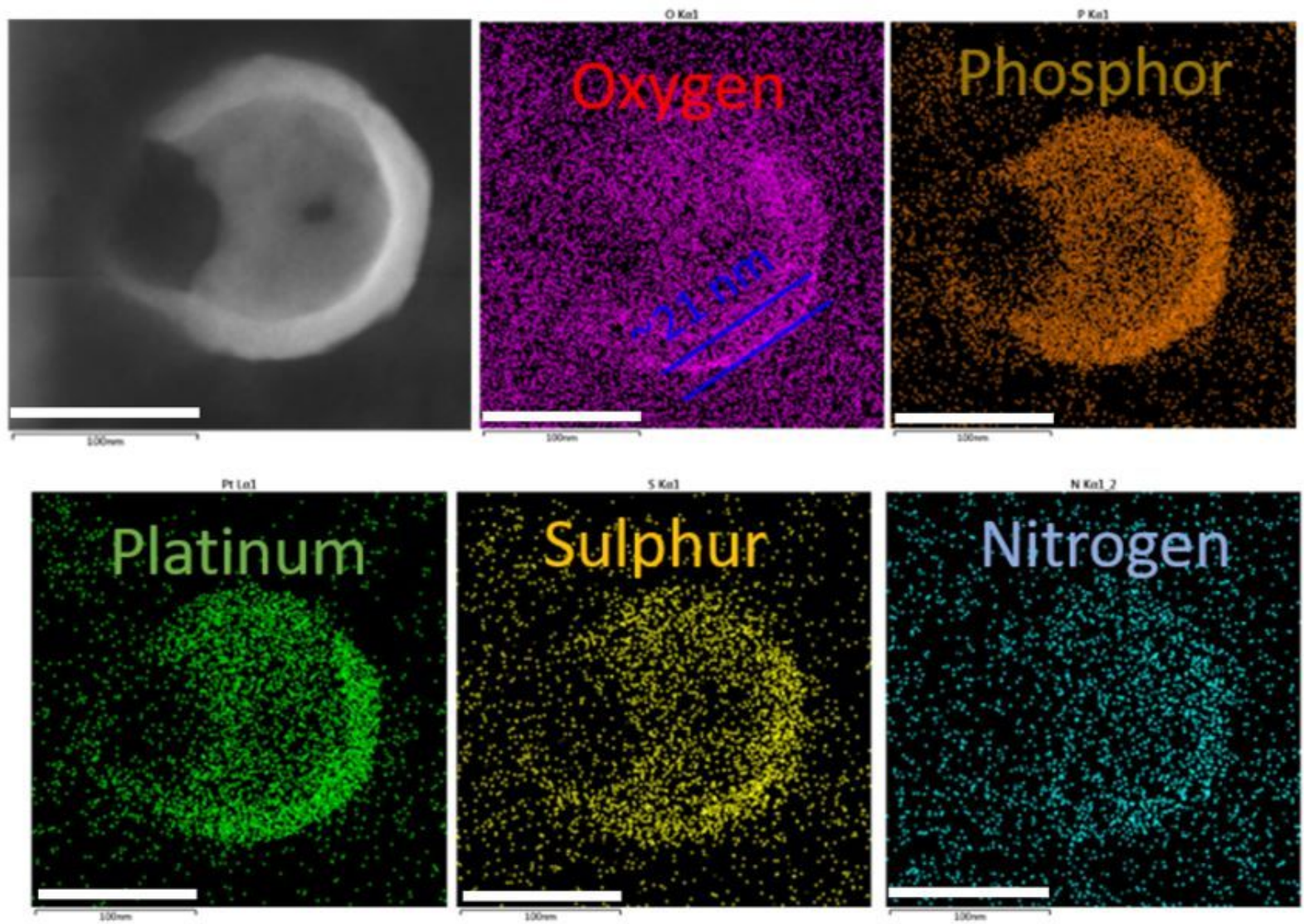

Figure S16. STEM image and the corresponding elemental mapping images of 6-Man in aqueous solution. Scale bar: $100 \mathrm{~nm}$. 

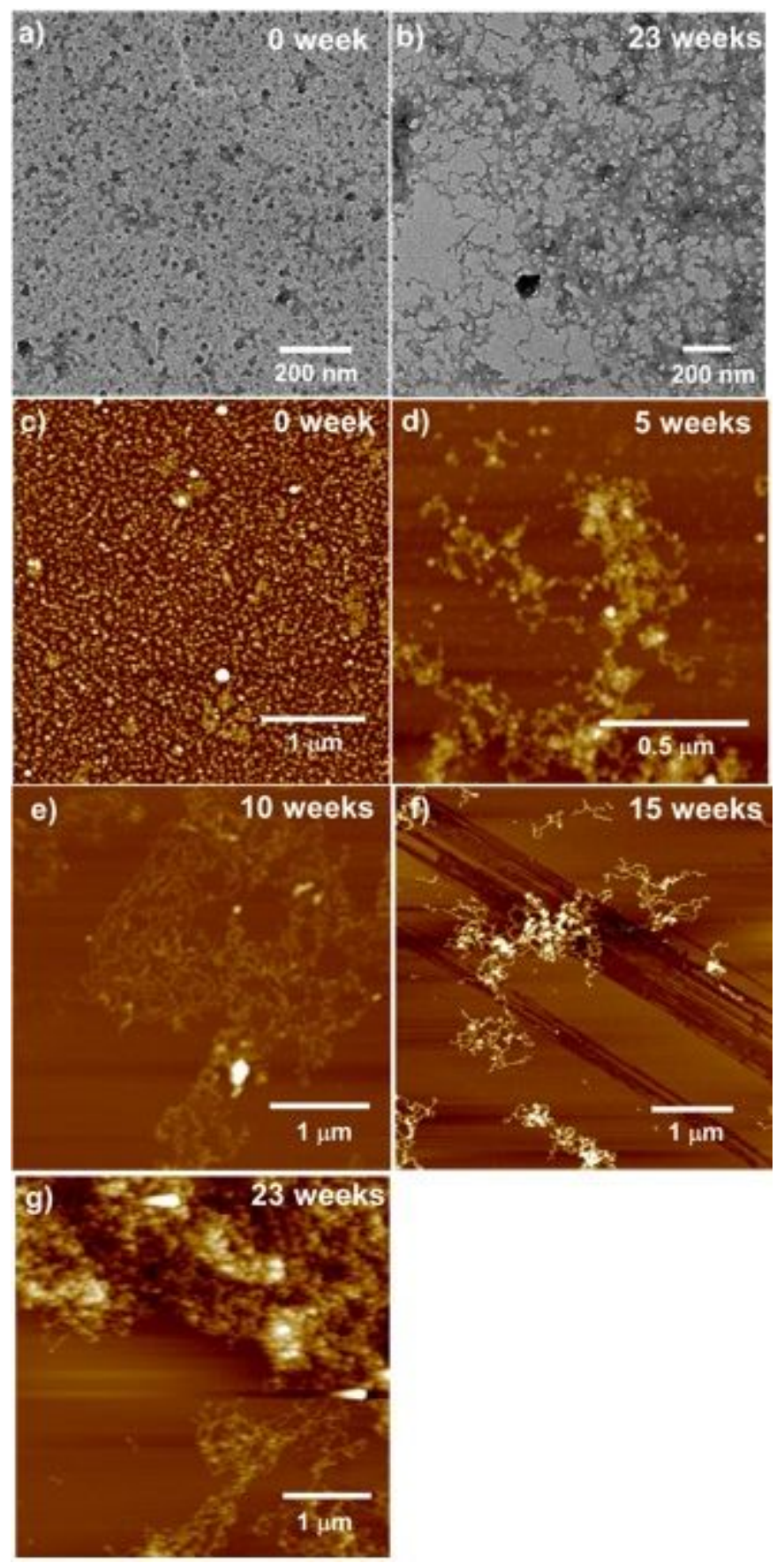

Figure S17. (a) TEM image of 3-Man in aqueous solution after standing for 0 week. (b) TEM image of 3-Man in aqueous solution after standing for 23 weeks. AFM images of 3Man in aqueous solution with standing time increasing. (c) 0 week, (d) 5 weeks, (e) 10 weeks, (f) 15 weeks, (g) 23 weeks. 


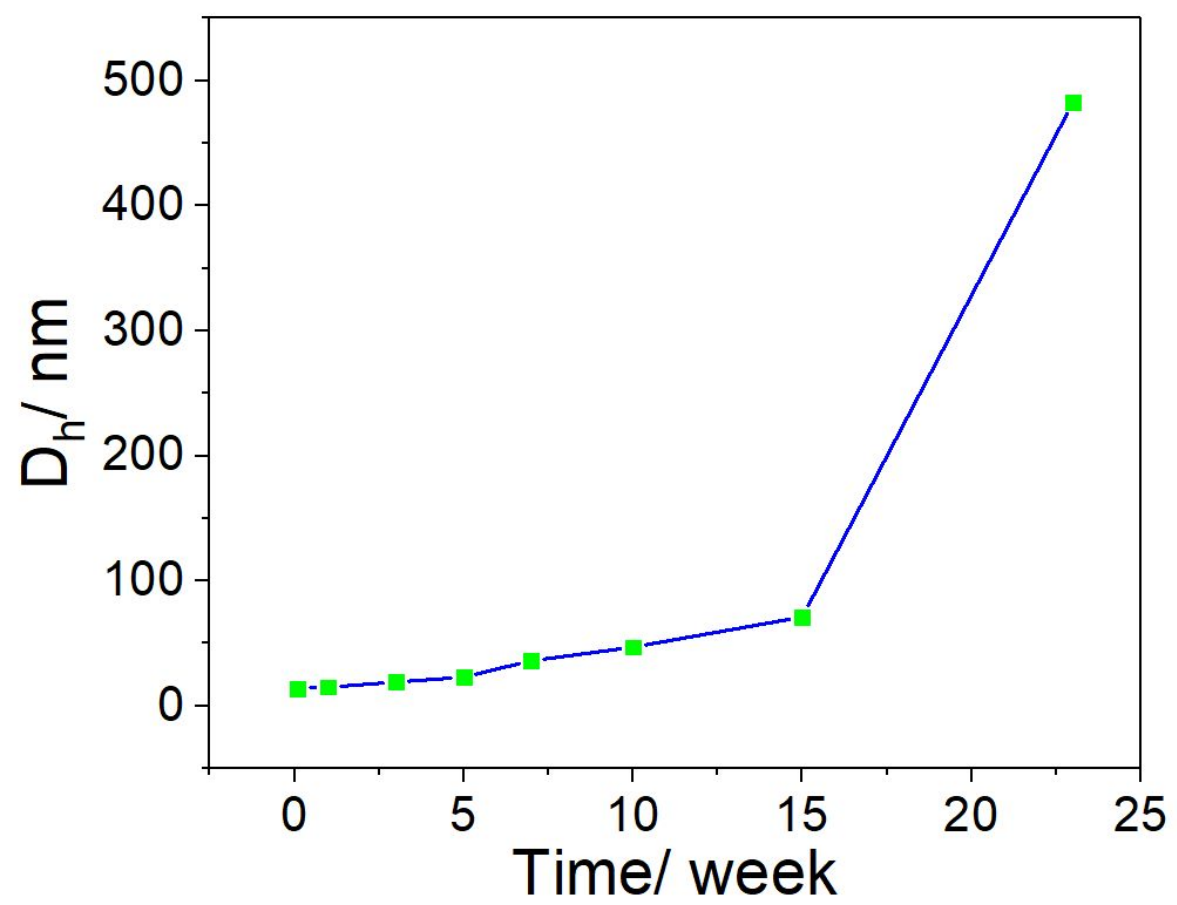

Figure S18. DLS results of 3-Man in aqueous solution with standing time increasing.
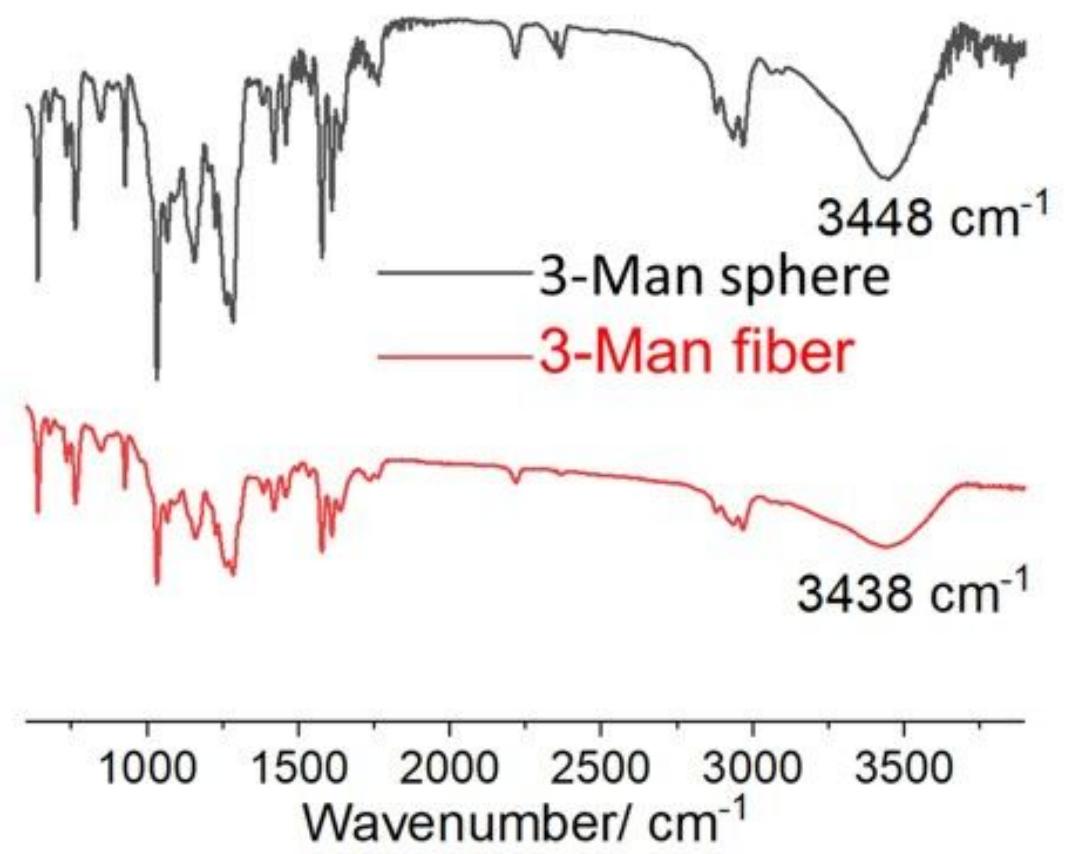

Figure S19. FT-IR spectra of the solid spheres (black line) and the fused fiber (after 23 weeks, red line) of 3-Man. 
viii. TEM image and ${ }^{31} \mathrm{P}$ NMR spectra of 2-Man with time increasing

(a)

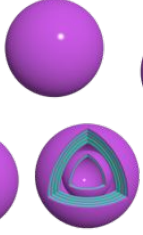

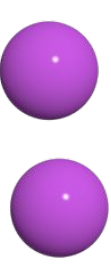

Morphology transformation of 2-Man with standing time increasing

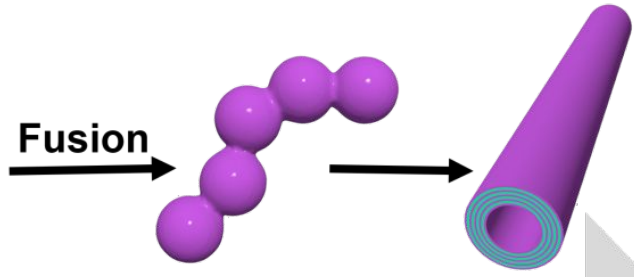
. 

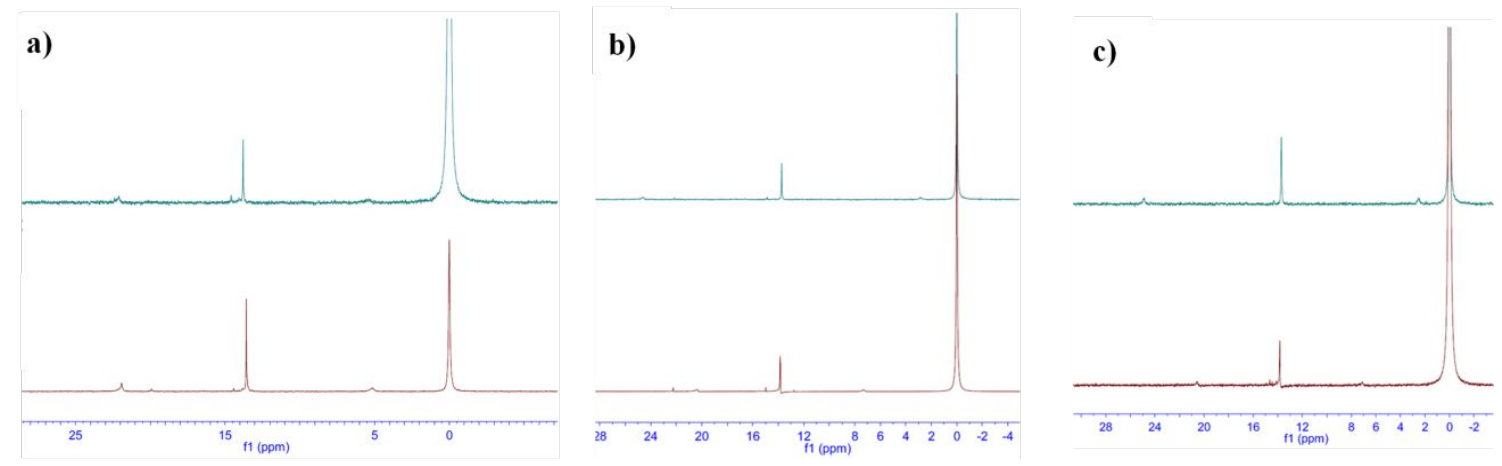

Figure S22. ${ }^{31} \mathrm{P}$ NMR spectra (161.9 $\mathrm{MHz}$, in $\left.\mathrm{CD}_{3} \mathrm{OD}, 25^{\circ} \mathrm{C}\right)$ of 2-Man, 3-Man and 6Man. (a) Redispersing 2-Man powder in $\mathrm{CD}_{3} \mathrm{OD}$ after freeze-drying 4-month 2-Man aqueous solution (above), and Fresh 2-Man (bottm). (b) Fresh 3-Man (above), redispersing powder in $\mathrm{CD}_{3} \mathrm{OD}$ after freeze-drying 3-month 3-Man aqueous solution (bottom); (c) Fresh 6-Man (above), Redispersing powder in $\mathrm{CD}_{3} \mathrm{OD}$ after freeze-drying 3month 6-Man aqueous solution (bottom). 
x. Characterization of 6-Man in aqueous solution with time increasing

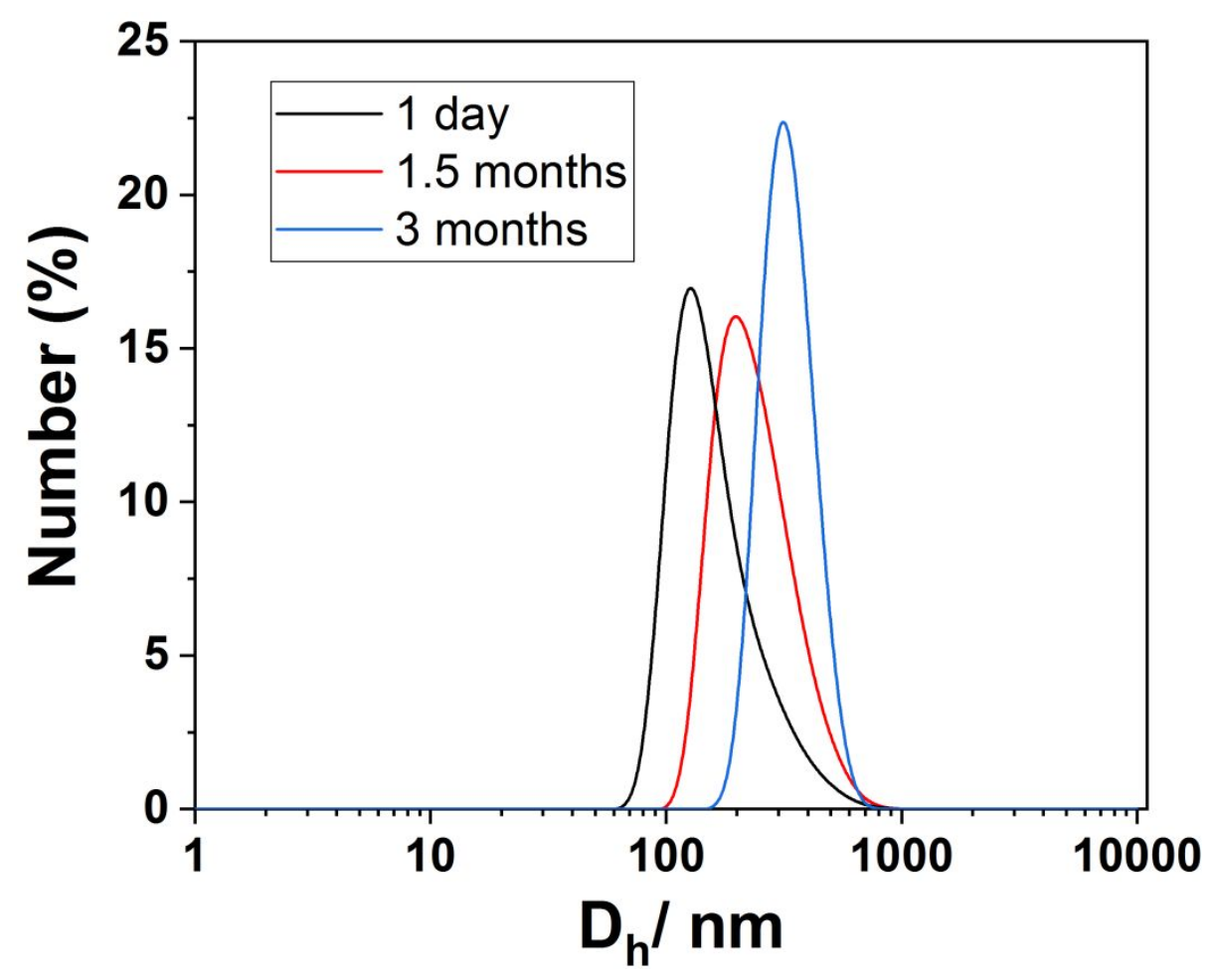

Figure S23. DLS spectra of 6-Man in aqueous solution with standing time increasing.

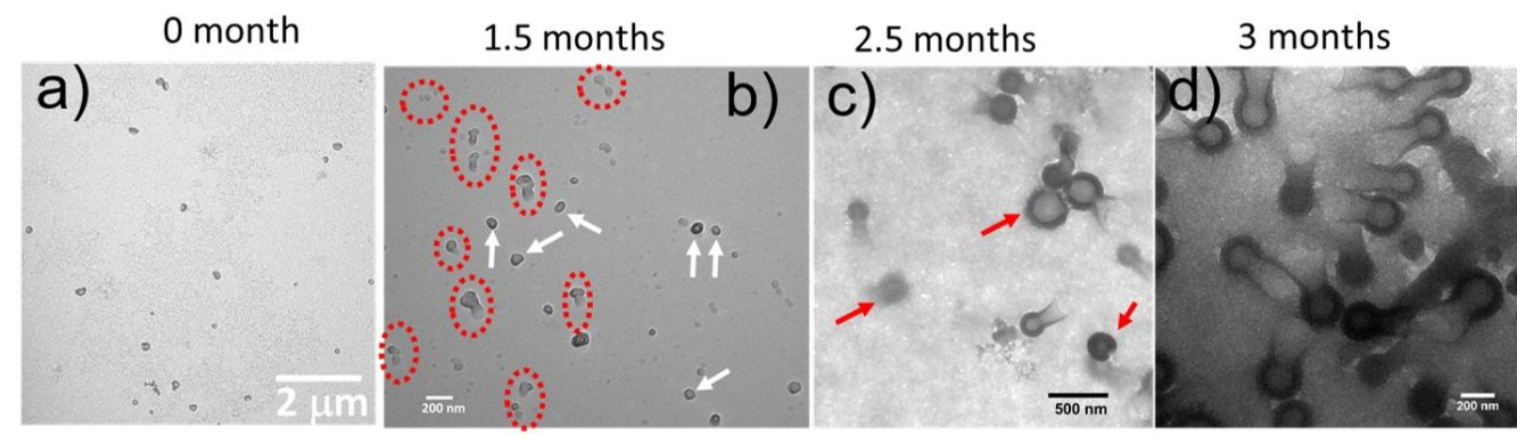

Figure S24. TEM images of 6-Man in aqueous solution with standing time increasing: (a) 0 month from Figure S13, (b) 1.5 months, cycles showed the fused open vesicles and white arrows showed the isolated open vesicles (c) 2.5 months, red arrows showed the isolated open vesicles and (e) 3 months. 


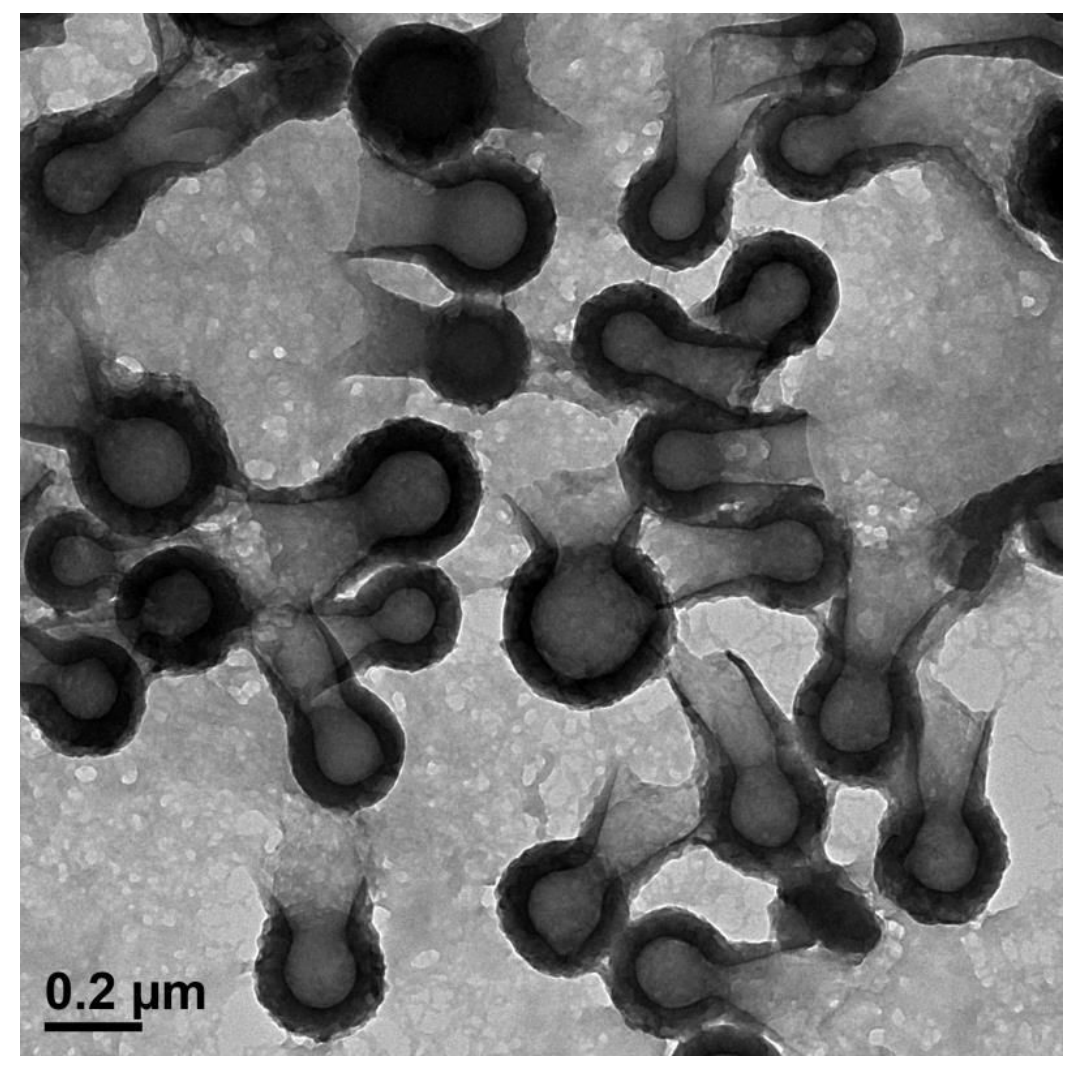

Figure S25. TEM images of 6-Man in aqueous solution for 7 months.

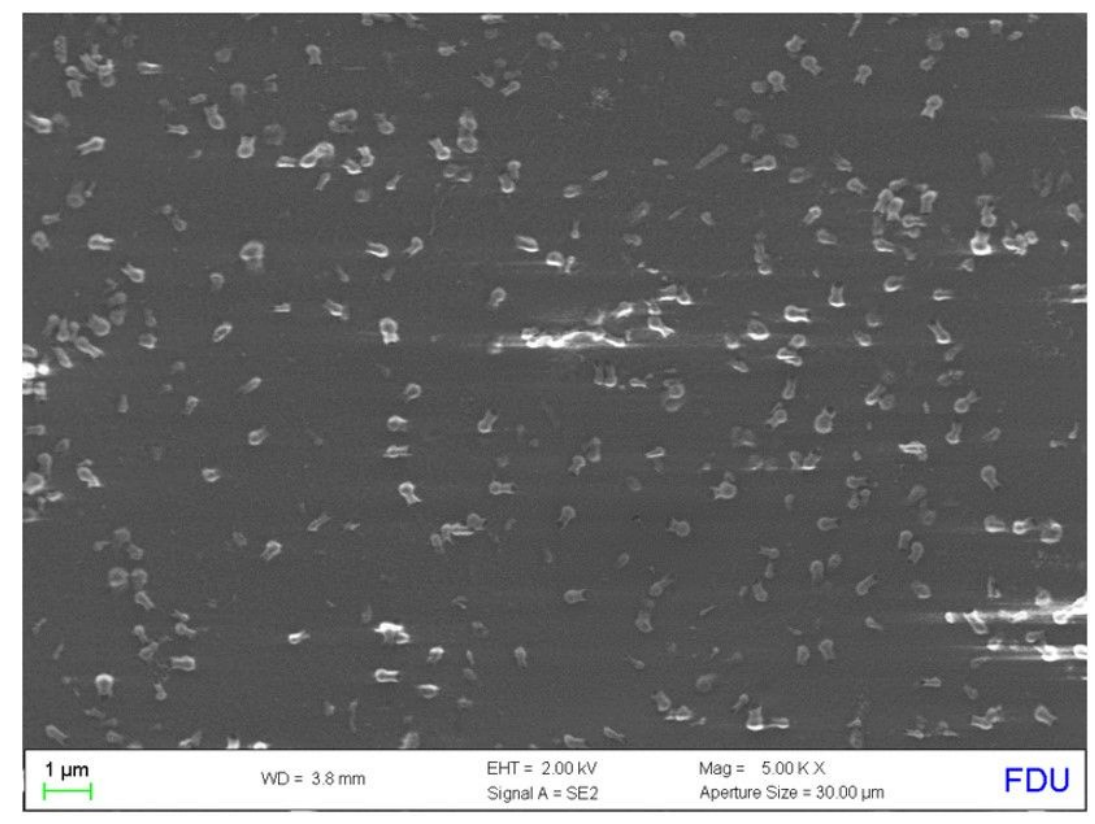

Figure S26. SEM image of 6-Man in aqueous solution after standing 3 months. 


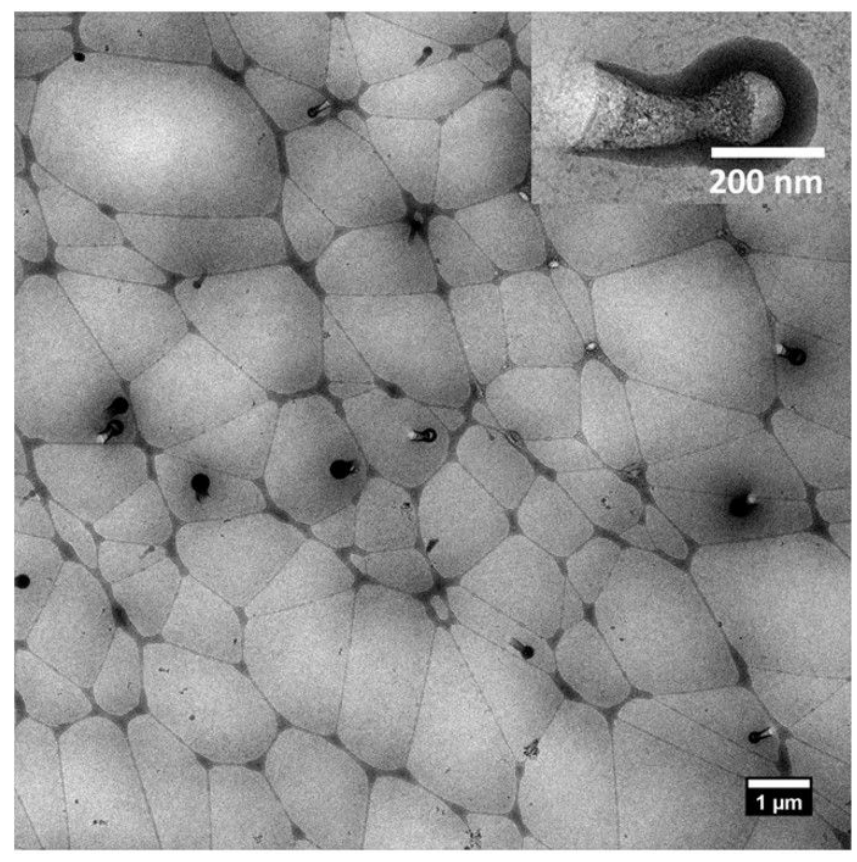

Figure S27. Cryo-TEM image of 6-Man in aqueous solution after standing 3 months. The inset is a Cryo-TEM image with high magnification.
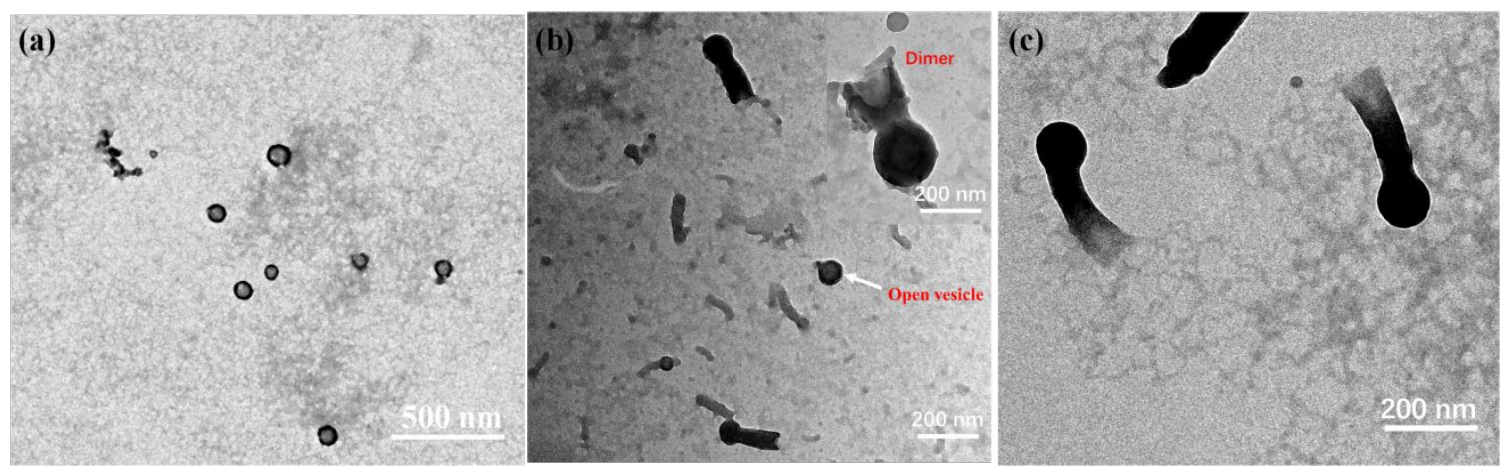

Figure S28. TEM images of assemblies from 6-Man at $60^{\circ} \mathrm{C}$ : (a) 0 week, (b) 2 weeks, (The inset is the dimer of opened vesicles) and (c) 4 weeks. 


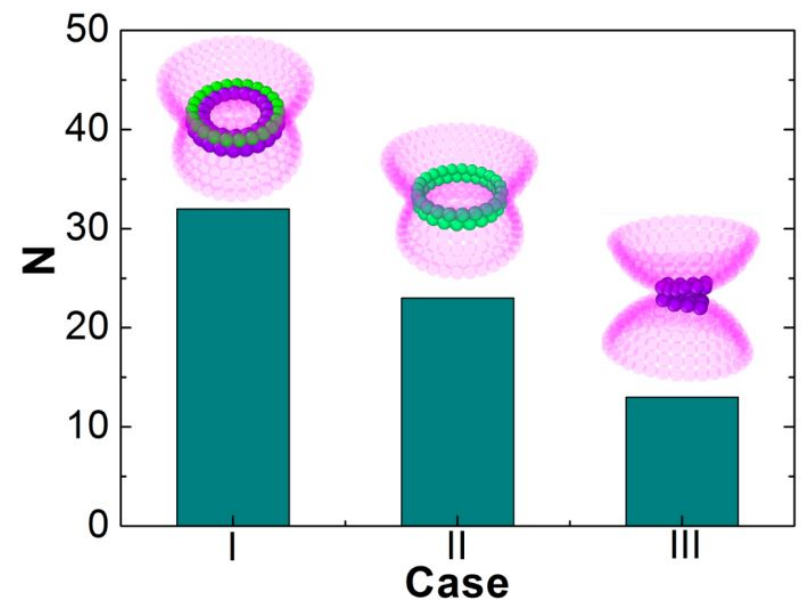

Figure S29. The contact number $\left(\mathrm{N}=\mathrm{N}_{\text {upper/2}}+\mathrm{N}_{\text {lower/2}}\right)$ of beads between the two opened vesicles in different cases, where $\mathrm{N}_{\text {upper }}$ is the number of upper vesicle beads in the contact region, and $\mathrm{N}_{\text {lower }}$ is the number of lower vesicle beads in the contact region. The beads in the contact region are highlighted in the inset snapshots. 
x. Characterization of 2-Mal, 3-Mal and 6-Mal in aqueous solution
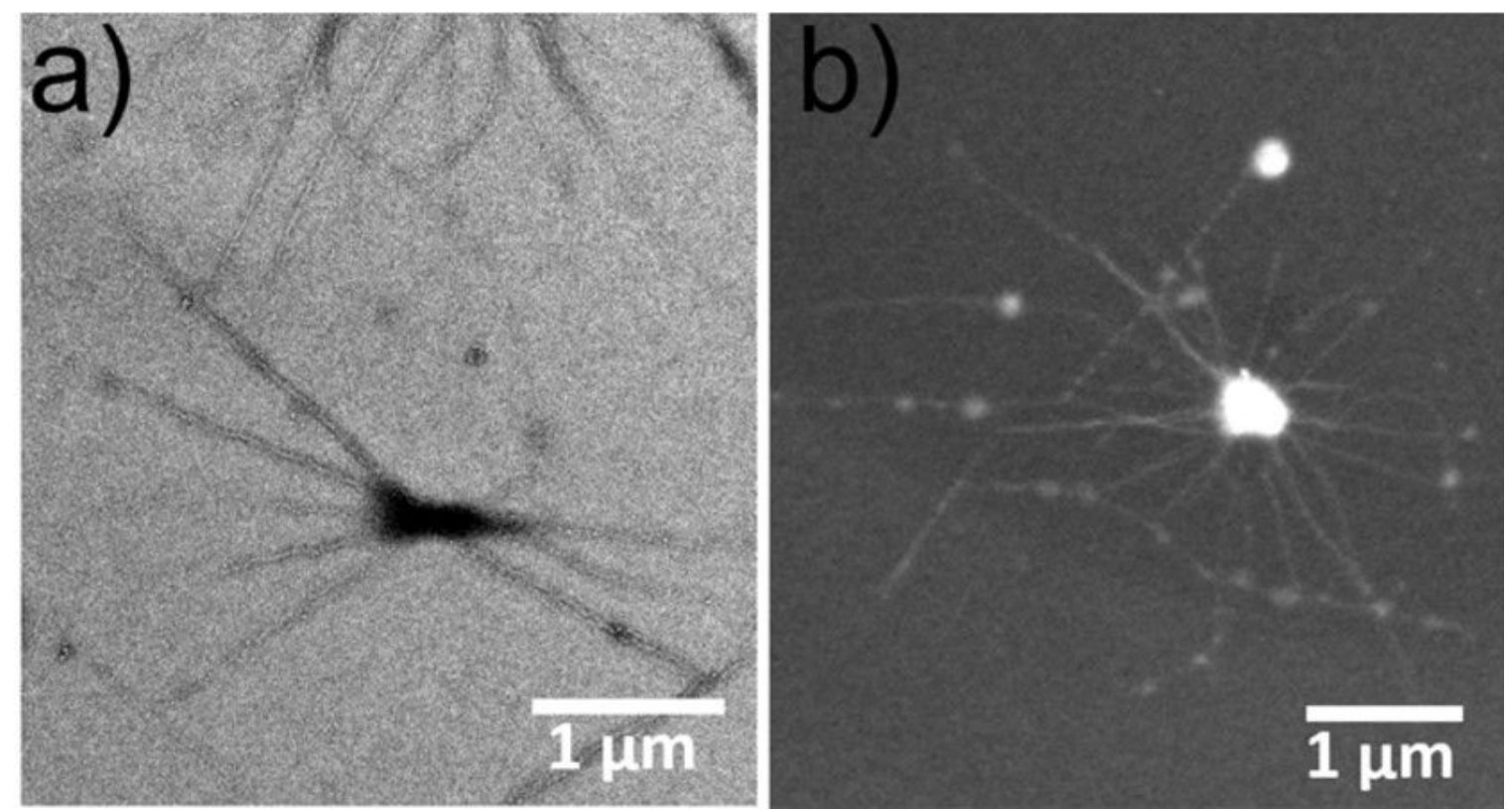

Figure S30. TEM (a) and STEM (b) images of 2-Mal in aqueous solution.

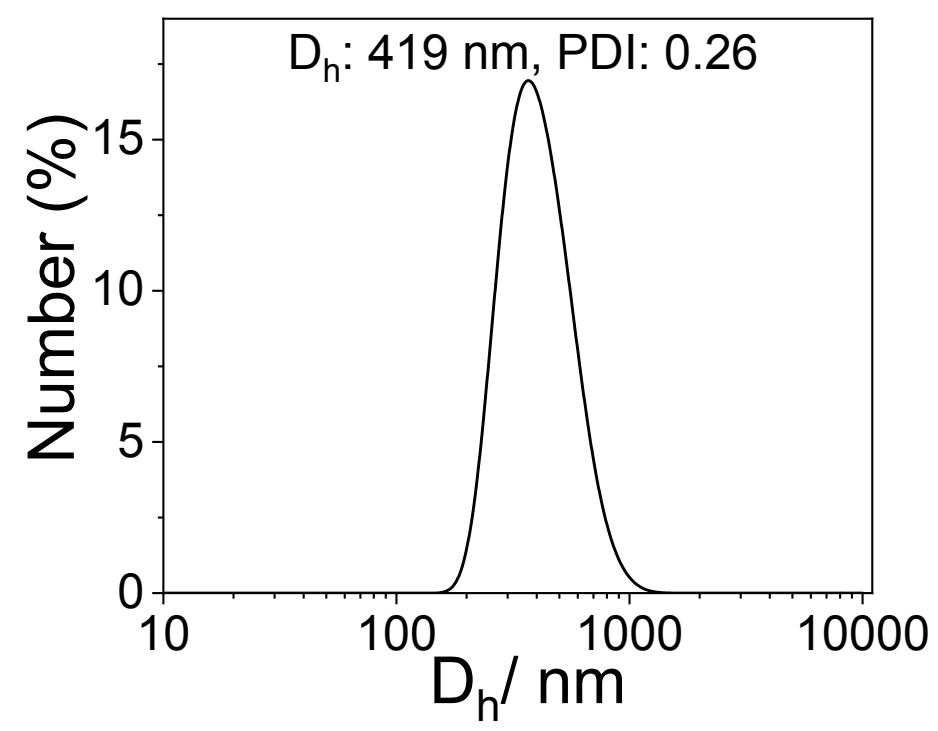

Figure S31. DLS results of 3-Mal $(0.4 \mathrm{mg} / \mathrm{mL})$ in aqueous solution. 


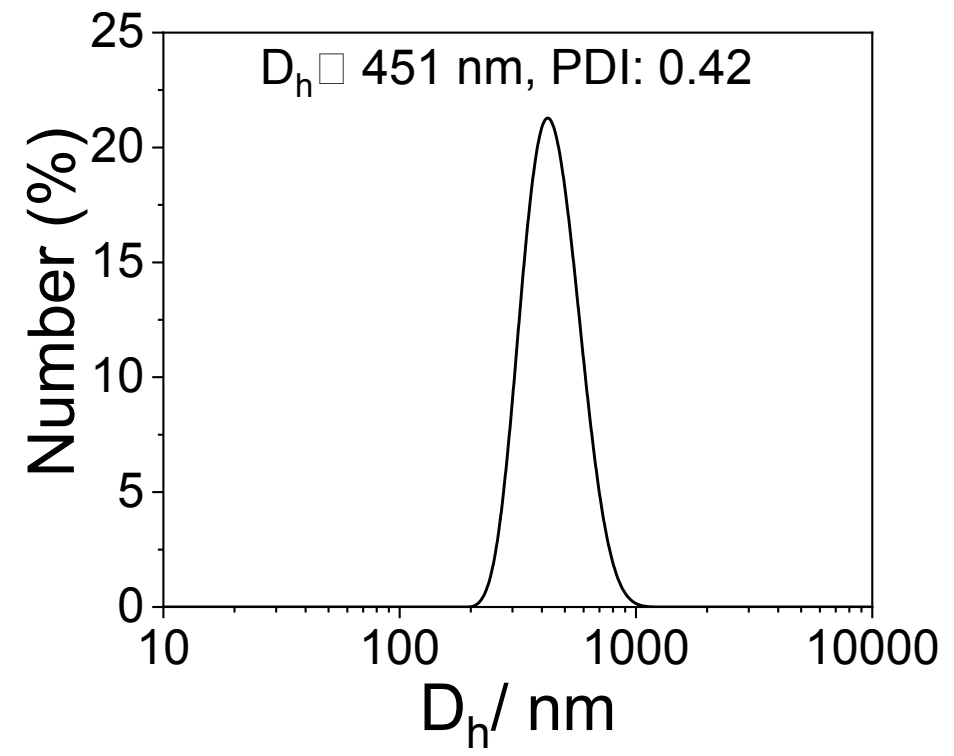

Figure S32. DLS results of 6-Mal $(0.4 \mathrm{mg} / \mathrm{mL})$ in aqueous solution.
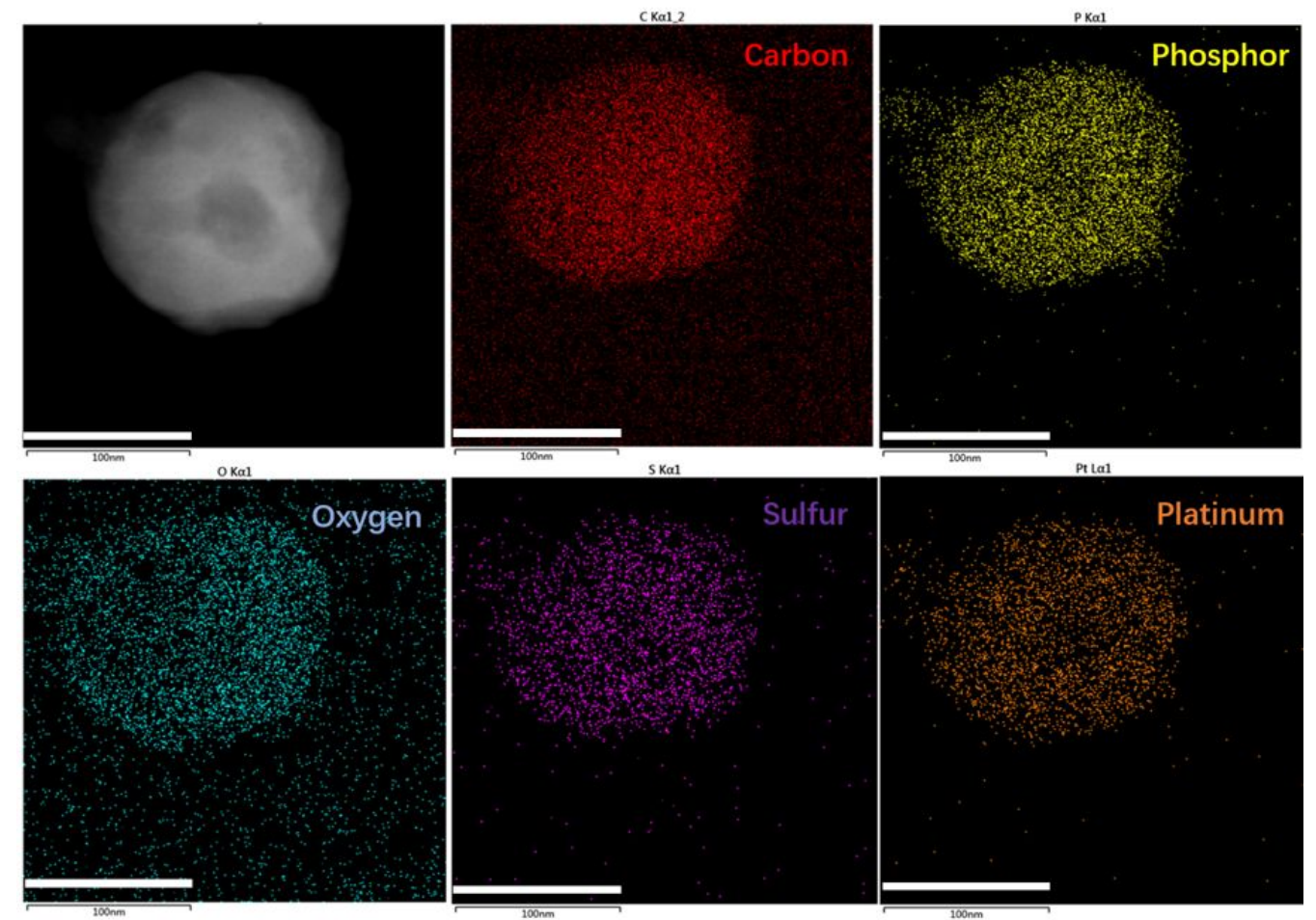

Figure S33. STEM image and the corresponding elemental mapping images of 3-Mal in aqueous solution. Scale bar: $100 \mathrm{~nm}$. 


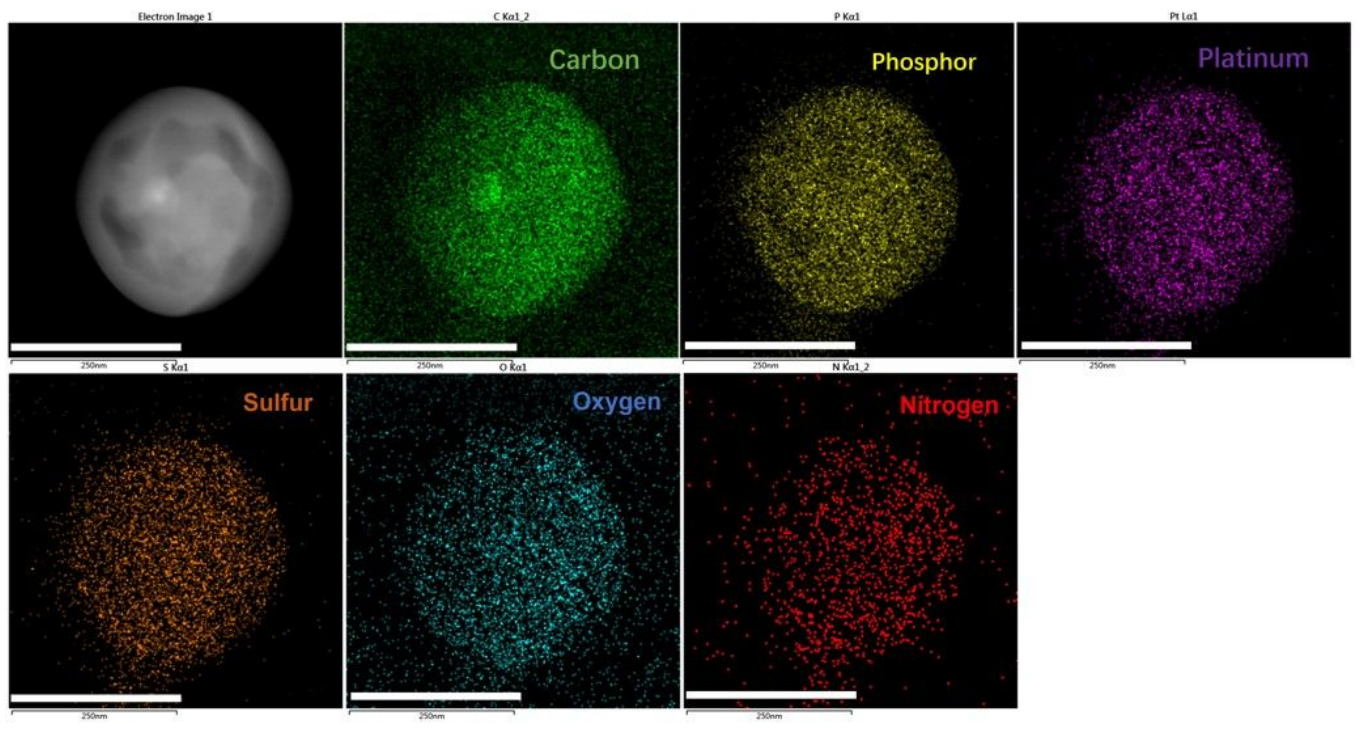

Figure S34. STEM image and the corresponding elemental mapping images of 6-Mal in aqueous solution. Scale bar: $250 \mathrm{~nm}$. 
xi. The binding between ConA and glyconanopaticles

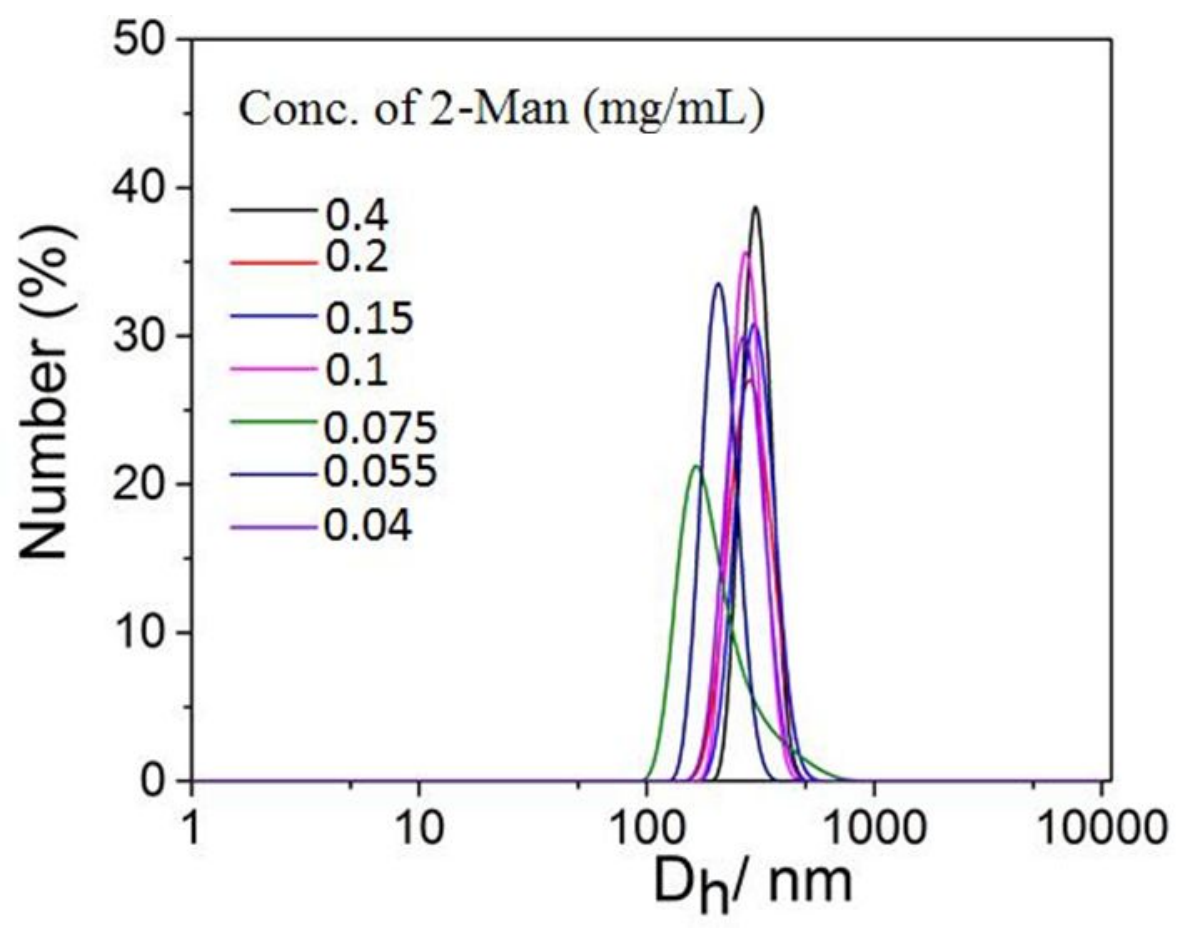

Figure S35. DLS spectra of 2-Man at different concentrations in HEPES buffer.
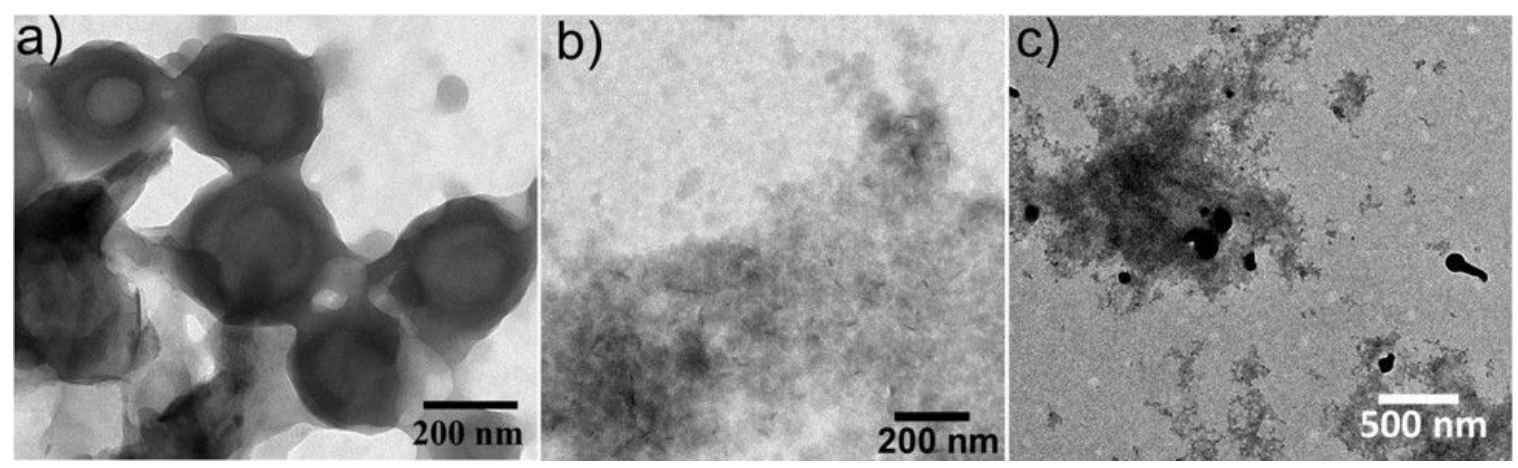

Figure S36. TEM images of 2-Man/ConA (a), 3-Man/ConA (b) and 6-Man/ConA (c) after incubating $30 \mathrm{~min}$. 


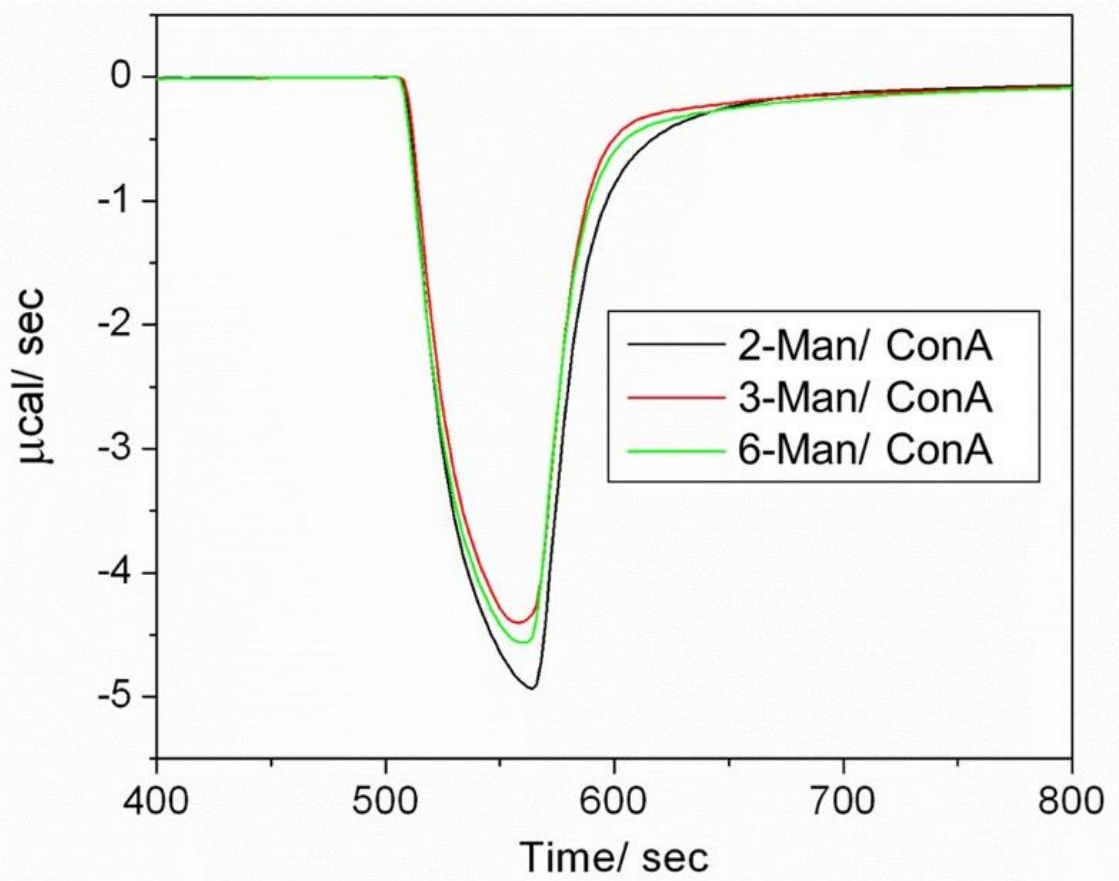

Figure S37. ITC data of $40 \mathrm{ul} \mathrm{ConA} \mathrm{(1} \mathrm{mg/} \mathrm{mL)} \mathrm{into} 1.456 \mathrm{~mL}$ 2-Man, 3-Man and 6Man. The concentation of sugar (mannose) all was $0.05 \mathrm{mM}$. 
vii. Characterization of all synthetic compounds

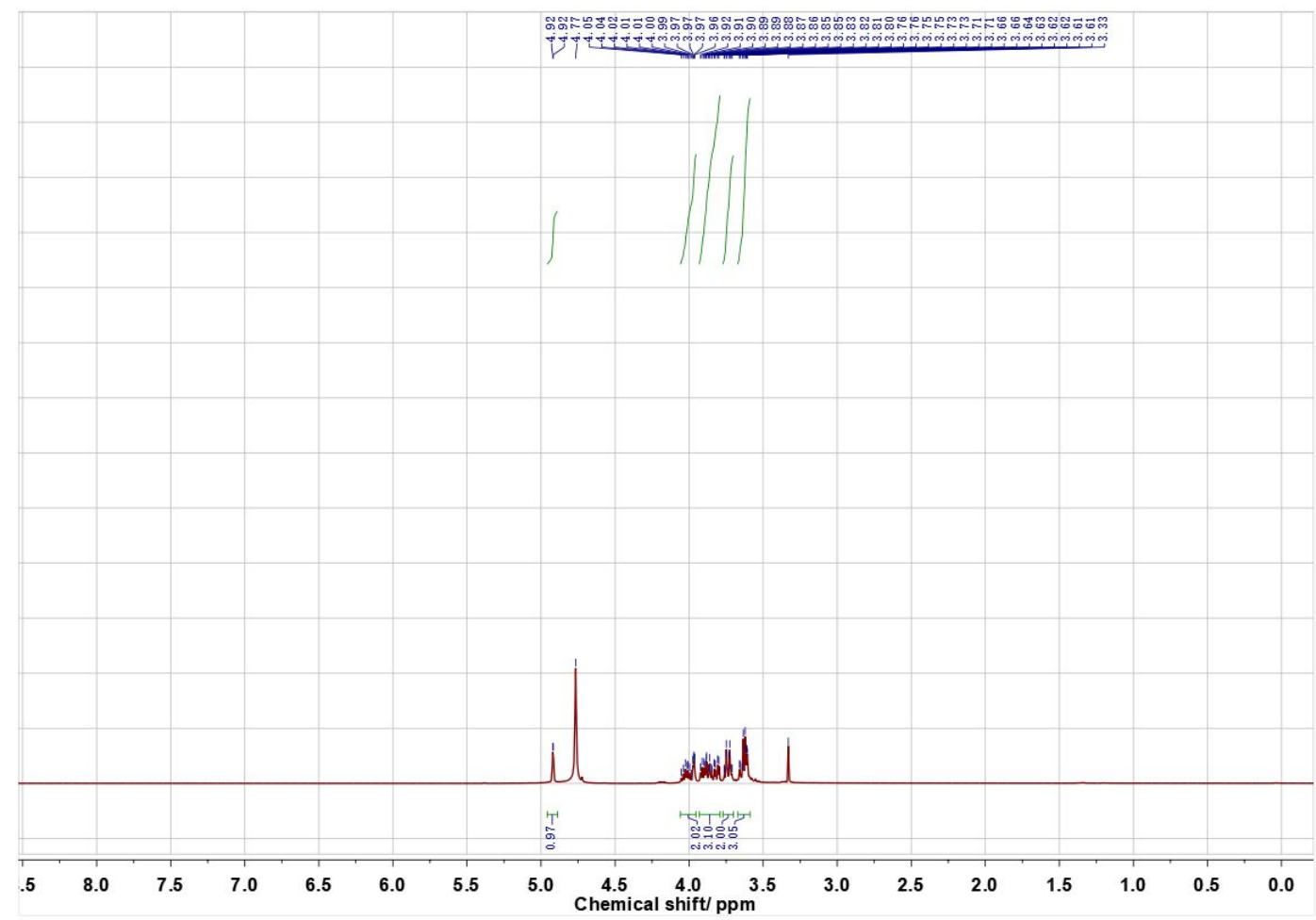

Figure S38. ${ }^{1} \mathrm{H}$ NMR spectrum of a1 in $\mathrm{CD}_{3} \mathrm{OD}$.

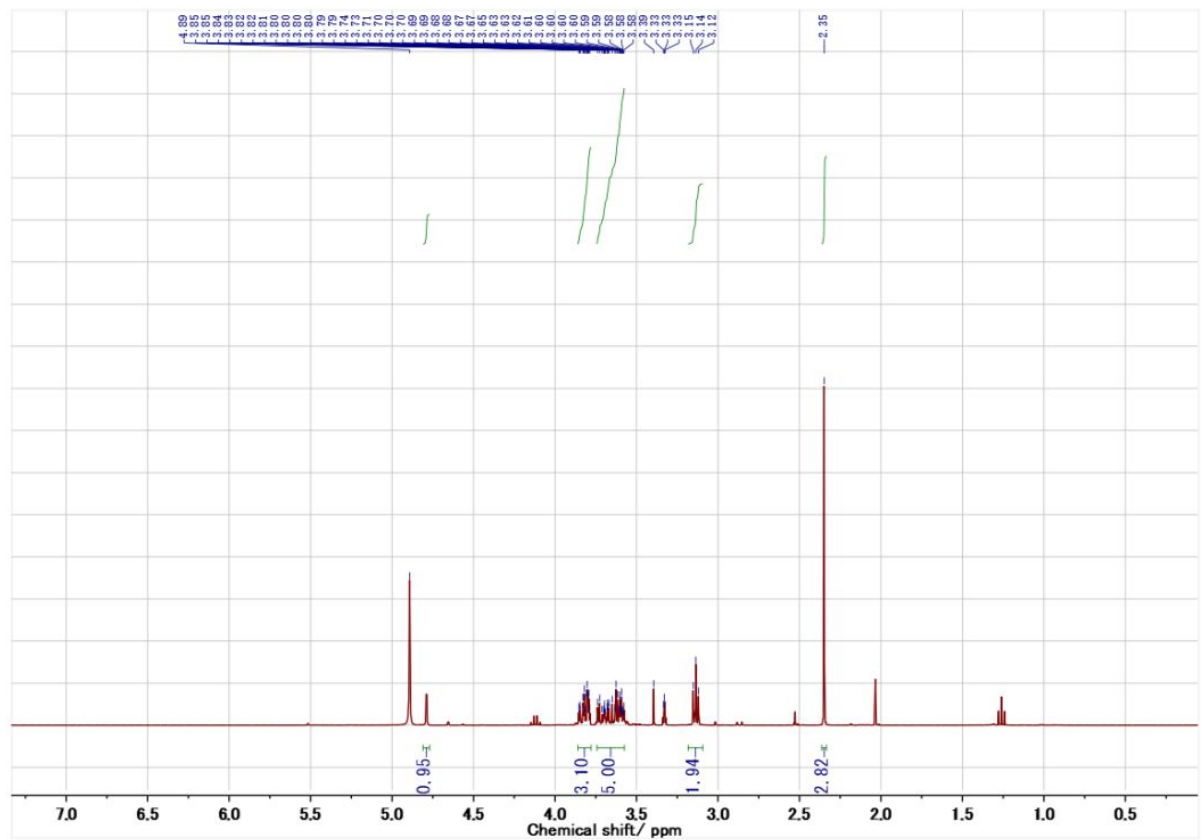

Figure S39. ${ }^{1} \mathrm{H}$ NMR spectrum of $\mathbf{a} 2$ in $\mathrm{CD}_{3} \mathrm{OD}$. 


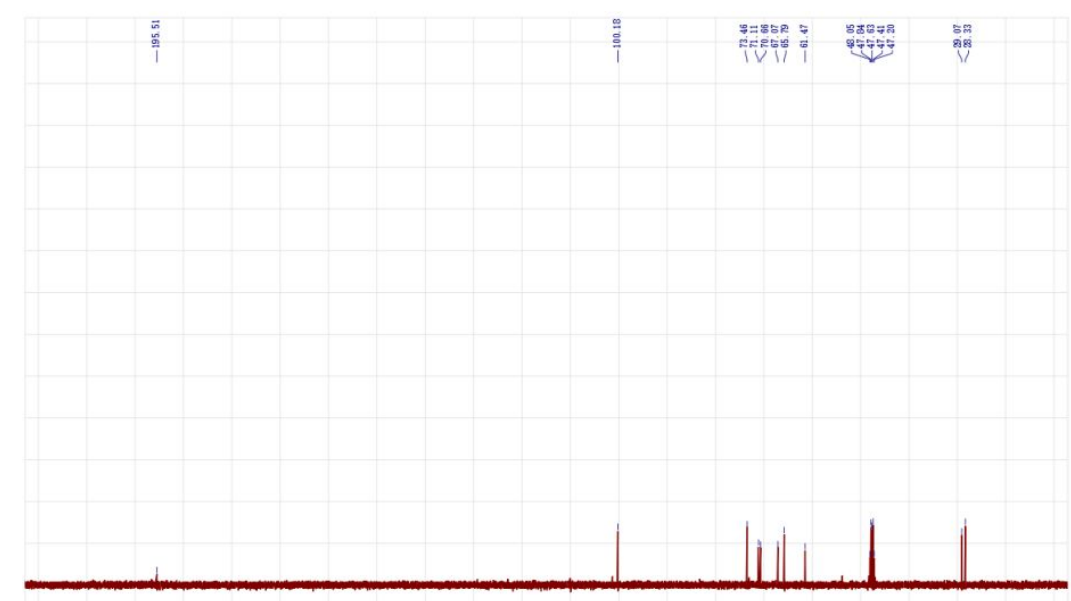

$\begin{array}{llllllllllllllllllllllllllllllll}220 & 210 & 200 & 190 & 180 & 170 & 160 & 150 & 140 & 130 & 120 & 110 & 100 & 90 & 80 & 70 & 60 & 50 & 40 & 30 & 20 & 10\end{array}$

Figure S40. ${ }^{13} \mathrm{C}$ NMR spectrum of $\mathbf{a} 2$ in $\mathrm{CD}_{3} \mathrm{OD}$.

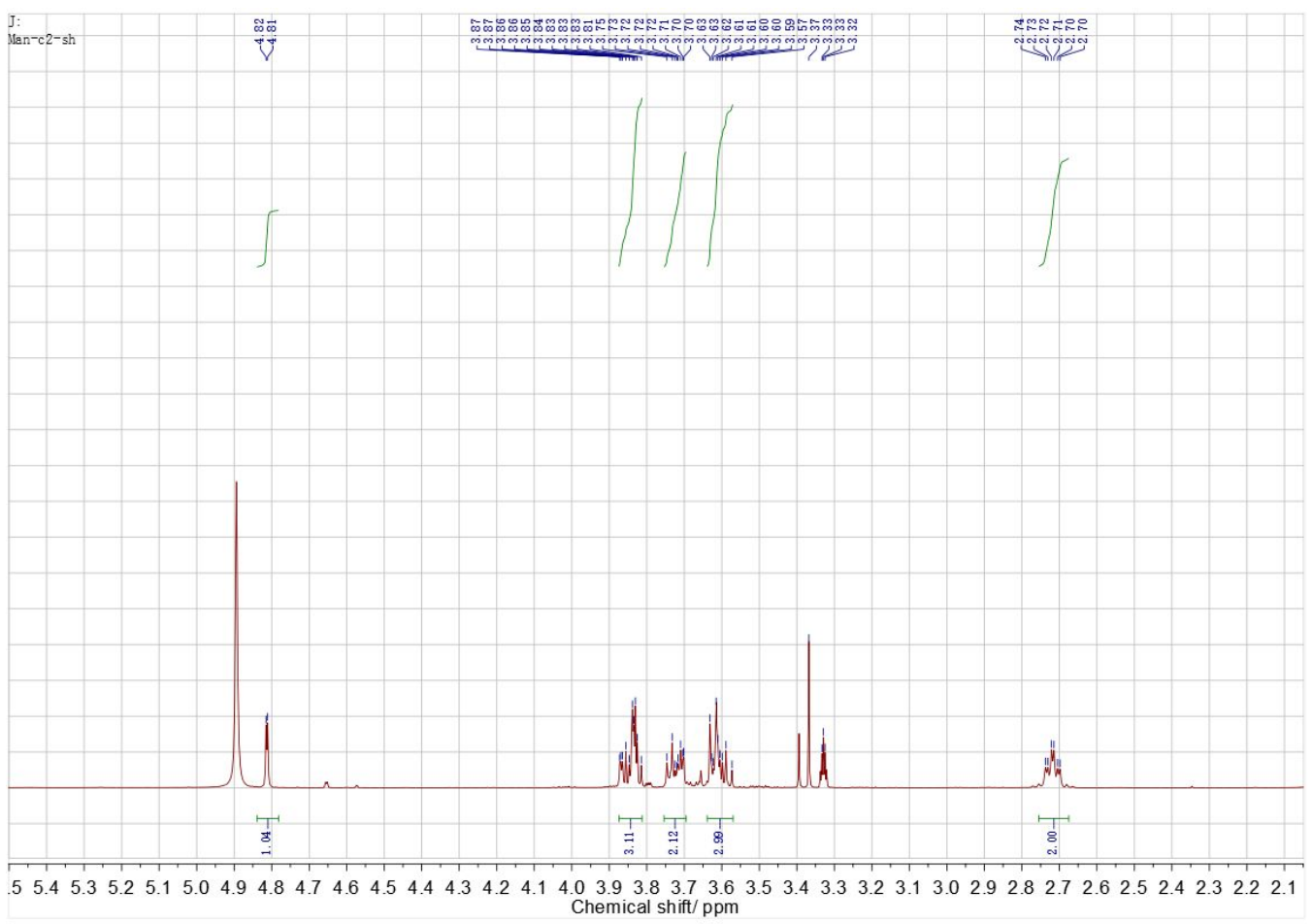

Figure S41. ${ }^{1} \mathrm{H}$ NMR spectrum of $\mathbf{a} 3$ in $\mathrm{CD}_{3} \mathrm{OD}$. 


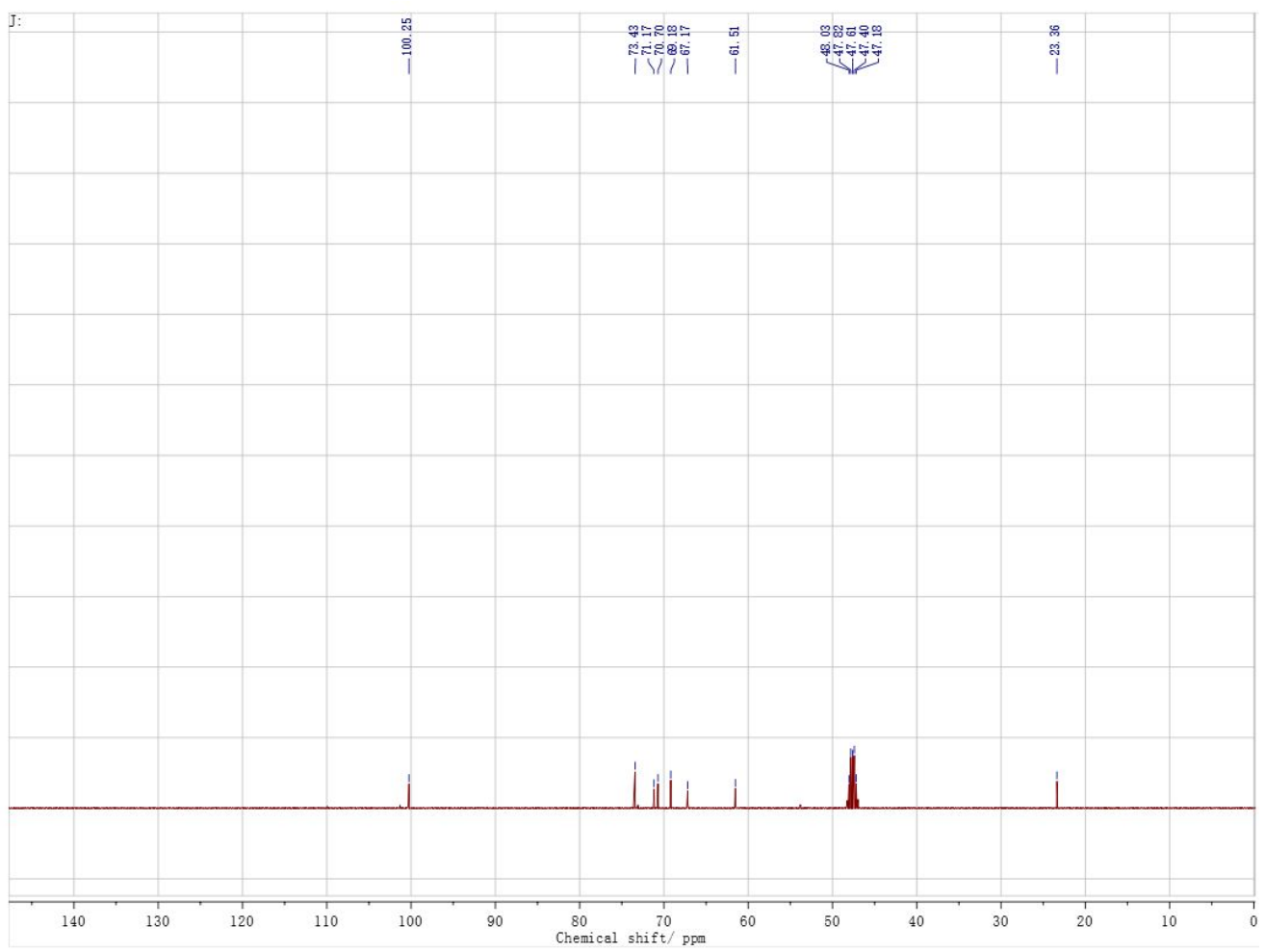

Figure $\mathbf{S 4 2} \cdot{ }^{13} \mathrm{C}$ NMR spectrum of $\mathbf{a} 3$ in $\mathrm{CD}_{3} \mathrm{OD}$.

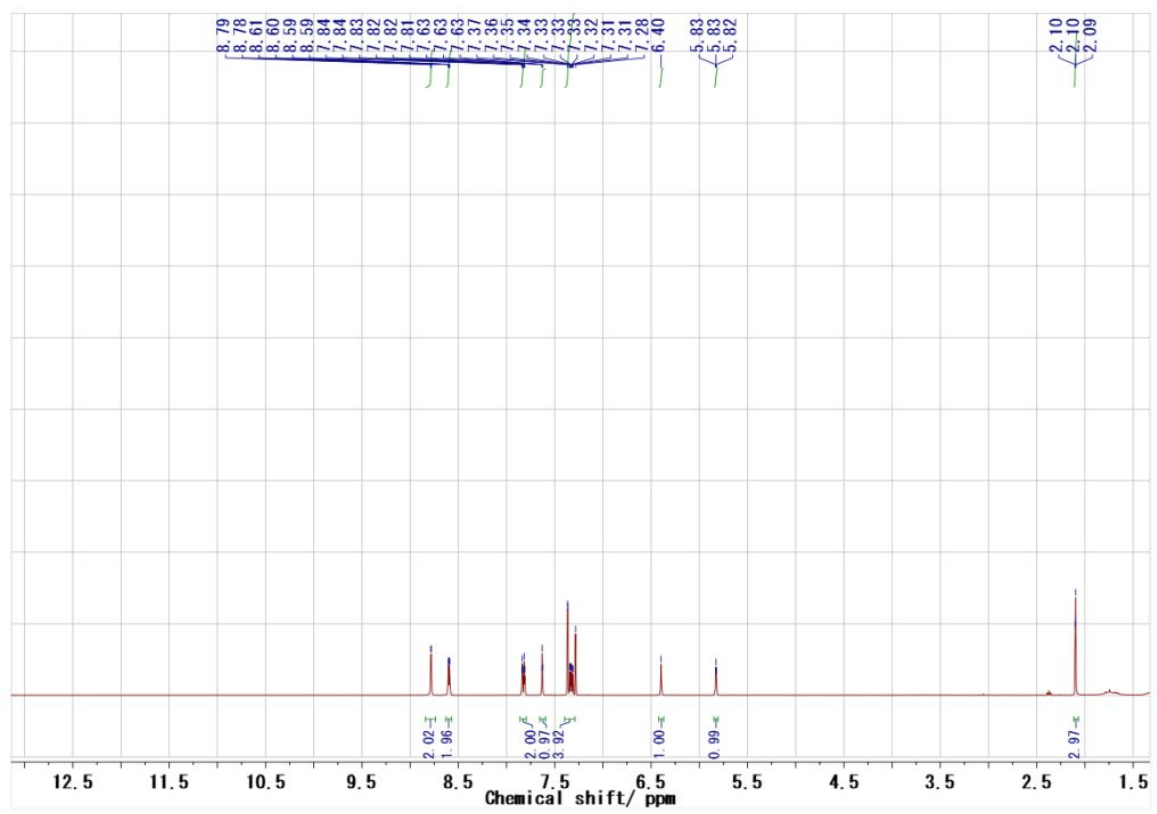

Figure S43. ${ }^{1} \mathrm{H}$ NMR spectrum of a5 in $\mathrm{CDCl}_{3}$. 


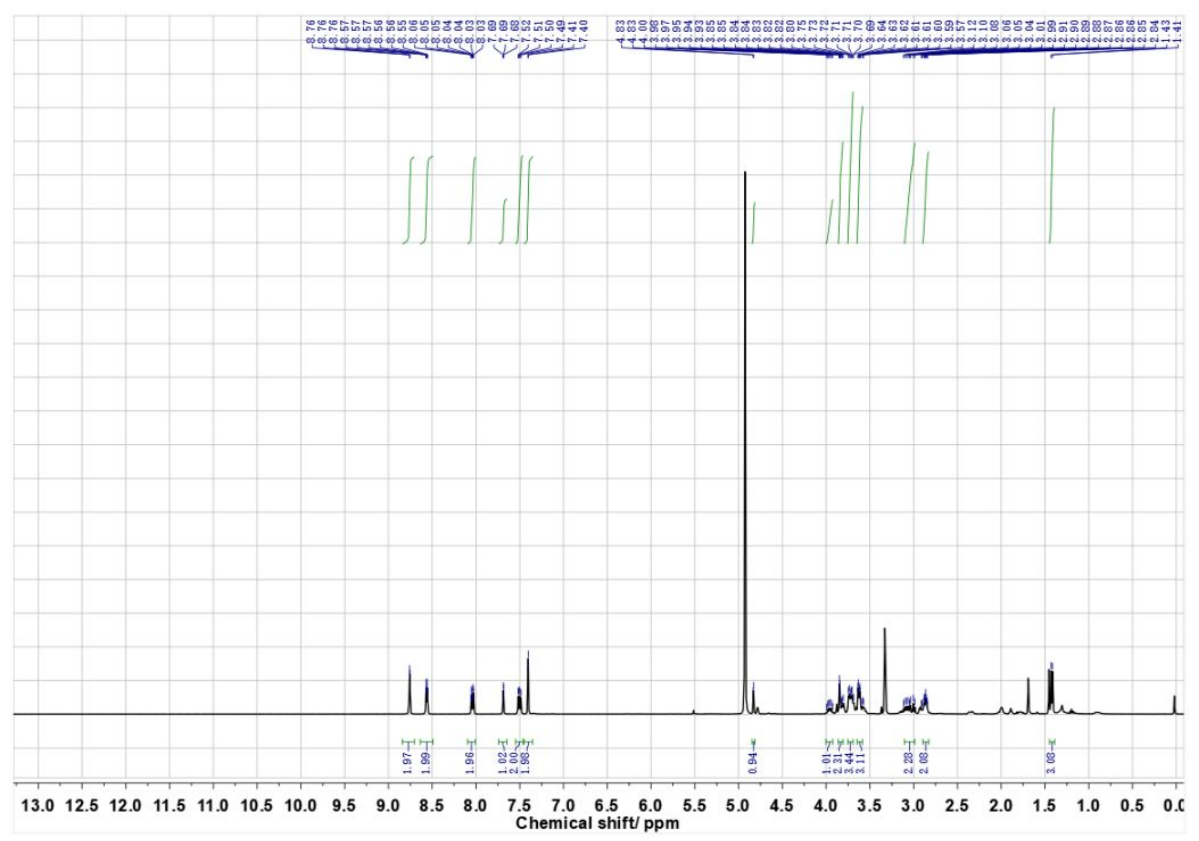

Figure S44. ${ }^{1} \mathrm{H}$ NMR spectrum of D1-Man in $\mathrm{CD}_{3} \mathrm{OD}$.

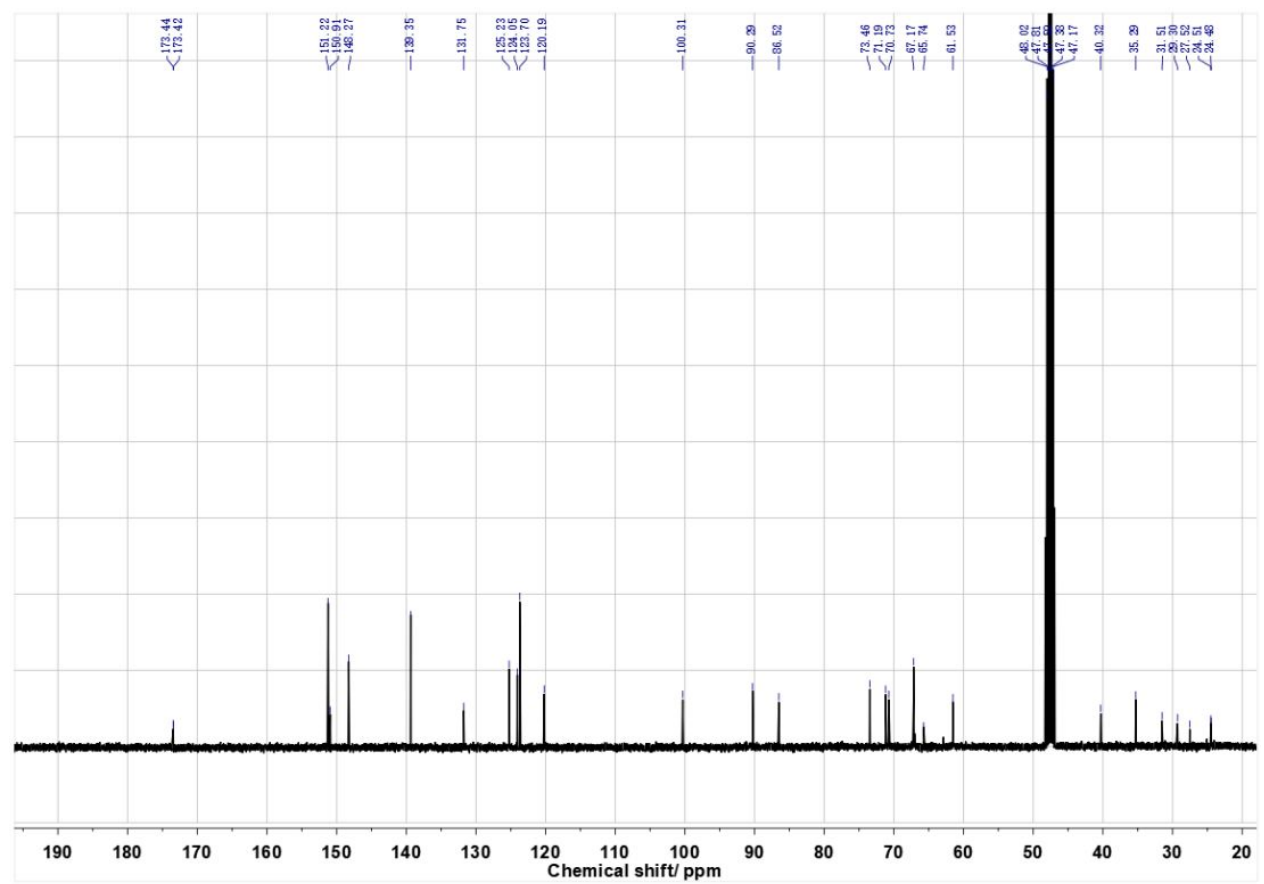

Figure S45. ${ }^{13} \mathrm{C}$ NMR spectrum of D1-Man in $\mathrm{CD}_{3} \mathrm{OD}$. 


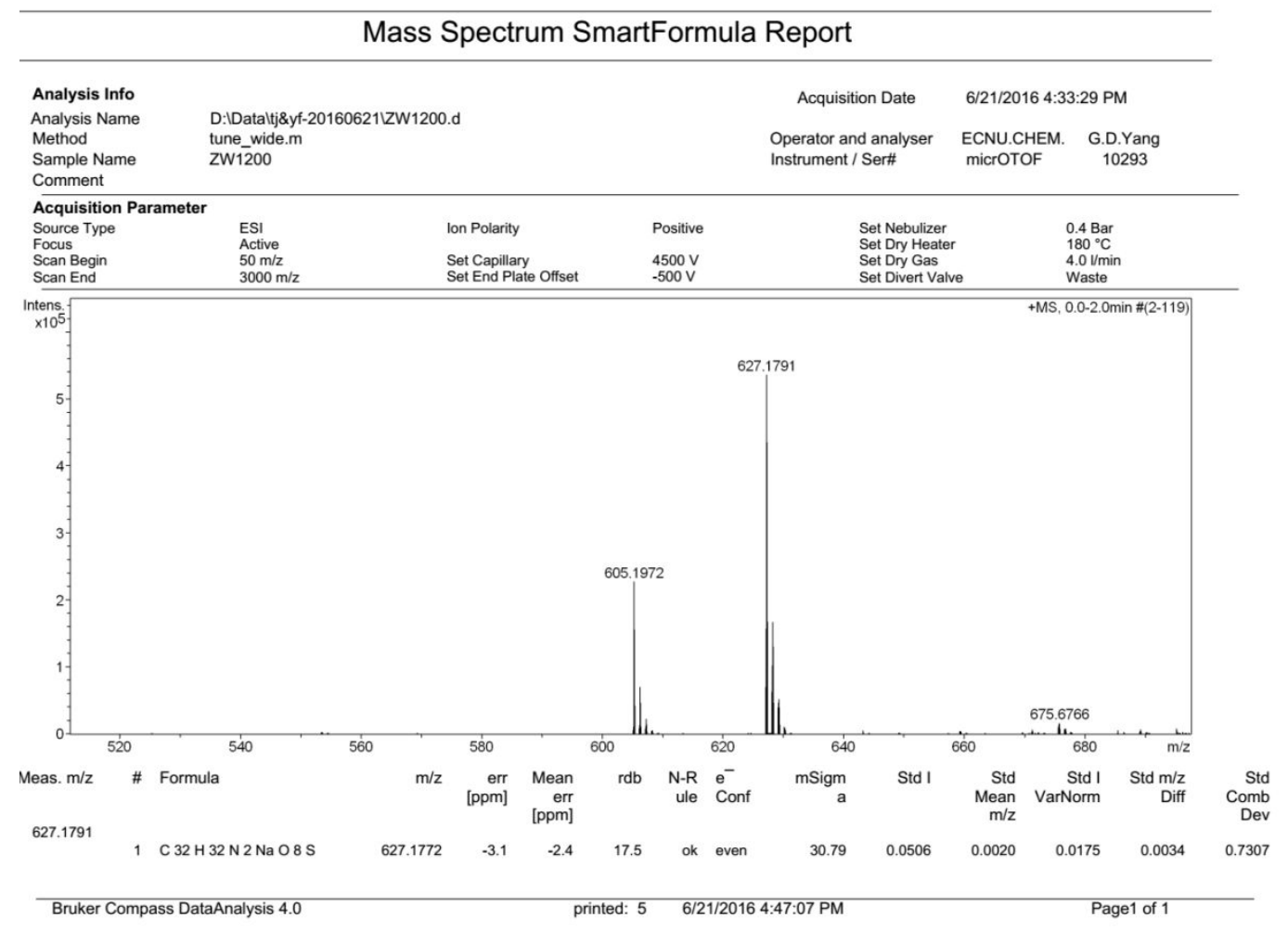

Figure S46. ESI-MS spectrum of D1-Man (m/z).

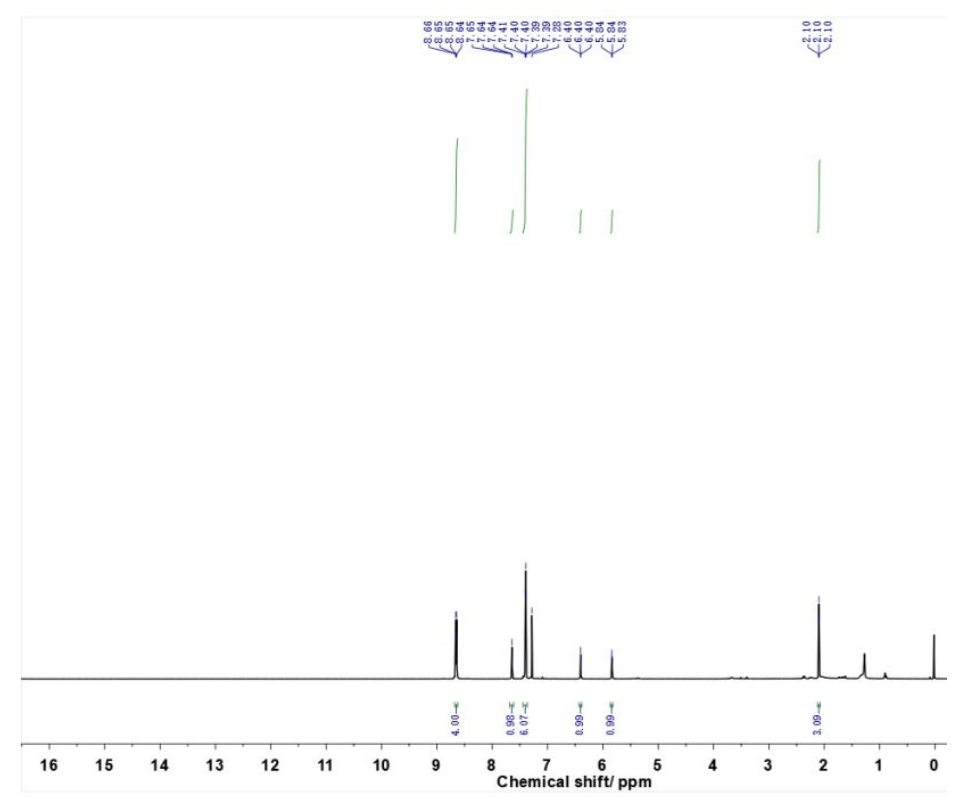

Figure S47. ${ }^{1} \mathbf{H}$ NMR spectrum of a7 in $\mathrm{CDCl}_{3}$. 


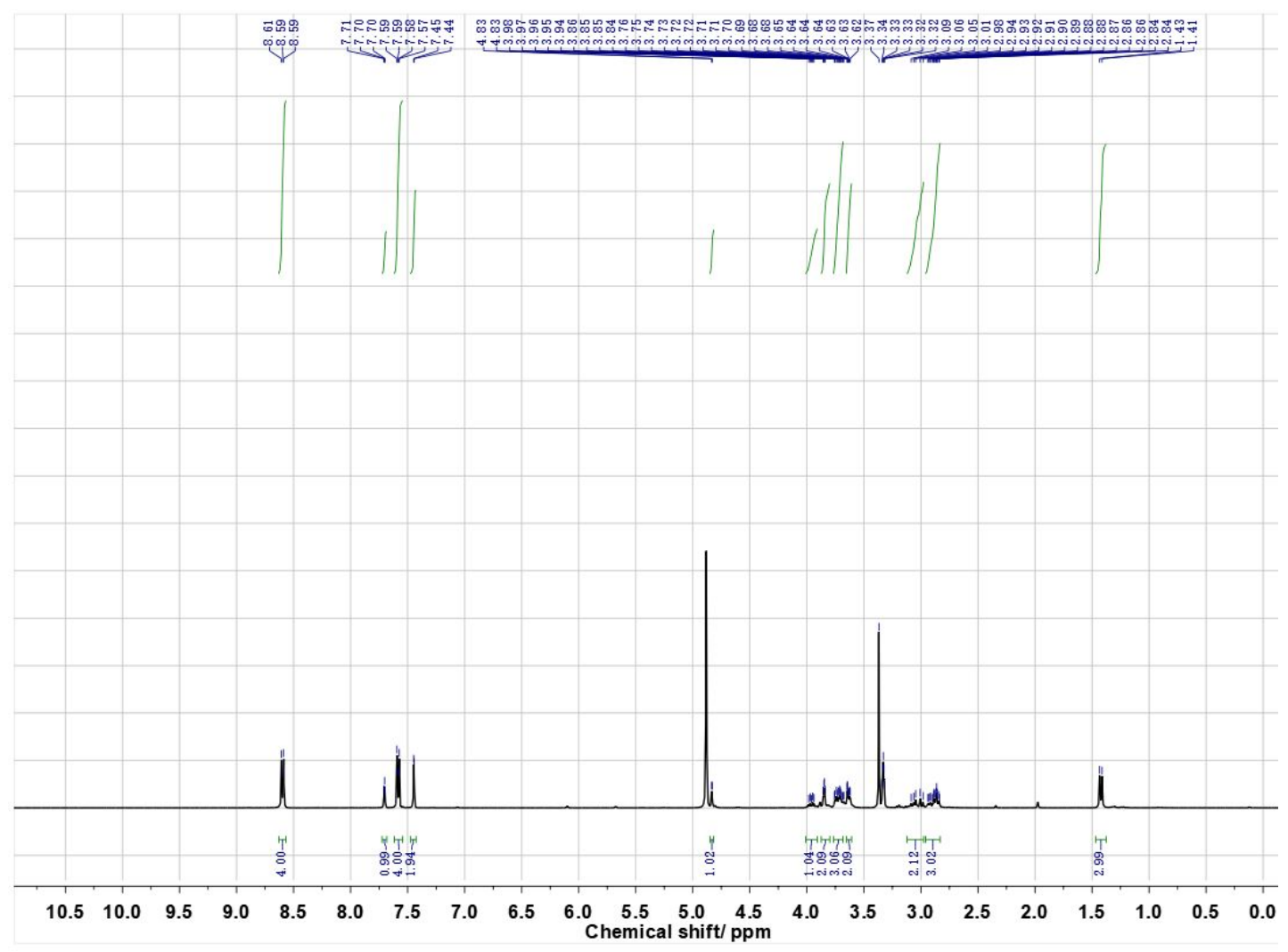

Figure S48. ${ }^{1} \mathrm{H}$ NMR spectrum of D2-Man in $\mathrm{CD}_{3} \mathrm{OD}$.

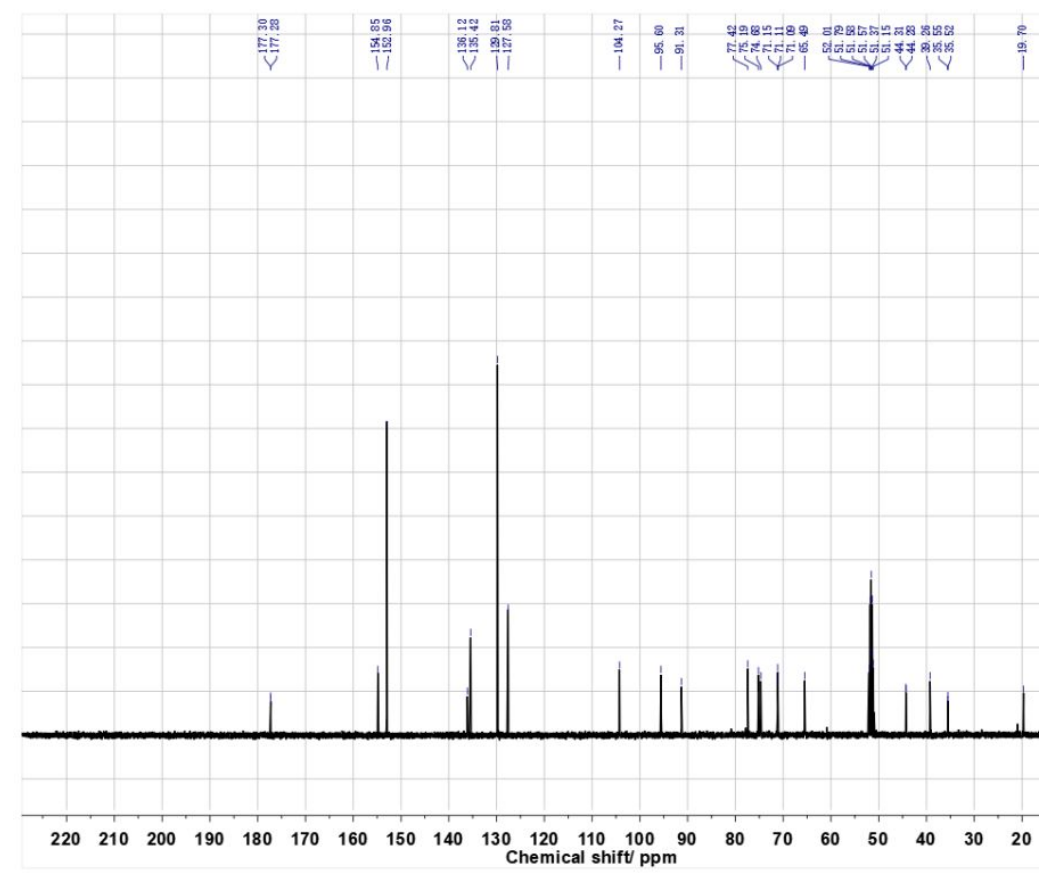

Figure S49. ${ }^{13} \mathrm{C}$ NMR spectrum of D2-Man in $\mathrm{CD}_{3} \mathrm{OD}$. 


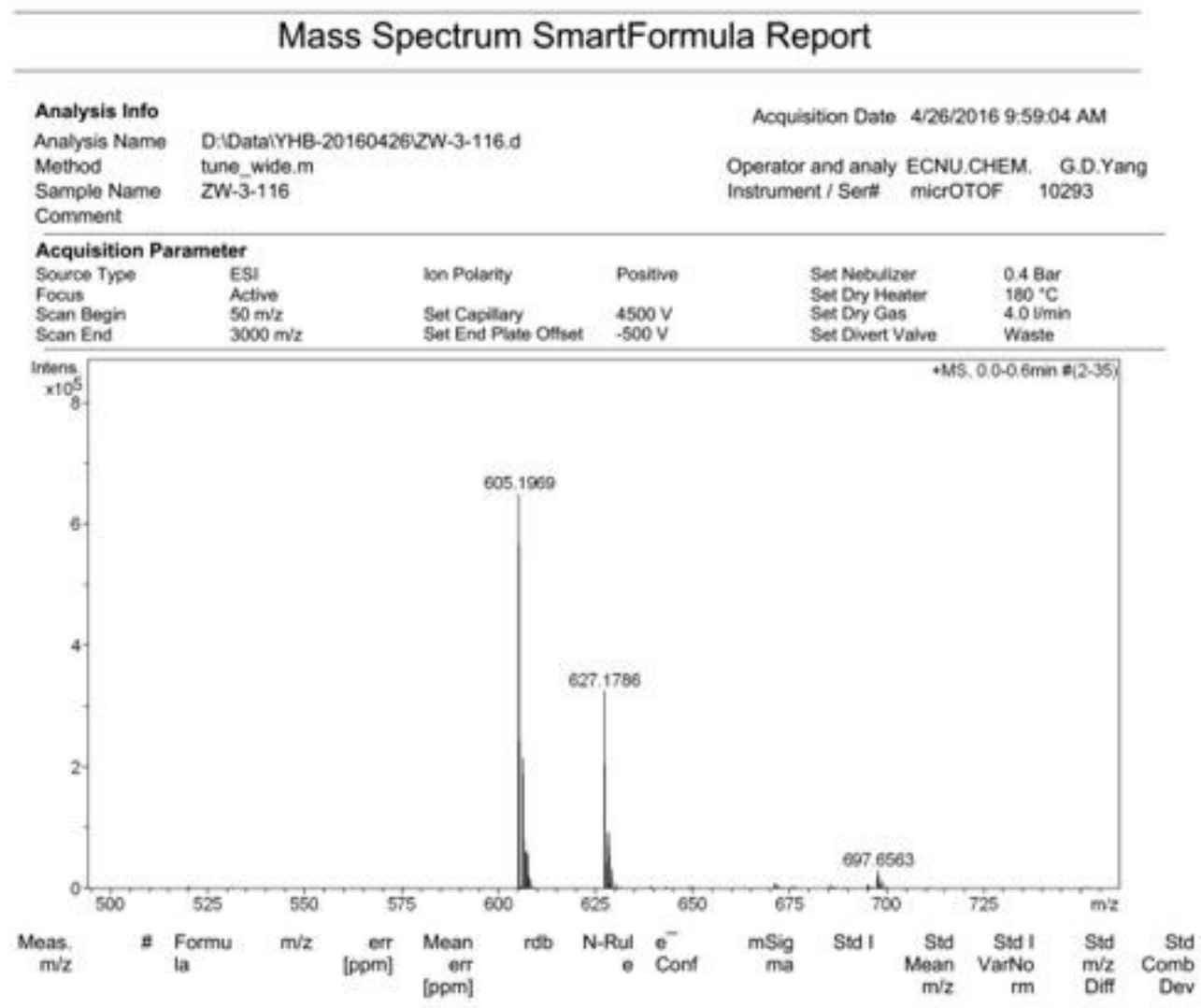

Figure S50. ESI-MS spectrum of D2-Man (m/z).

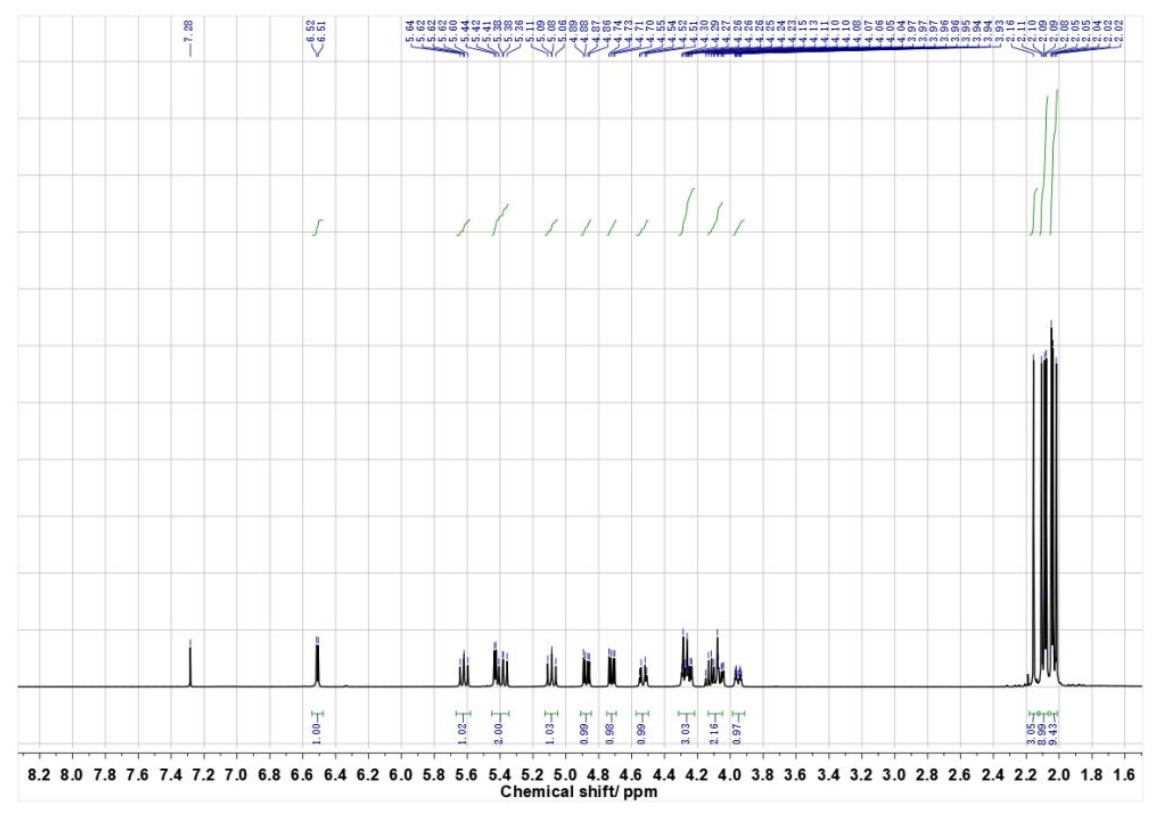

Figure S51. ${ }^{1} \mathrm{H}$ NMR spectrum of $\mathbf{b 2}$ in $\mathrm{CDCl}_{3}$. 


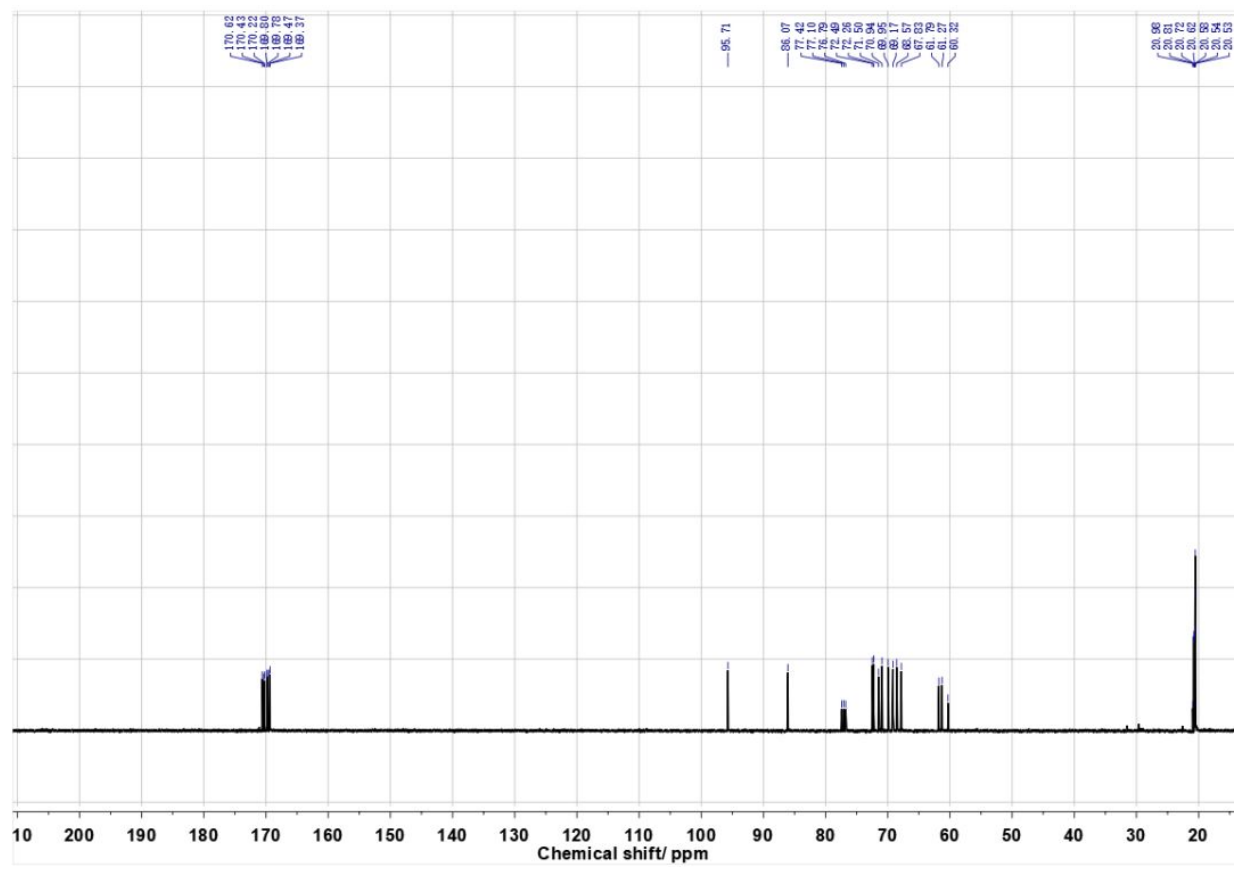

Figure $\mathbf{S 5 2} .{ }^{13} \mathrm{C}$ NMR spectrum of $\mathbf{b 2}$ in $\mathrm{CDCl}_{3}$.

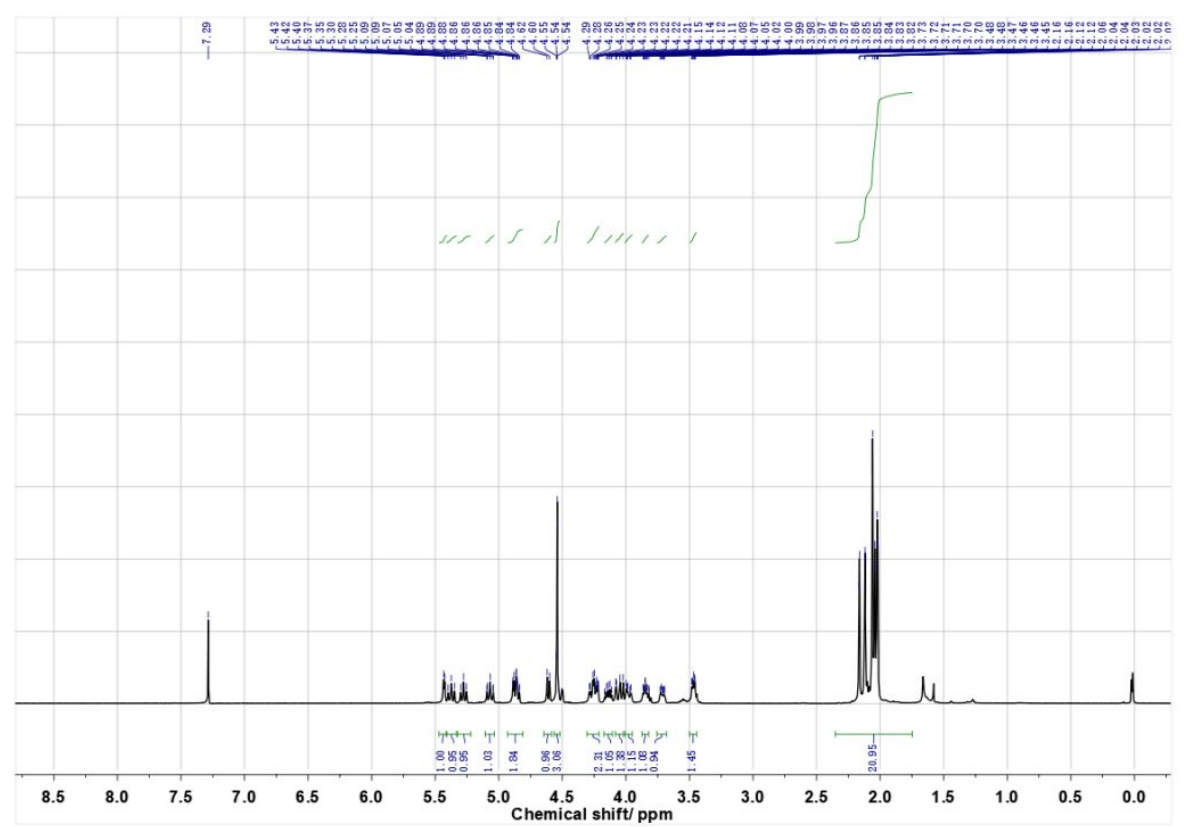

Figure S53. ${ }^{1} \mathrm{H}$ NMR spectrum of $\mathbf{b 3}$ in $\mathrm{CDCl}_{3}$. 


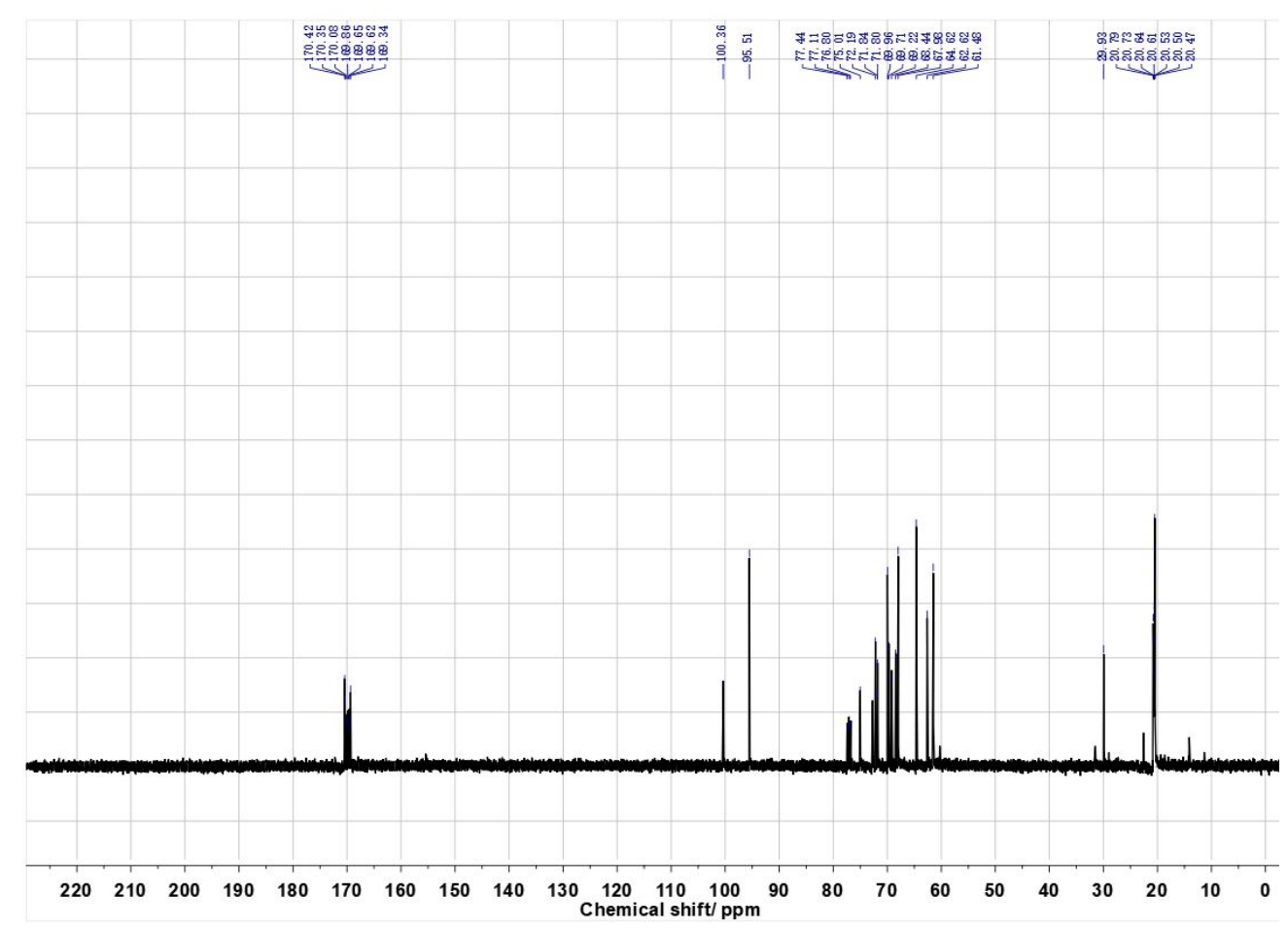

Figure S54. ${ }^{13} \mathrm{C}$ NMR spectrum of $\mathbf{b 3}$ in $\mathrm{CDCl}_{3}$.

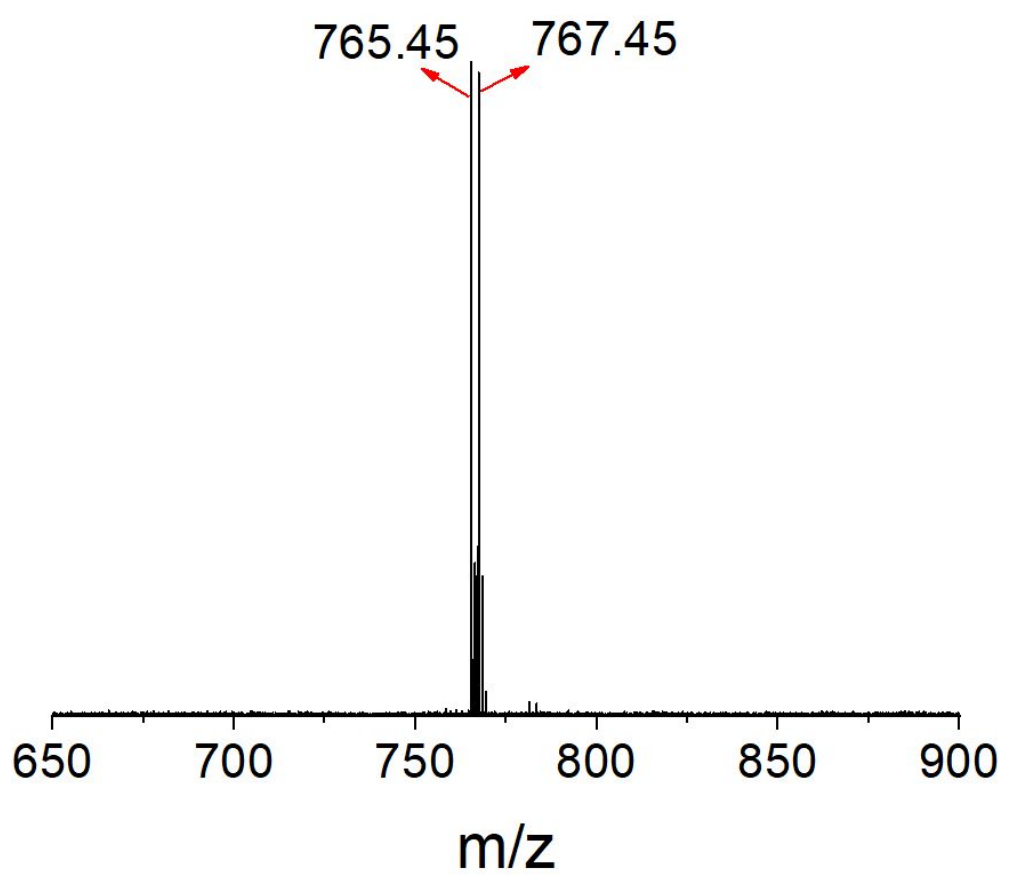

Figure S55. MALDI-TOF-MS spectrum of $\mathbf{b 3}(\mathrm{m} / \mathrm{z})$. 


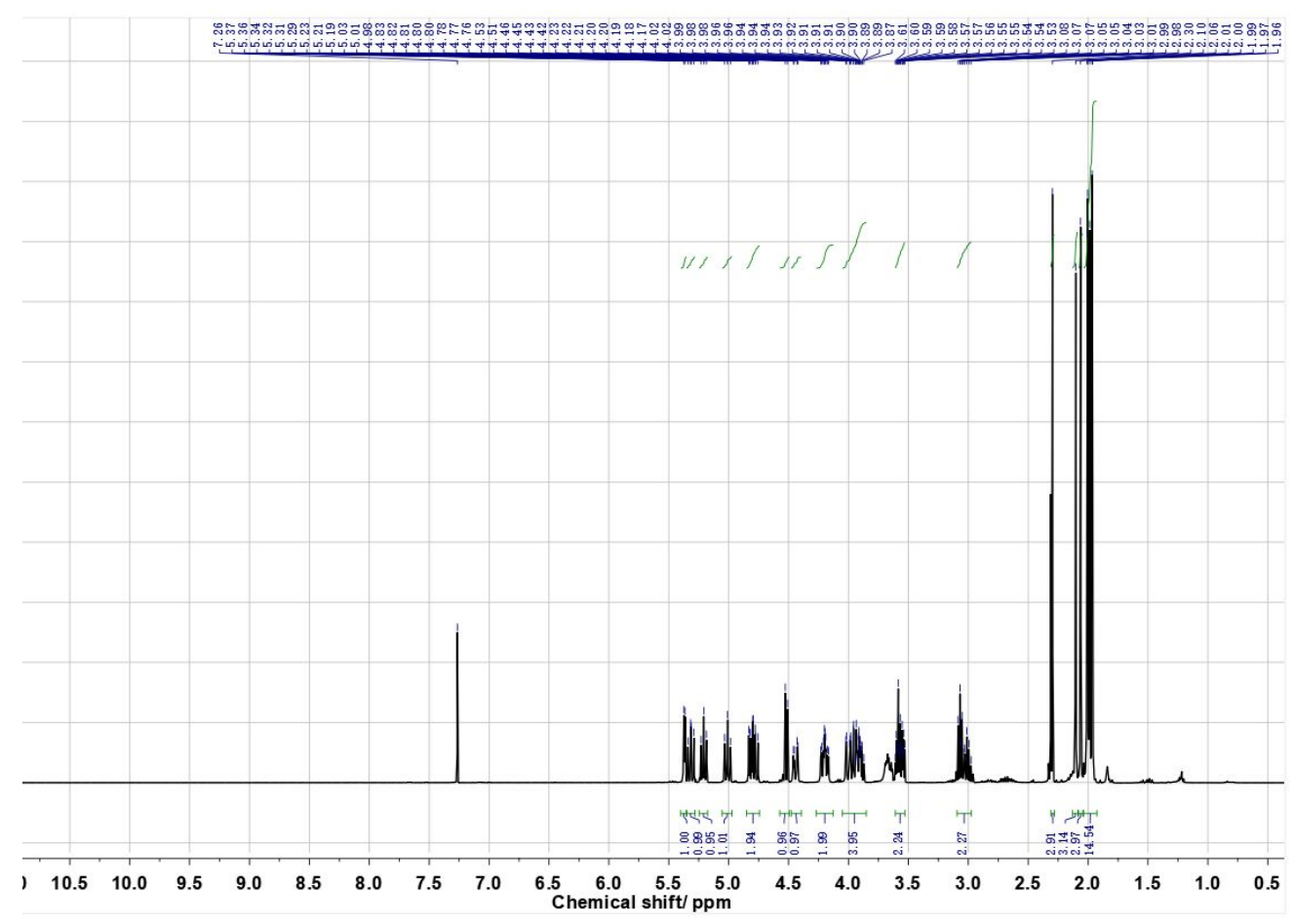

Figure S56. ${ }^{1} \mathrm{H}$ NMR spectrum of $\mathbf{b} 4$ in $\mathrm{CDCl}_{3}$.

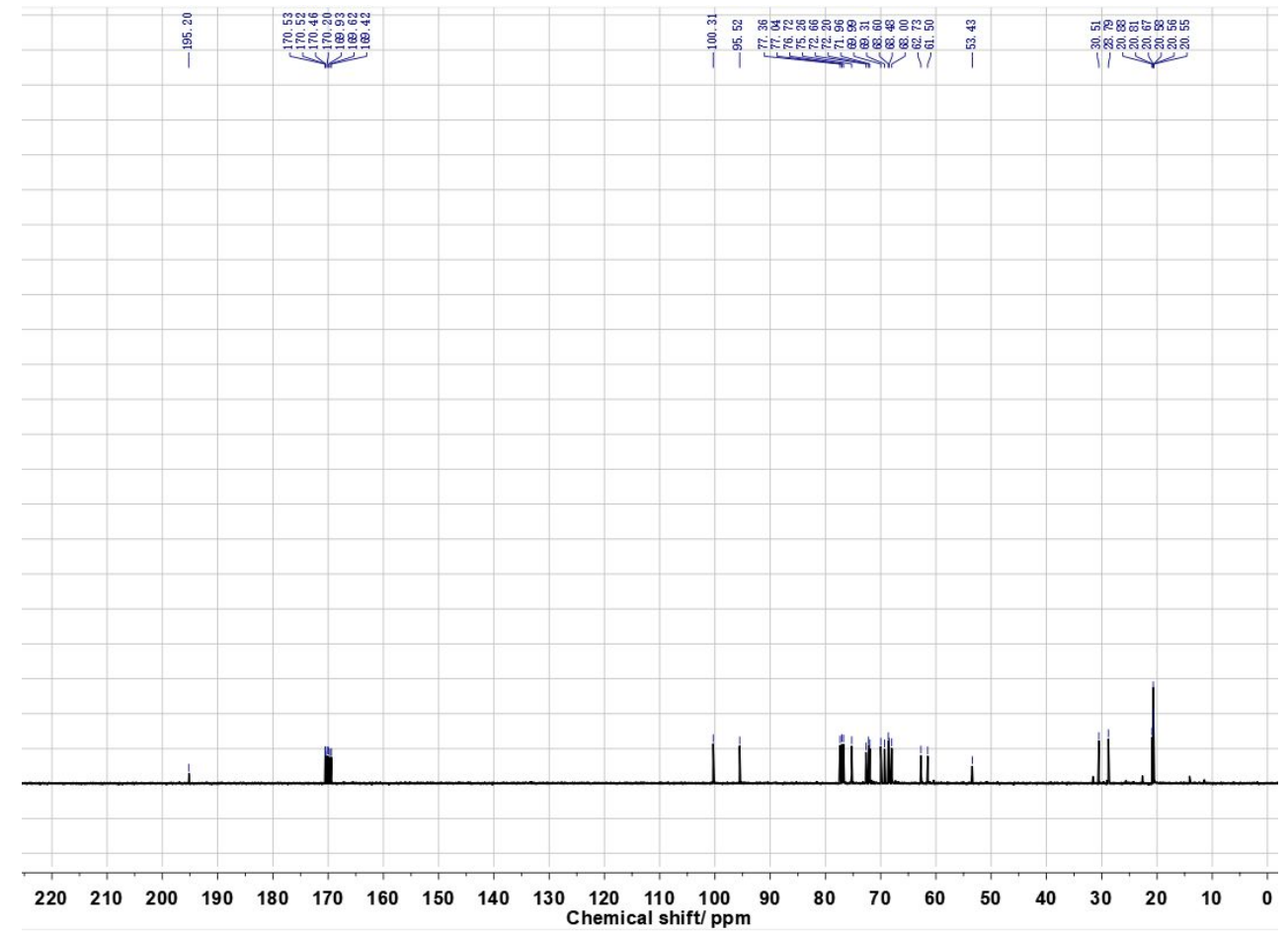

Figure S57. ${ }^{13} \mathrm{C}$ NMR spectrum of $\mathbf{b} 4$ in $\mathrm{CDCl}_{3}$. 


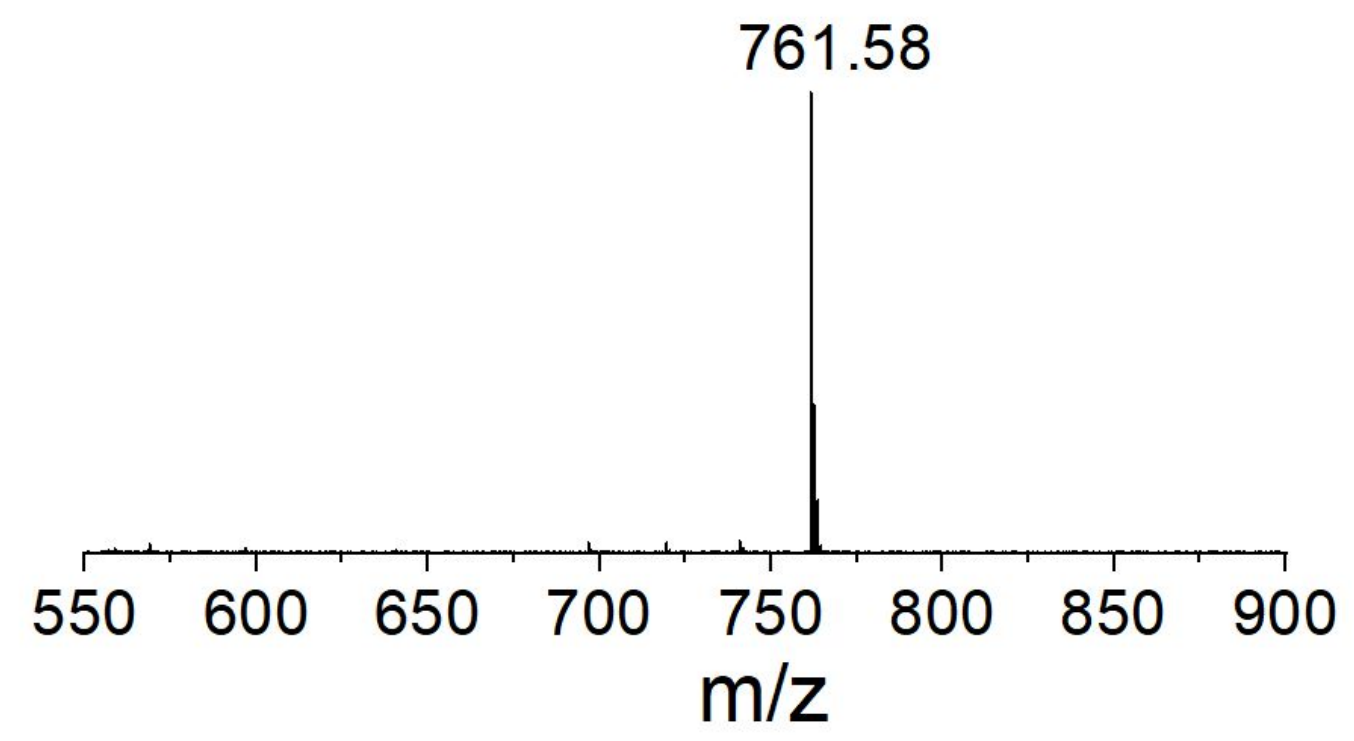

Figure S58. MALDI-TOF-MS spectrum of b4 (m/z).

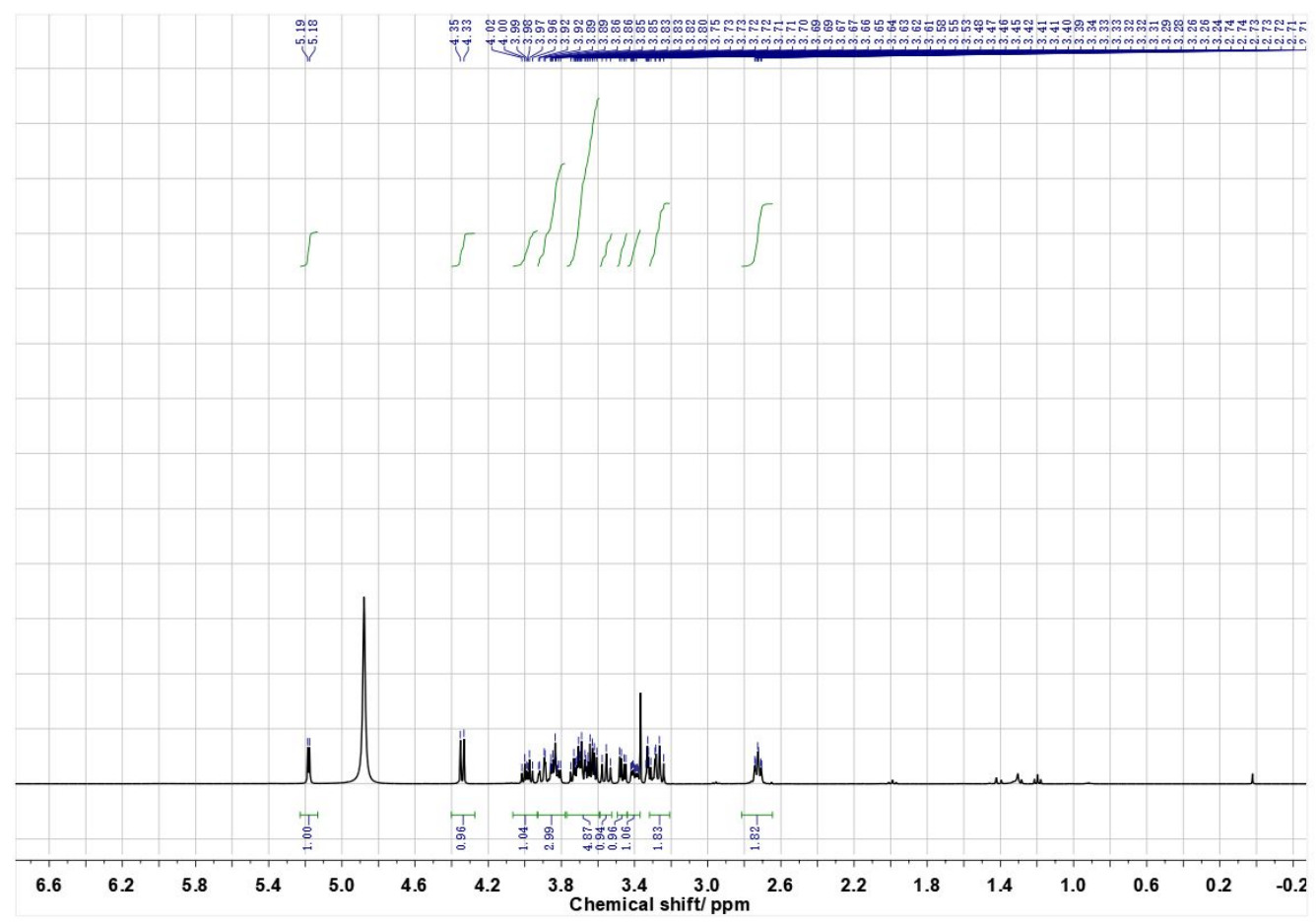

Figure S59. ${ }^{1} \mathrm{H}$ NMR spectrum of $\mathbf{b 5}$ in $\mathrm{CD}_{3} \mathrm{OD}$. 


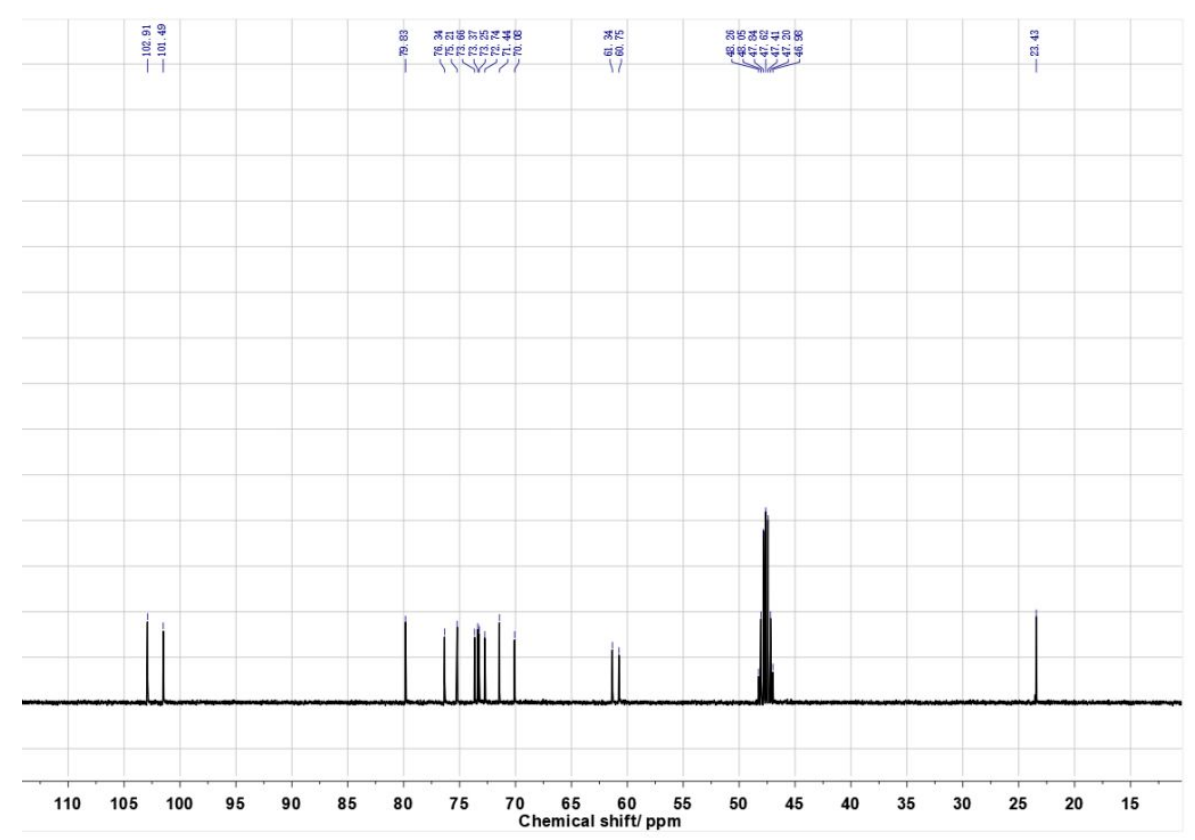

Figure S60. ${ }^{13} \mathrm{C}$ NMR spectrum of $\mathbf{b 5}$ in $\mathrm{CD}_{3} \mathrm{OD}$.

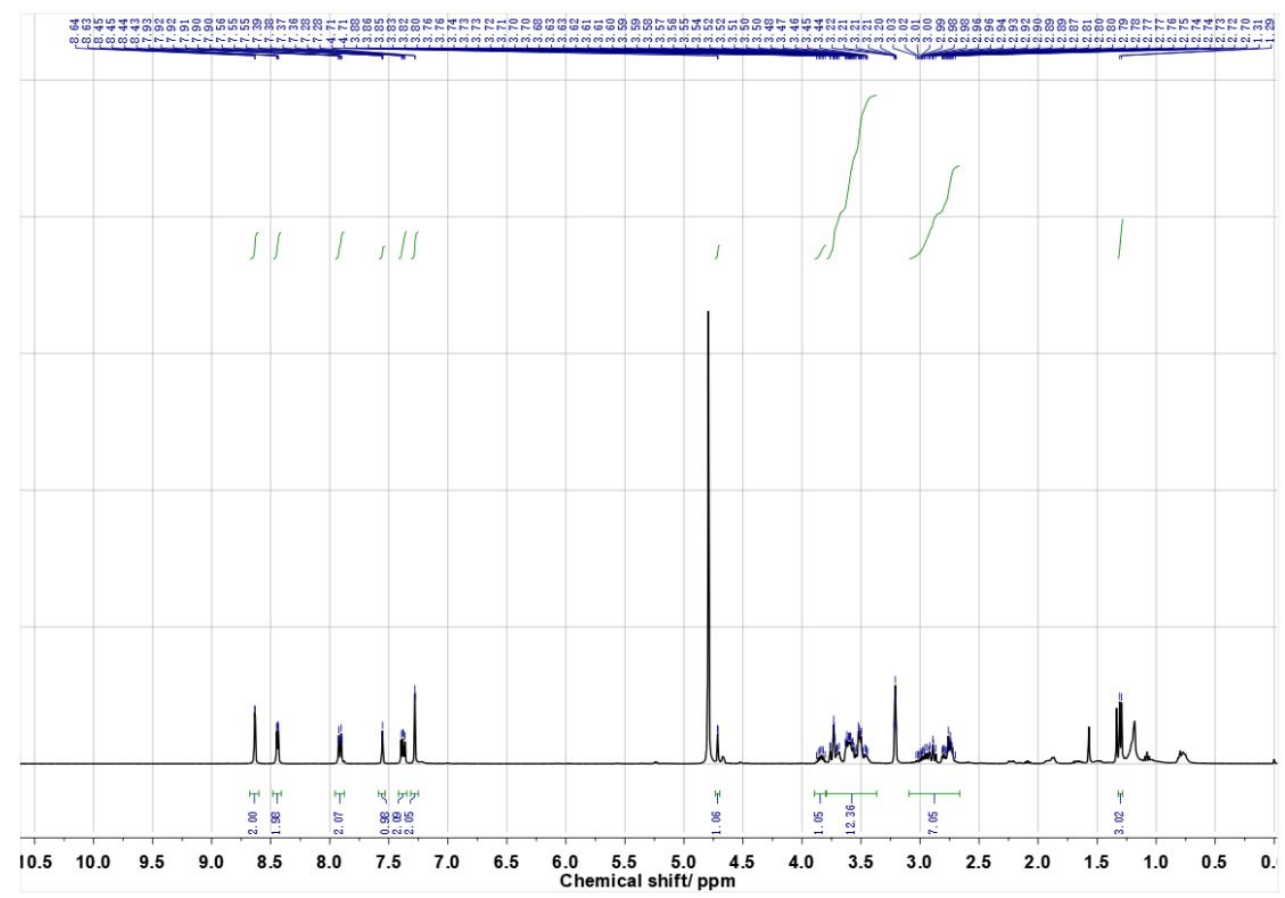

Figure S61. ${ }^{1} \mathrm{H}$ NMR spectrum of D1-Mal in $\mathrm{CD}_{3} \mathrm{OD}$. 


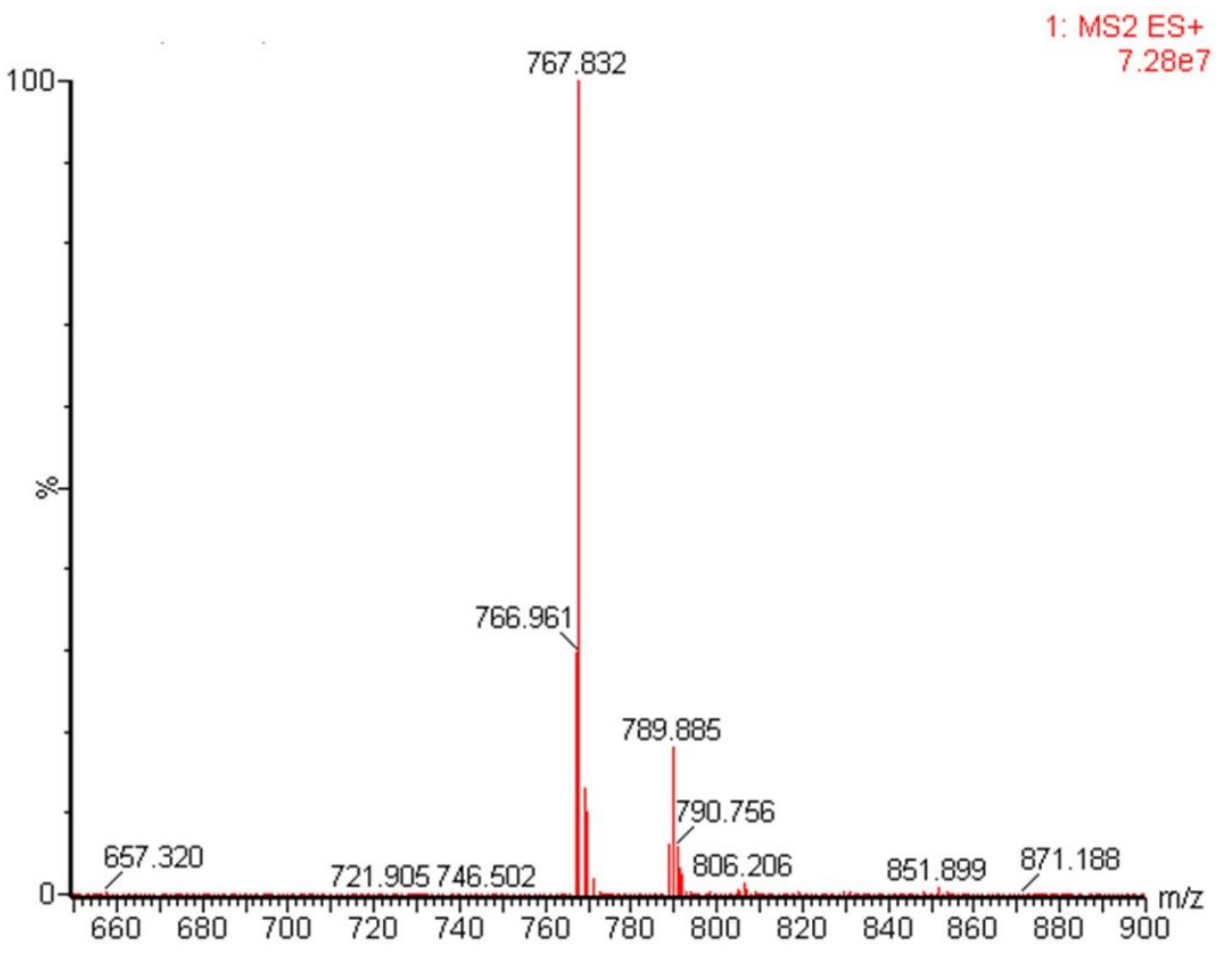

Figure S62. ESI-MS spectrum of D1-Mal (m/z)

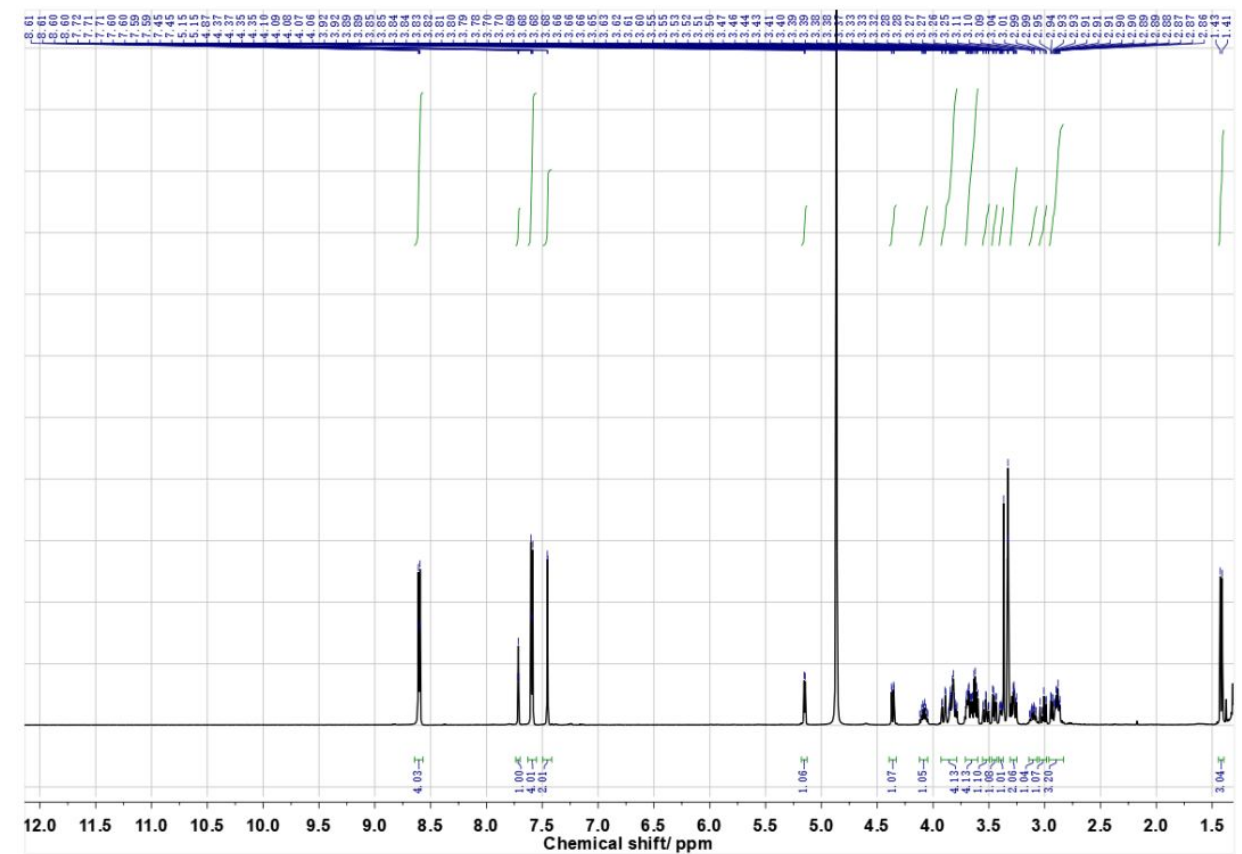

Figure S63. ${ }^{1} \mathrm{H}$ NMR spectrum of D2-Mal in $\mathrm{CD}_{3} \mathrm{OD}$. 


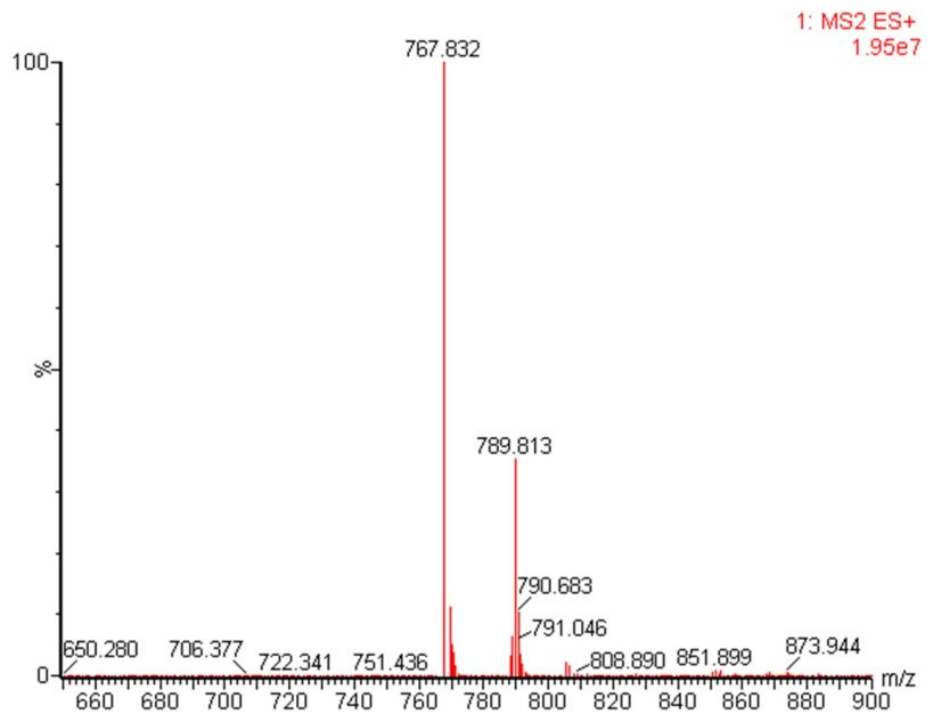

Figure S64. ESI-MS spectrum of D2-Mal (m/z)

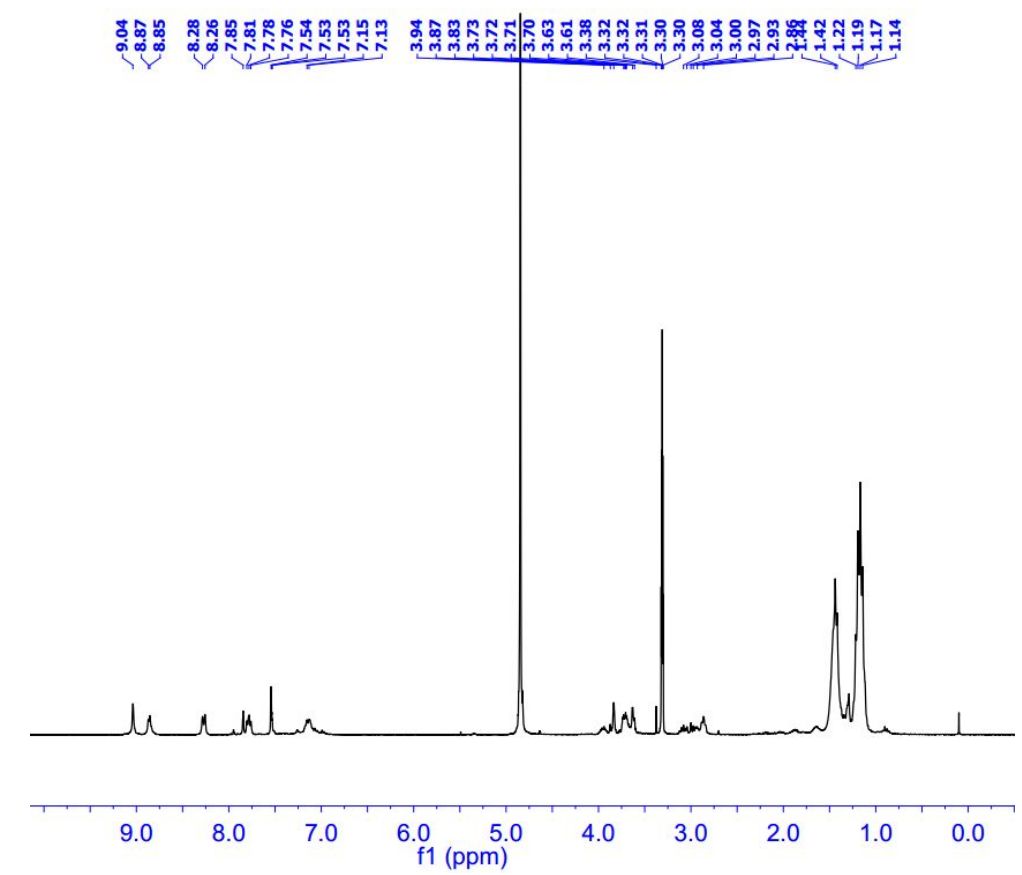

Figure S65. ${ }^{1} \mathrm{H}$ NMR spectrum of 2-Man in $\mathrm{CD}_{3} \mathrm{OD}$. 


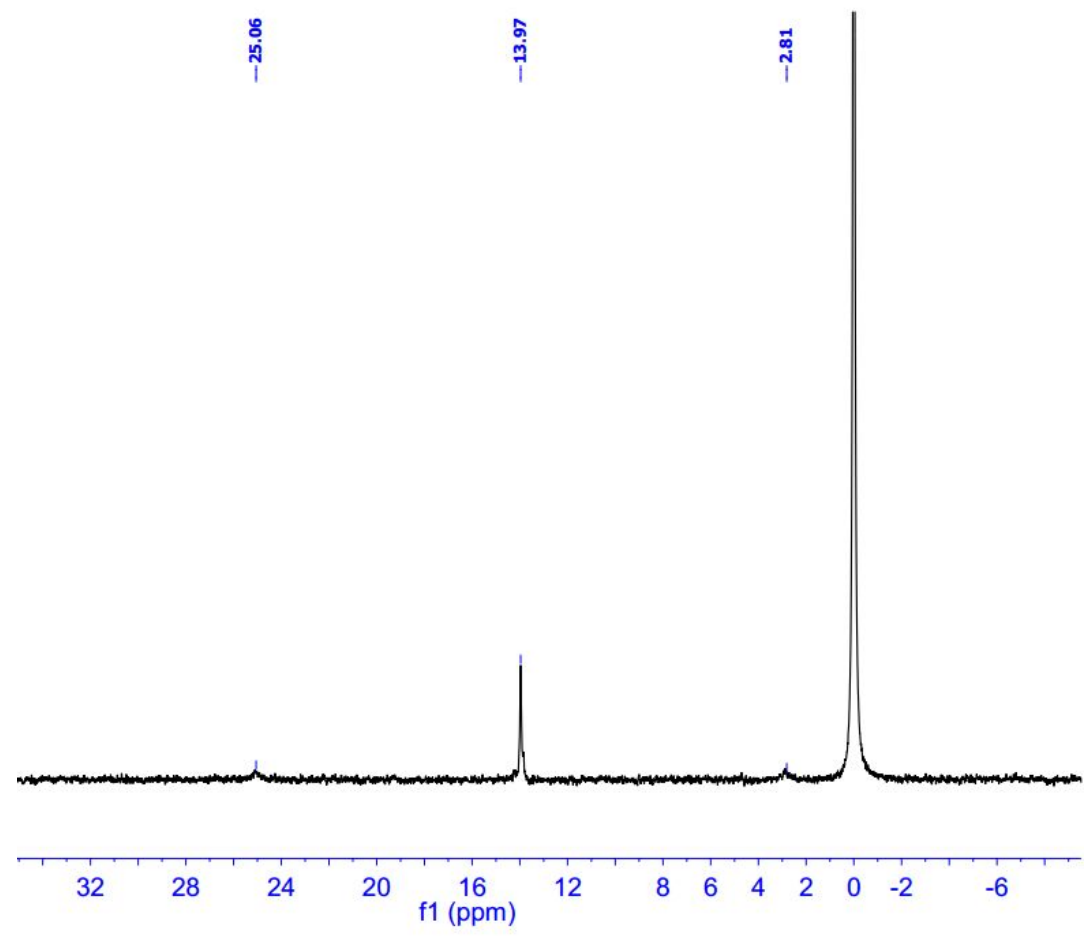

Figure S66. ${ }^{31} \mathrm{P}$ NMR spectrum of 2-Man in $\mathrm{CD}_{3} \mathrm{OD}$.
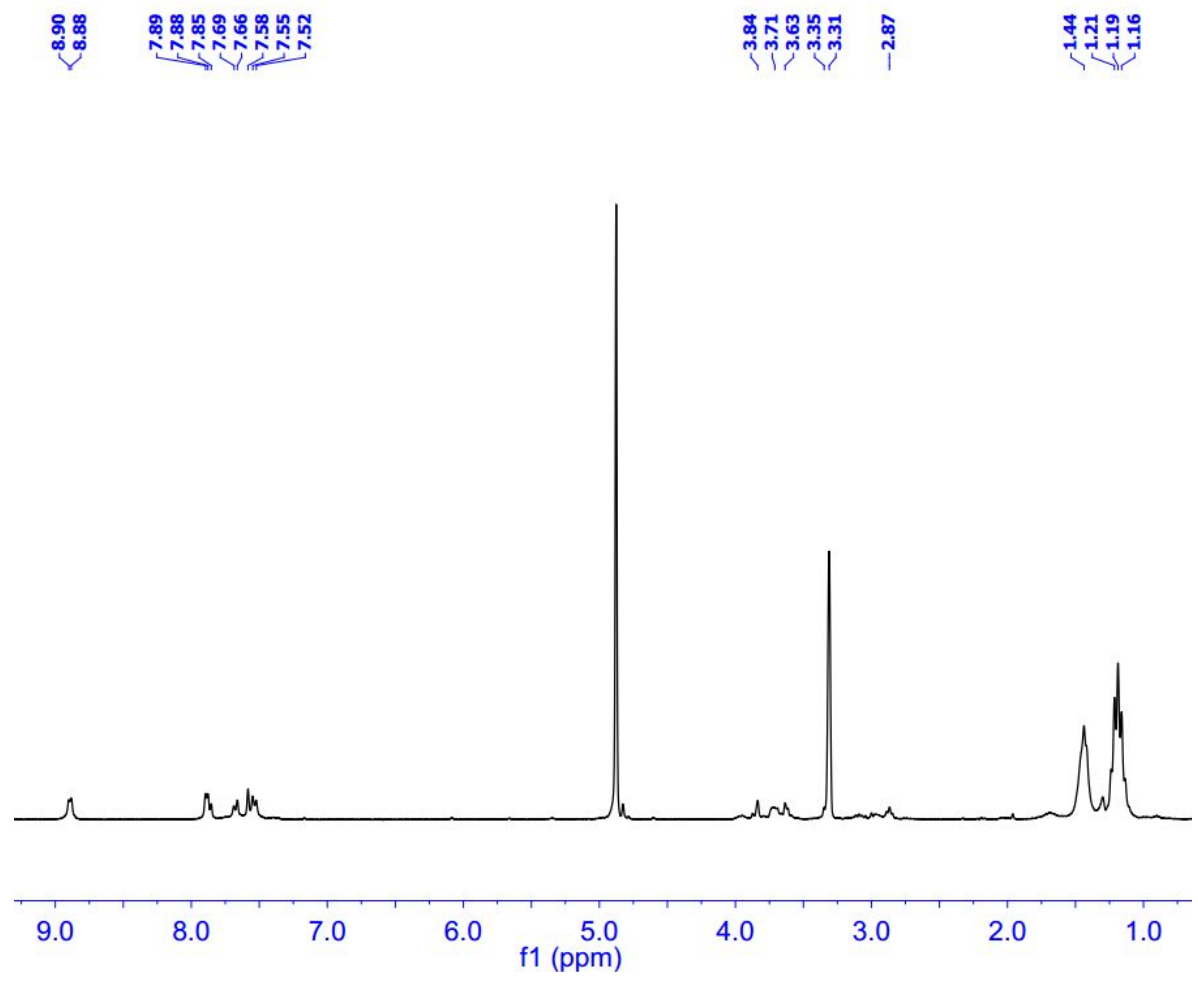

Figure S67. ${ }^{1} \mathrm{H}$ NMR spectrum of 3-Man in $\mathrm{CD}_{3} \mathrm{OD}$. 


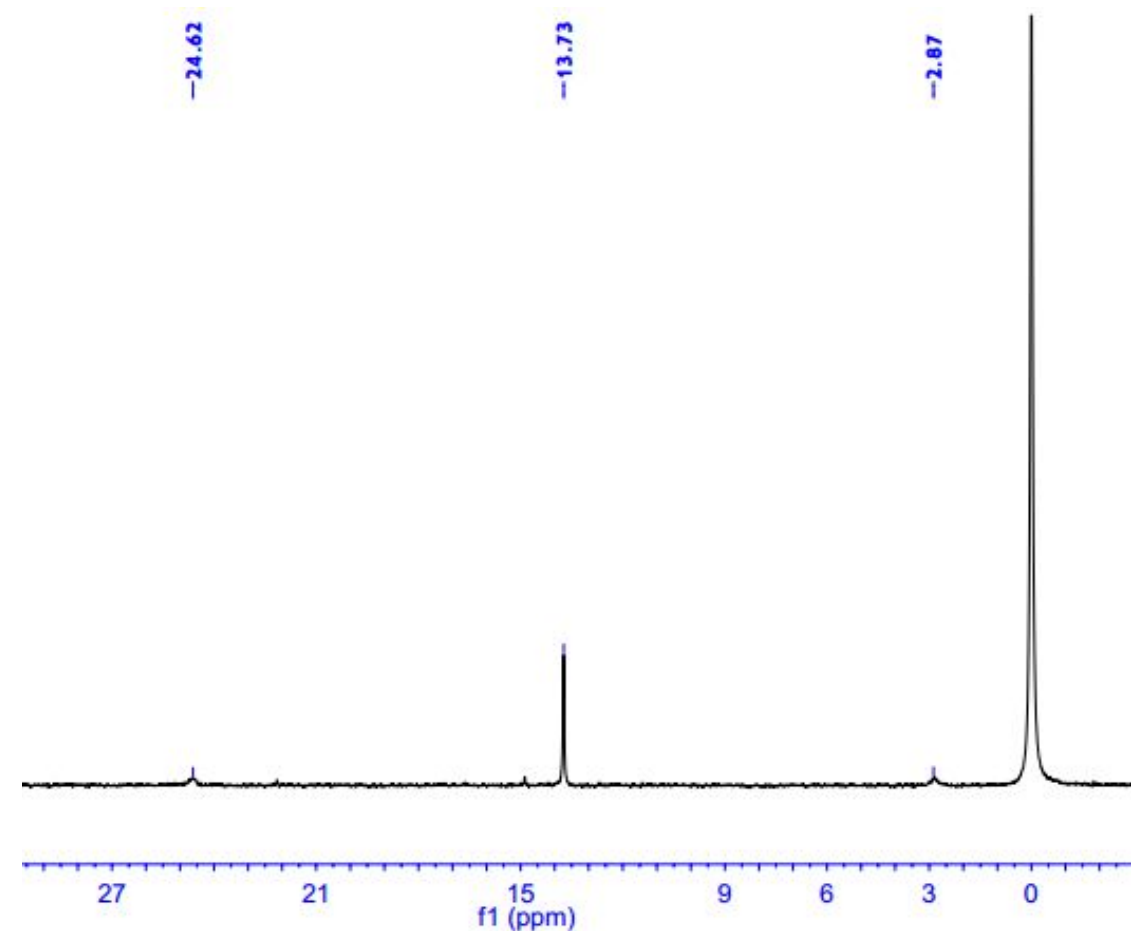

Figure S68. ${ }^{31} \mathrm{P}$ NMR spectrum of 3-Man in $\mathrm{CD}_{3} \mathrm{OD}$.

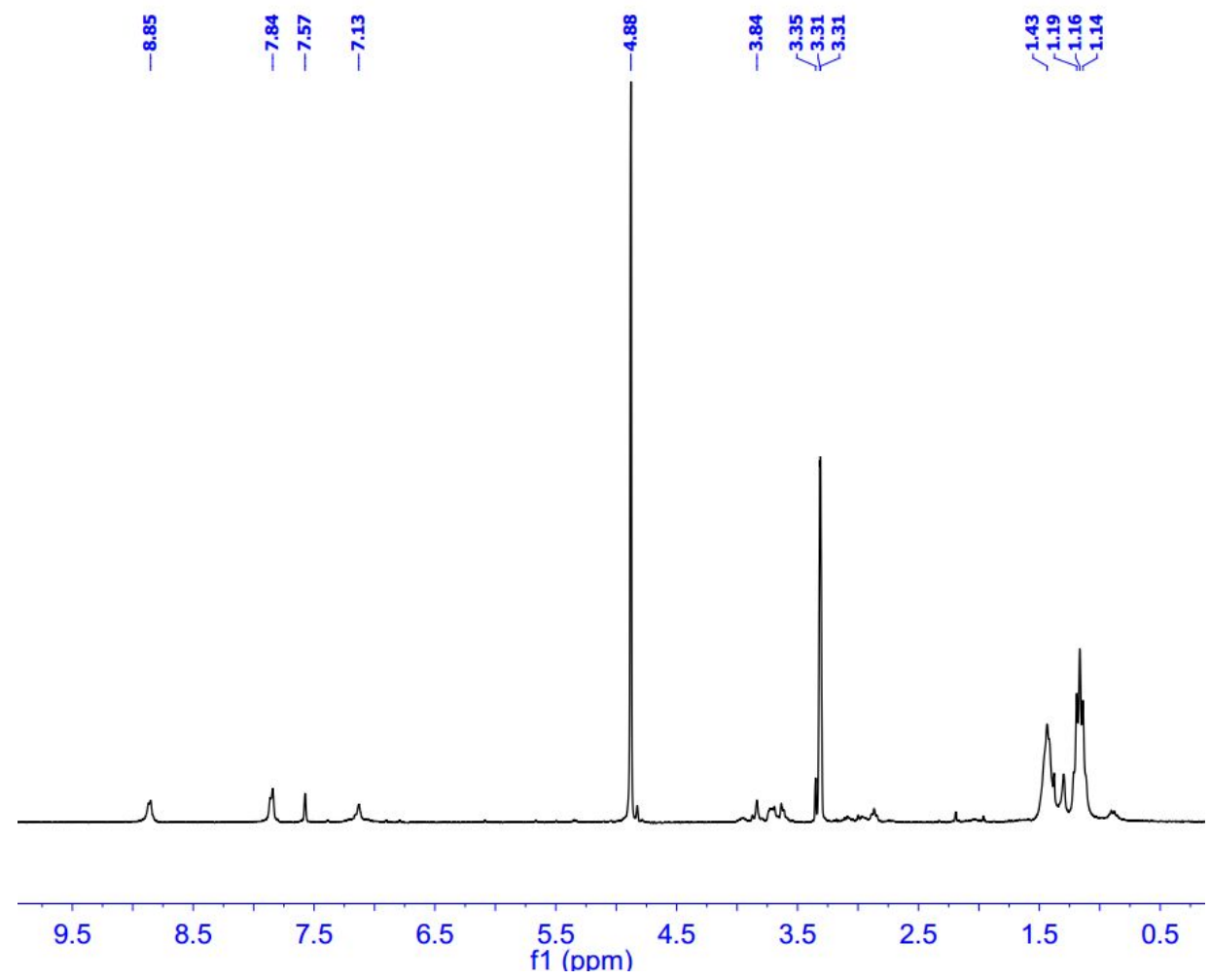

Figure S69. ${ }^{1} \mathrm{H}$ NMR spectrum of 6-Man in $\mathrm{CD}_{3} \mathrm{OD}$. 


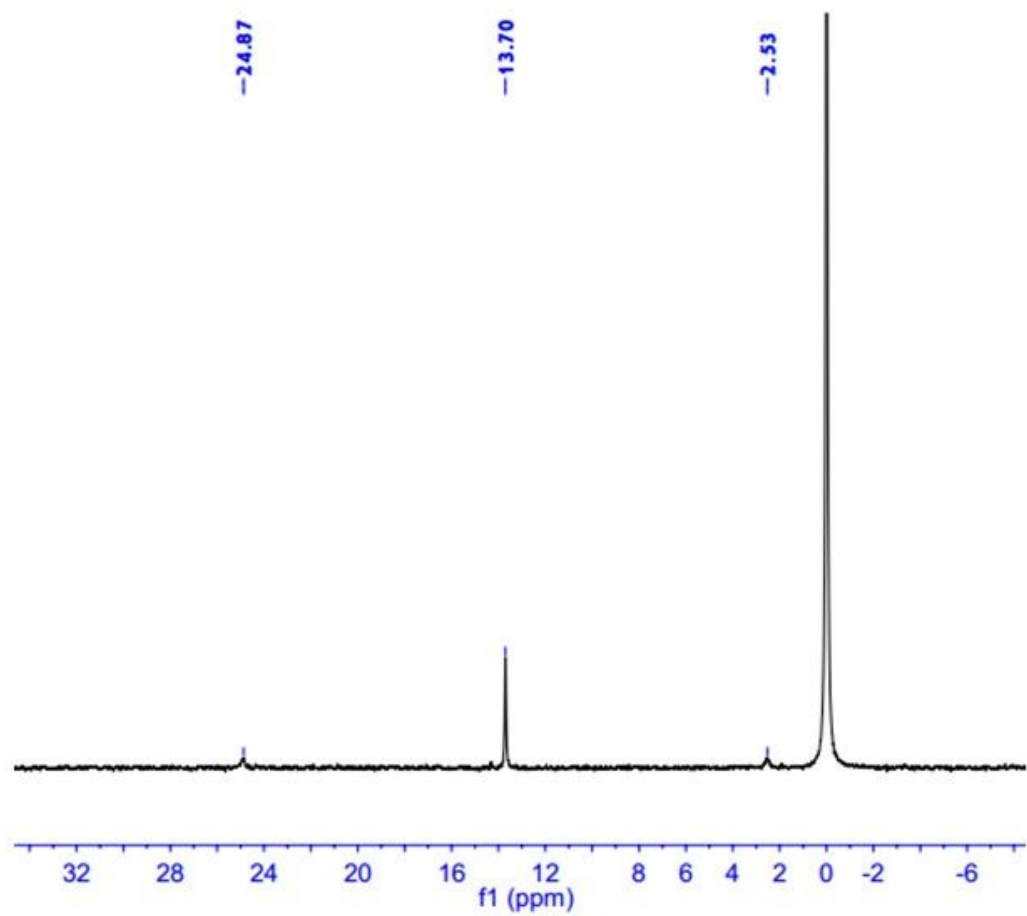

Figure S70. ${ }^{31} \mathrm{P}$ NMR spectrum of 6-Man in $\mathrm{CD}_{3} \mathrm{OD}$.

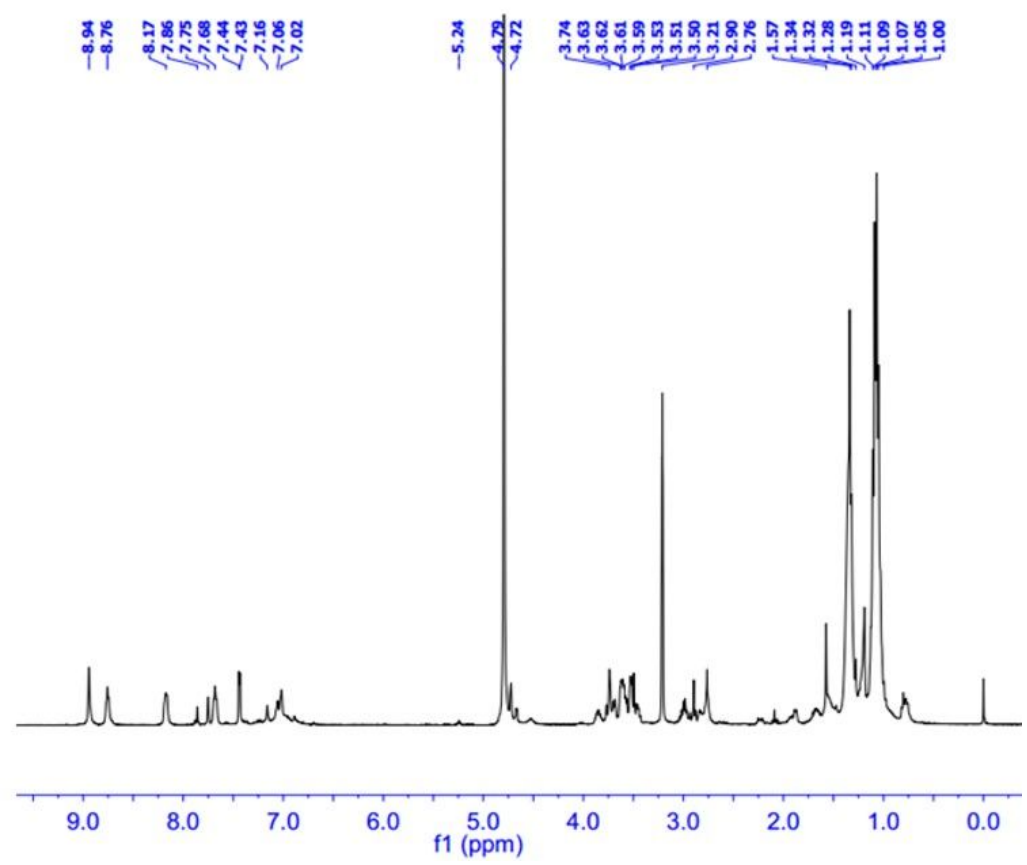

Figure S71. ${ }^{1} \mathrm{H}$ NMR spectrum of 2-Mal in $\mathrm{CD}_{3} \mathrm{OD}$. 


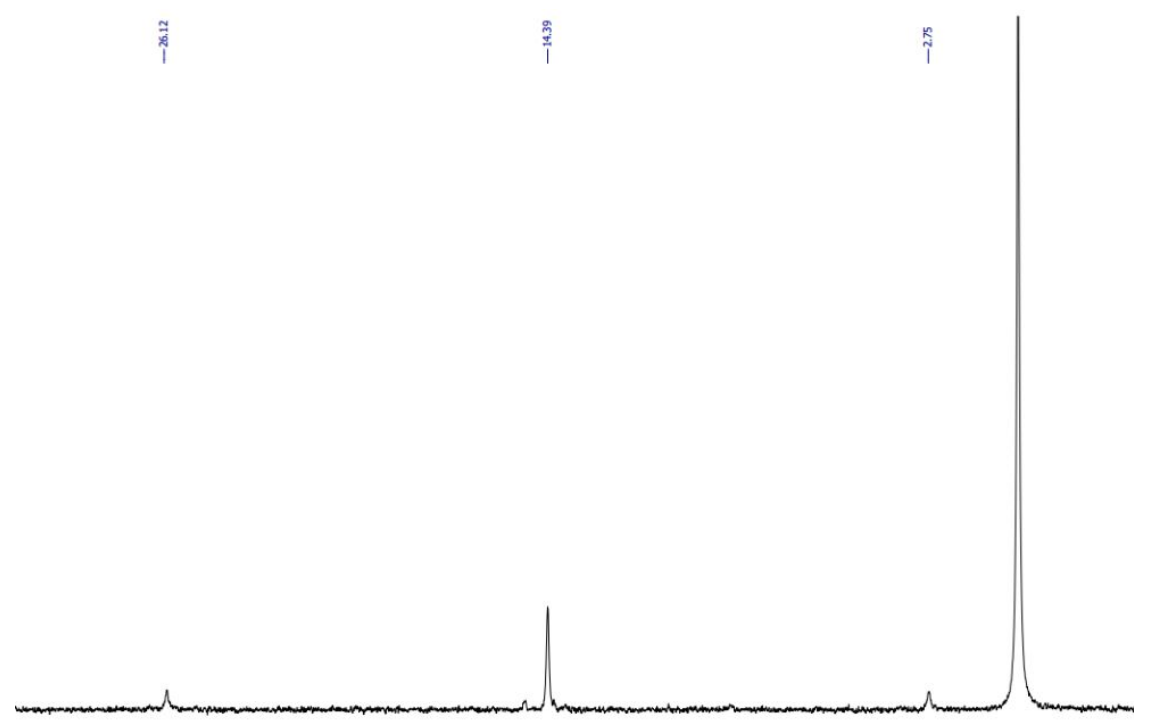

$\begin{array}{lllllllllllllllllllllllllllllllllll}30 & 29 & 28 & 27 & 26 & 25 & 24 & 23 & 22 & 21 & 20 & 19 & 18 & 17 & 16 & 15 & 14 & 13 & 12 & 11 & 10 & 9 & 8 & 7 & 6 & 5 & 4 & 3 & 2 & 1 & 0 & -1 & -2 & -3\end{array}$

Figure S72. ${ }^{31} \mathrm{P}$ NMR spectrum of 2-Mal in $\mathrm{CD}_{3} \mathrm{OD}$.

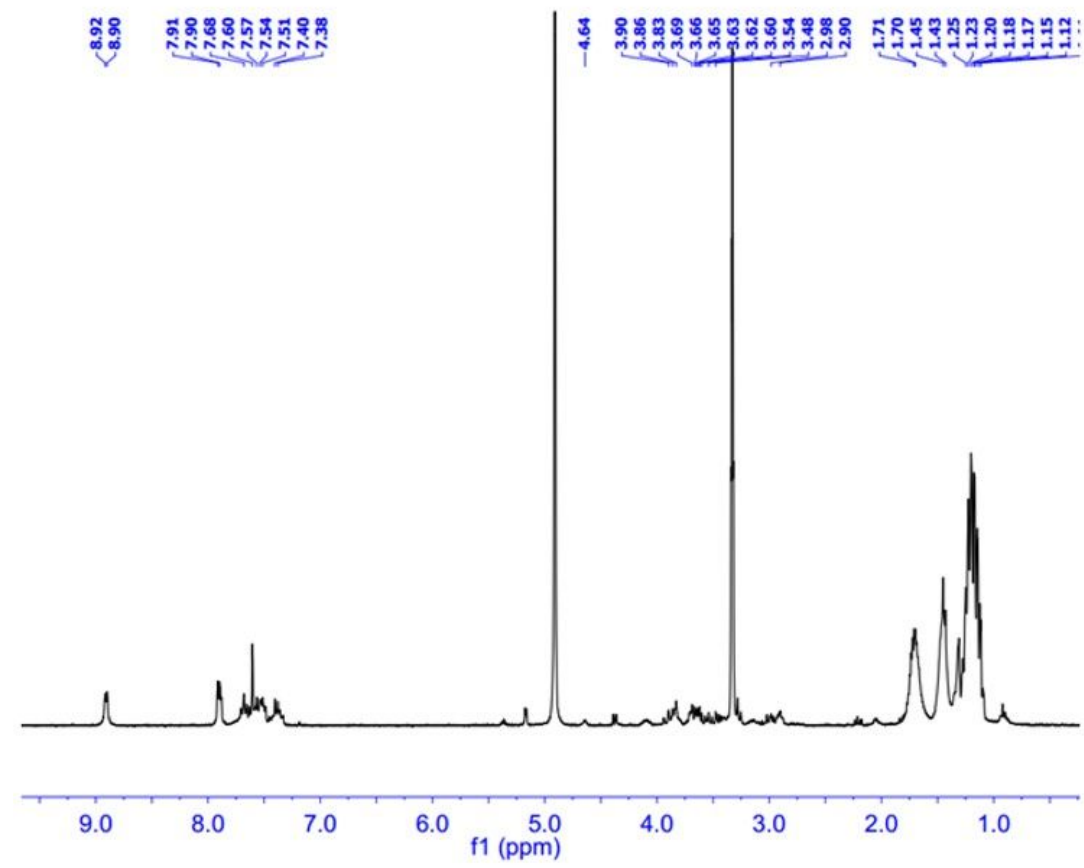

Figure S73. ${ }^{1} \mathrm{H}$ NMR spectrum of 3-Mal in $\mathrm{CD}_{3} \mathrm{OD}$. 
萬

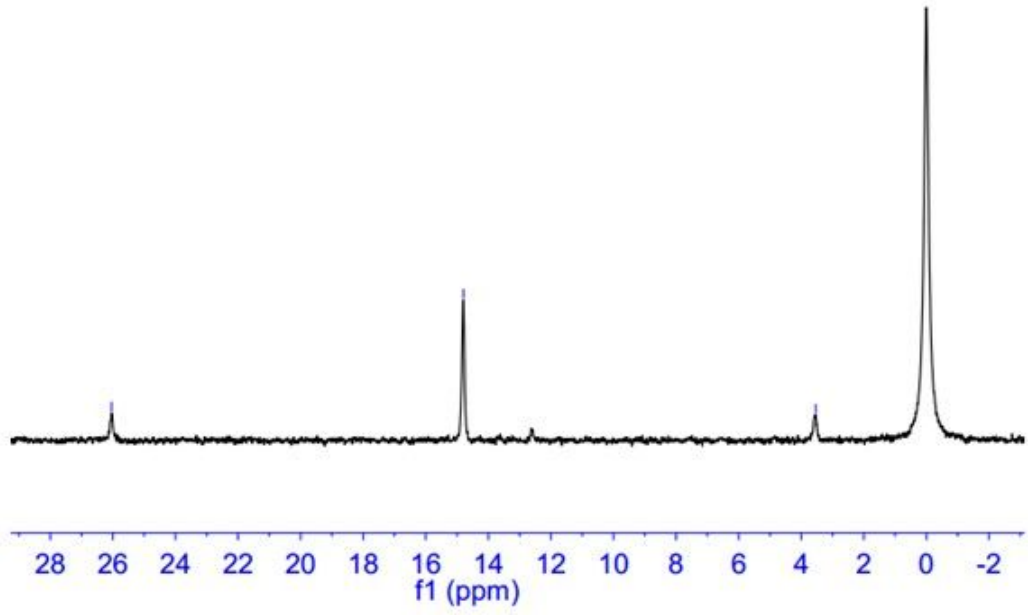

Figure S74. ${ }^{31} \mathrm{P}$ NMR spectrum of 3-Mal in $\mathrm{CD}_{3} \mathrm{OD}$.

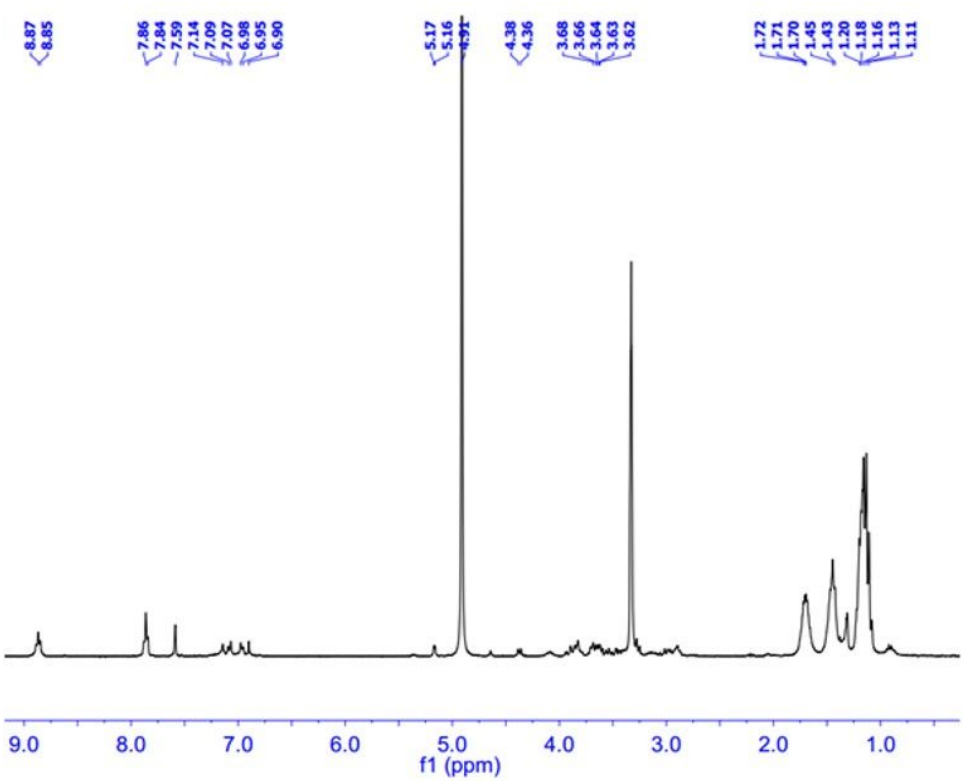

Figure S75. ${ }^{1} \mathrm{H}$ NMR spectrum of 6-Mal in $\mathrm{CD}_{3} \mathrm{OD}$. 


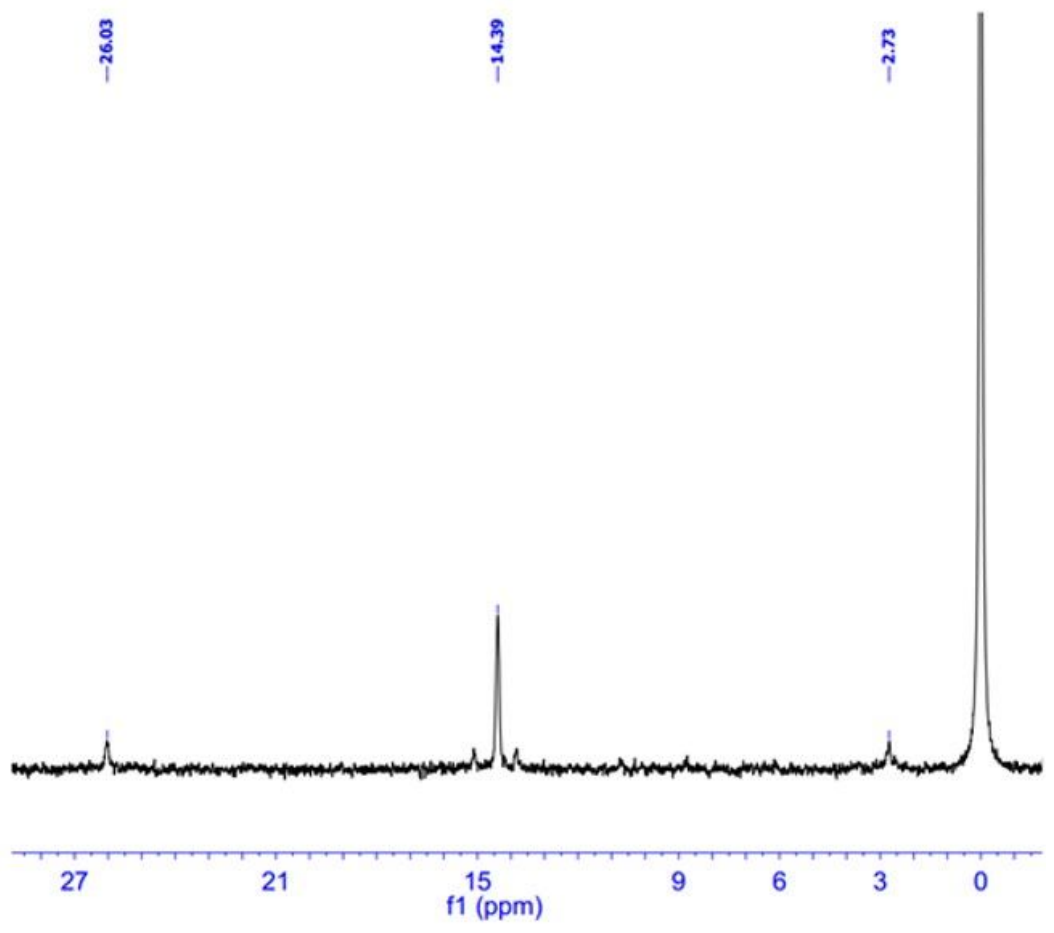

Figure S76. ${ }^{31} \mathrm{P}$ NMR spectrum of 6-Mal in $\mathrm{CD}_{3} \mathrm{OD}$. 
xiii. Reference

1. Yang, H. B.; Das, N.; Huang, F.; Hawkridge, A. M.; Muddiman, D. C.; Stang, P. J. Molecular Architecture via Coordination: Self-Assembly of Nanoscale Hexagonal Metallodendrimers with Designed Building Blocks. J. Am. Chem. Soc. 2006, 128, 1001410015.

2. Yang, G.; Kochovski, Z.; Ji, Z.; Lu, Y.; Chen, G.; Jiang, M. Three-Dimensional Protein Assemblies Directed by Orthogonal Non-Covalent Interactions. Chem. Commun. 2016, 52, 9687-9690.

3. Hoogerbrugge, P. J.; Koelman, J. M. V. A. Simulating Microscopic Hydrodynamic Phenomena with Dissipative Particle Dynamics. Europhys. Lett. 1992, 19, 155-160.

4. Espagnol, P.; Warren, P. Statistical Mechanics of Dissipative Particle Dynamics. Europhys. Lett. 1995, 30, 191-196.

5. Groot, R. D.; Warren, P. B. Dissipative Particle Dynamics: Bridging the Gap between Atomistic and Mesoscopic Simulation. J. Chem. Phys. 1997, 107, 4423-4435.

6. Liu, Y.; Yong, X.; McFarlin, G. T.; Kuksenok, O.; Aizenberg, J.; Balazs, A. C. Designing a Gel-Fiber Composite to Extract Nanoparticles from Solution. Soft Matter 2015, 11, 8692-8700.

7. Plimpton, S. J. Fast Parallel Algorithms for Short-Range Molecular Dynamics. J. Comput. Phys. 1995, 117, 1-19.

8. Schneider, T.; Stoll, E. Molecular-Dynamics Study of a Three-Dimensional OneComponent Model for Distortive Phase Transitions. Phys. Rev. B 1978, 17, 1302-1322. 